\title{
ESTUDIO TAXONÓMICO PRELIMINAR DE LOS GRYLLOIDEA DE ESPAÑA (INSECTA, ORTHOPTERA)
}

\author{
A. V. Gorochov * y V. Llorente **
}

\begin{abstract}
RESUMEN
En el presente trabajo se realiza un estudio taxonómico y faunístico de la superfamilia Grylloidea de España, incluyendo las islas Baleares y Canarias. Se examinan las 60 especies y subespecies que se han encontrado hasta ahora en este país, siendo seis de ellas nuevas para la ciencia: Petaloptila (P.) fermini, P. (P.) isabelae, P. (Zapetaloptila) venosa, P. (Z.) barrancoi, Paramogoplistes dentatus sp. n. y Grylloderes orlovskajae adventicius subsp. n.; asimismo se crean dos nuevos subgéneros Italoptila y Zapetaloptila.

Se establece una sinonimia correcta del género Grylloderes Bolívar, 1894 (= Platygryllus Chopard, 1961, syn. dist. ), así como siete sinonimias específicas: Gryllomorpha (G.) dalmatina (Ocskay, 1832) (= Gryllomorpha dalmatina strumae Andreeva, 1982, syn. n.), Petaloptila (P.) aliena (Brunner-Wattenwyl, 1882) (= Discoptila eitschbergeri Harz, 1976, syn. n.), Acheta hispanicus Rambur, 1839 (= Gryllus erythrospilus Walker, 1869 , syn. n., Gryllus hispanicus var. fusculus Bolívar, 1927, syn. n.), Eumodicogryllus bordigalensis (Latreille, 1802) (= Gryllodes ferdinandi Bolívar, 1899, syn. n., Gryllus chinensis var intermedia Bolívar, 1927, syn. n.), Eugryllodes pipiens (Dufour, 1820) (= Gryllodes pipiens var. provincialis Azam, 1901, syn. n.), y además cinco estatus nuevos y una combinación nueva.

Se citan por primera vez para la Península Ibérica tres especies [Eumodicogryllus theryi (Chopard, 1943), Sciobia natalia Gorochov, 1985 y Oecanthus dulcisonans Gorochov, 1993], las dos primeras de las cuales, lo son también para Europa; para la España peninsular una (Svercus p. palmetorum Krauss, 1902) y tres para las islas Canarias [Natula averni (Costa, 1855), comb. n., Acanthogryllus acus Gorochov, 1988, bajo este nombre, y Pseudomogoplistes vicentae Gorochov, 1996], esta última además se cita por primera vez para Argelia; así como Modicogryllus (M.) algirius (Saussure, 1877), para Francia. Por otra parte, se vuelve a considerar como buena especie Eugryllodes panteli (Cazurro, 1888).

Asimismo se presenta una clave de identificación acompañada de figuras para las especies del género Petaloptila. También se estudia por primera vez la genitalia del macho de varias especies. Además, se han localizado las series tipo de Gryllodes macropterus Fuente, 1894 y Gryllotalpa septemdecimchromosomica Ortiz, 1958, así como dos paratipos de Gryllomorpha adspersa merobricensis Fernandes, 1959, stat. n. Se designan lectotipos y paralectotipos de 17 taxones y se revisa la geonemia de todas las especies.

Palabras clave: Orthoptera, Grylloidea, taxonomía, distribución, nuevas especies, nuevas sinonimias, nuevos status, nuevas combinaciones, designación lectotipos, clave identificación, Petaloptila, España, islas Baleares y Canarias.
\end{abstract}

* Zoological Institute, Russian Academy of Sciences, St. Petersburg, 199034, Universitetskaya nab., 1, Russia.

** Museo Nacional de Ciencias Naturales (CSIC). José Gutiérrez Abascal, 2. Madrid 28006. 


\begin{abstract}
Preliminary taxonomic study of the Grylloidea of Spain (Insecta, Orthoptera)

In the present paper a taxonomic and faunistic study of the superfamily of Grylloidea of Spain including the Balearic and Canary Islands is carried on. Sixty species and subspecies are reported for the study area, six of them new to science: Petaloptila (P.) fermini, P. (P.) isabelae, P. (Zapetaloptila) venosa, P. (Z.) barrancoi, Paramogoplistes dentatus sp. n. and Grylloderes orlovskajae adventicius subsp. n.; likewise are erected two new subgenera Italoptila and Zapetaloptila.

One correct synonymy of the genus Grylloderes Bolívar, 1894 (= Platygryllus Chopard, 1961, syn. dist. ), seven specific synonymies are established: Gryllomorpha (G.) dalmatina (Ocskay, 1832) (= Gryllomorpha dalmatina strumae Andreeva, 1982, syn. n.), Petaloptila (P.) aliena (Brunner-Wattenwyl, 1882) (= Discoptila eitschbergeri Harz, 1976, syn. n.), Acheta hispanicus Rambur, 1839 (= Gryllus erythrospilus Walker, 1869, syn. n., Gryllus hispanicus var. fusculus Bolívar, 1927, syn. n.), Eumodicogryllus bordigalensis (Latreille, 1802) (= Gryllodes ferdinandi Bolívar, 1899, syn. n., Gryllus chinensis var intermedia Bolívar, 1927, syn. n.), Eugryllodes pipiens (Dufour, 1820) (= Gryllodes pipiens var. provincialis Azam, 1901, syn. n.) and besides five new status and one new combination.

Three species [Eumodicogryllus theryi (Chopard, 1943), Sciobia natalia Gorochov, 1985 and Oecanthus dulcisonans Gorochov, 1993] are recorded for the first time for the Iberian Peninsula, being the former two also new for Europe, one (Svercus p. palmetorum Krauss, 1902) for Peninsular Spain, three [Natula averni (Costa, 1855), comb. n., Acanthogryllus acus Gorochov, 1988, under this name, and Pseudomogoplistes vicentae Gorochov, 1996], for the Canary Islands, being latter recorded also for the first time for Algeria and Modicogryllus (M.) algirius (Saussure, 1877) is also recorded for the first time for France. On the other hand, we recognise Eugryllodes panteli (Cazurro, 1888) as a good species.

An identification key with figures for the species of the genus Petaloptila is presented. The male genitalia of several species is also studied for the first time. The type series of Gryllodes macropterus Fuente, 1894 and Gryllotalpa septemdecimchromosomica Ortiz, 1958 and two paratypes of Gryllomorpha adspersa merobricensis Fernandes, 1959 , stat. n. are localized. Lectotypes and paralectotypes of 17 taxons are designated. The distribution of all species is revised.

Key words: Orthoptera, Grylloidea, taxonomy, distribution, new species, new synonymies, new status, new combinations, lectotypes designations, identification key, Petaloptila, Spain, Balearic and Canary Islands.
\end{abstract}

\section{Introducción}

La fauna entomológica de España está considerada como una de las más ricas de Europa, debido a su posición geográfica y a sus peculiaridades geomorfológicas, climáticas, edáficas y diversidad de paisaje lo que ha originado el gran número de endemismos que en ella existen. Esto se manifesta en muchos grupos y entre ellos los Orthoptera y en particular, en los Grylloidea.

El estudio de los Orthopteroidea de nuestro país, en especial de los Grylloidea, se inició a mediados del siglo pasado con la espléndida labor realizada por los insignes entomólogos Rambur (1839), Bolívar (1876-1927), Brunner-Wattenwyl (1882), Cazurro (1888), Krauss (1892), Pantel (1890-1896), etc. $\mathrm{Y}$ aunque durante bastantes años discurrió por determinadas etapas de menor esplendor, la publicación de las monografías de Chopard $(1943,1951)$ y Harz (1969), los catálogos de Chopard $(1967,1968)$ y Herrera (1982), así como los trabajos de Fernandes (1967), Gangwere y Morales Agacino (1970), Gangwere et al. (1972), alentaron a los jóvenes ortopterólogos a continuar su investigación. Así se han realizado numerosos trabajos en los que se recoge la presencia de distintas especies en determinadas provincias, comunidades o regiones geográficas más o menos amplias (Morales Agacino, 1933; Ragge, 1965; Johnsen, 1974; Pascual, 1978a, 1978b; Del Cerro, 1978, 1980; Llorente, 1980; Herrera 1980, 1993; Aguirre y Pascual, 1986; Arcos y Pascual, 1986, 1988; Burgos y Herrera, 1986; Eiroa y Novoa, 1987; Pinedo y Llorente, 1988a, 1988b; Gómez et al., 1991; Barranco y Pascual, 1991, 1992, 1994; 
Olmo, 1990, 1993; Pardo et al., 1993; Torralba, 1995; Blasco-Zumeta, 1998; Barranco Vega, 1998; Hernández et al., 1998; Schmidt, 1999; Olmo-Vidal y Hernando, 2000). Aunque en algunas de estas aportaciones se realiza el estudio de una forma bastante superficial, todas ellas son imprescindibles y muy útiles en la confección de mapas de distribución de las especies y en la realización de trabajos de conjunto, como los mencionados más arriba y los que han surgido después (Kevan y Hsiung, 1992; Gangwere y Llorente, 1992; los catálogos de Otte, 1994 y París,1994; Bland et al., 1996; Heller et al., 1998 y el presente estudio).

Este trabajo ofrece un paso intermedio en el estudio de los grillos españoles. El objetivo principal está en precisar el estatus y el área de distribución de una serie de taxones, completar la lista de especies, dando su distribución geográfica nacional y mundial y presentar esta lista en relación con las ideas actuales de la clasificación de la superfamilia Grylloidea.

La clasificación que aquí se adopta es la de Gorochov (1995a), provista de argumentos filogenéticos y evolutivos basados en el estudio morfológico de muy diversos órganos, en datos paleontológicos y en información de las especies actuales de gríllidos de todas las regiones biogeográficas.

Para facilitar el trabajo de los no especialistas en el grupo, consideramos necesario incluir algunas referencias donde se dan claves de identificación de la mayoría de especies, así como de los géneros y familias. Por tratarse aquí de los grillos españoles, recordamos la existencia del Catálogo sinóptico de I. Bolívar $(1898,1900)$, obra inicial y básica para el conocimiento de la fauna española. Son de consulta imprescindible las obras de Chopard $(1943,1951)$ y Harz (1969). Para sinonimias de géneros y especies y bibliografía de gríllidos en general, pueden consultarse los catálogos de Chopard (1967, 1968), Herrera (1982), Otte (1994) y Heller et al. (1998).

\section{Material y métodos}

Para la realización de este trabajo se ha procedido al estudio de unos 2.646 ejemplares de las diferentes especies de grillos que habitan la España peninsular, islas Baleares y Canarias y sólo en casos excepcionales figura algún material de otros países.

Los ejemplares estudiados son todos procedentes de colecciones de diversos centros nacionales y extranjeros. En primer lugar se hará mención de la colección depositada en el Museo Nacional de Ciencias Naturales de Madrid (MNCN). Este material, por regla general, aparece en la relación de
Material estudiado sin ningún tipo de referencia. Por el contrario, el resto del material, procedente de los centros que a continuación se relacionan, tiene especificada su procedencia mediante las letras clave del centro correspondiente, que figura entre paréntesis.

DBUC Departamento de Biología Animal (Zoología), Universidad Complutense de Madrid.

DEESIM Departamento de Entomología. Escuela Técnica Superior de Ingenieros de Montes de Madrid.

DZM Departamento de Biología Animal (Zoología), Universidad de Murcia.

GNHM Muséum d'Histoire Naturelle. Ginebra.

MZB Museo de Zoología de Barcelona.

MNHN Museum National d'Histoire Naturelle. París

MNHU Museum für Naturkunde der Humboldt Universität. Berlín.

NHM Natural History Museum., ex BMNH. Londres.

NHMW Naturhistorisches Museum. Viena.

ZIAS Zoological Institut, Russian Academy of Sciences. San Petersburgo.

De cada una de las especies, a excepción de algunas muy abundantes, se da el material estudiado, indicando las provincias y localidades de captura, en orden alfabético, altitud (cuando está registrada), número de ejemplares, adultos machos $\left(\sigma^{7} \sigma^{3}\right)$, ninfas primeros estadios $\left(\sigma^{7} \mathrm{n}, 1\right.$-os. est.), ninfas últimos estadios ( $\sigma^{7} \mathrm{n}$, últs. est.), adultos hembras $(\stackrel{\circ}{\circ}$ ) y las ninfas de éstas igual que en los machos; fecha de captura, con los días en números arábigos y meses en románicos; apellido del colector; en algunos ejemplares etiquetas de identificación y/o de tipos y por último, las siglas de la Institución a la que pertenece el material.

Aparte se dan el ciclo fenológico y la distribución nacional y mundial, donde se comentan las citas de otros autores.

Cuando es necesario se incluyen también las nuevas sinonimias, el estudio más detallado de algunos caracteres como la genitalia del macho, el oviscapto de la hembra, etc., reflejados en figuras. Para el género Pelaloptila se confecciona una clave de identificación de las especies.

\section{Estudio sistemático}

$$
\begin{gathered}
\text { Grylloidea } \\
\text { Gryllidae } \\
\text { Nemobiinae } \\
\text { Nemobiini }
\end{gathered}
$$

Nemobius sylvestris sylvestris (Bosc, 1792)

Por tratarse de una especie bastante común en la Península Ibérica, no incluimos el material estudiado. 
Encontrada adulta desde marzo a noviembre y, según Herrera (1980), también en diciembre; ninfas en los primeros estadios en marzo, julio y agosto y en los últimos, desde junio a septiembre.

DisTRIBUCIÓN. Aunque citada por varios autores (Bolívar, 1927; Harz, 1969) de toda la Península Ibérica, lo cierto es que del tercio meridional sólo se conocía de la provincia de Jaén (Ragge, 1965). Ahora la hemos encontrado, pero siempre en menor número, en las de Cádiz, Granada, Huelva y Sevilla, quedando por confirmar su presencia en el resto de las andaluzas, en las del País Valenciano y Murcia y en algunas del interior como Palencia, Valladolid, Cáceres, Badajoz y Albacete. Además, está citada de la isla de Mallorca (Ehrmann, 1988) y a pesar de que varios autores (Harz, 1969; Herrera, 1982 y Kruseman, 1988) la dan para las Canarias, otros posteriores (Gangwere et al., 1972; Kevan y Hsiung, 1992; Bland et al., 1996) la excluyen. Fuera de España su distribución abarca el suroeste de Europa desde el sur de Inglaterra, Francia, norte y sur de Portugal (Lock, 1999) hasta Polonia y la ex-Yugoslavia.

En Marruecos y Argelia se encuentra otra subespecie, N. sylvestris tingitanus Bolívar, 1914, cuya serie tipo consta de 30 sintipos y está depositada en el MNCN (París, 1994). Después de haber estudiado la serie, designamos como lectotipo un macho con las siguientes etiquetas: "Tanger, M. Escalera", "Nem. sylv. f. tingitana, Tipo", "Nemobius sylvestris tingitanus Bol. det. E. Morales Agacino", "MNCN Cat. Tipos $\mathrm{N}^{\circ} 1107$ " genitalia pegada en etiqueta, y el resto, $12 \sigma^{\pi} \sigma^{\top}$ y 17 ᄋ , con la misma etiqueta "Tanger, M. Escalera" y "MNCN Cat. Tipos $\mathrm{N}^{\mathrm{o}}$ 1108-1136", como paralectotipos. Esta subespecie se diferencia de la nominada únicamente por su menor tamaño, aunque con una diferencia poco notable, así como por la coloración menos contrastada de la cabeza.

\section{Pteronemobiini}

\section{Pteronemobius (Pteronemobius) heydenii heydenii (Fischer, 1853) \\ (Fig. 1A-C)}

Material Estudiado: BARCELONA: Moncada, $10^{7}$ (Masferrer). CIUDAD REAL: Quero, $10^{7}$ n, (últ. est.), V-1908 (J. Sanz). CÓRDOBA: Posadas, $10^{\pi}$ y 1 ㅇ (C. Bolívar). GRANADA: Pto. Camacho, 1 ㅇ, VII-1945 (E. Zarco). MADRID: Madrid, 1 ( (Vide Brunner). NAVARRA: Elizondo, valle del Baztán, $10^{\prime}$ y 1 ㅇ , 20-23-VI-1947 (Exp. IEE). VALENCIA: Valencia, $1 \delta^{\prime \prime}$ y 1 ơ (C. Bolívar).

Encontrada adulta en junio y julio y, según Blasco-Zumeta (com. pers.) y Schmidt (1999), tam- bién en agosto; varias ninfas ya en los últimos estadios, en mayo.

Distribución. Además de estas provincias se conoce de las de Cantabria (Bolívar, 1878; Cazurro, 1888), Murcia (Fuente, 1894b), Cuenca (Pantel, 1896), Alicante (Herrera, 1982) y Granada, en Sierra Nevada (Schmidt, 1999). Recientemente ha sido citada como P. concolor Walker, 1871, de los Montes de Toledo (Ciudad Real), por dos ninfas en mayo y un macho adulto en junio (Pardo et al., 1993) y de Los Monegros (Zaragoza), por una hembra (Blasco-Zumeta, 1998), siendo nueva para la de Navarra. Por tanto, aunque el material es muy escaso, su área ocuparía aproximadamente la mitad oriental de la Península, mientras que en la insular todavía no ha sido hallada. Fuera de España se extiende desde la mitad meridional de Francia hasta Grecia y Ucrania, Asia Menor, parte noroccidental de África, desde Marruecos a Túnez.

Esta especie además tiene otras cuatro subespecies: P. (P.) h. tartarus (Saussure, 1874), P. (P.) h. concolor (Walker, 1871), P. (P.) h. massaicus (Sjostedt, 1909), stat. n. y P. (P.) h. madagascariensis Gorochov, 1984a, stat. n. La primera se distribuye en la parte central de la paleártica meridional desde la Transcaucasia y Arabia Saudí hasta el Asia Central; la segunda se distribuye en la región Indo-Malaya; la tercera, en la región Etiópica y la cuarta, en Madagascar (todavía no está claro qué subespecie se encuentra en la parte nororiental de África). La subespecie nominada se diferencia de éstas por la ausencia casi completa de la f. macróptera; por la estructura de la genitalia del macho no se diferencia de $P$. (P.) h. tartarus (Fig. 1A-C).

\section{Pteronemobius (Stilbonemobius) lineolatus (Brullé, 1835)}

(Fig. 1D-F)

Material Estudiado: ÁlAVA: Puerto de Vitoria, $700 \mathrm{~m}$, 10", 17-XI-1985 (Mikel) (IAN). Urbasa-Andía, 1 \& , IX-1947 (Español). ALBACETE: Molinicos (de la Sierra), 1 ㅇ (Escalera ?). ALICANTE: Albufera, 1 ㅇ, 26-VI-1995 (E. Camuñas) (DZM). BARCELONA: Calella, 1 ㅇ (Cuní). Sora, $10^{7}$ (Nemobius lineolatus Brullé det. I. Bol.); $30^{7} \sigma^{7}$ y 4 우 우 (Masferrer). CÁCERES: Miajadas, 2 ㅇ ㅇ , 6-XI-1988 (C. M. Albadalejo). CANTABRIA: Puente Viesgo, $10^{-1}$ y 1 오, VIIIXII (Bolívar). CORUÑA: Coruña, 19 (C. Bolívar). Villa Rutis, $10^{x}$ y 3 ㅇ ㅇ , VIII (Bolívar?). GERONA: Olot, 1 으, 20-VIII-1913. GUIPÚZCOA: Elgoibar, 2 ㅇ ㅇ , VII-1934 (O. Cendrero). San Sebastián, $10^{\pi}$ y 3 우 (Escalera). Zumaya, $10^{\pi}$ y 1 o (Escalera). LÉRIDA: Montarenyo, 2300-2600 m, Ribera de Cardós, $20^{7} \sigma^{\pi}$, 8-VIII-1966. MADRID: Alcalá (de Henares), 1 ㅇ (Escalera). El Paular, 10", X-1908 (Bolívar). Vaciamadrid, río Jarama, $20^{7} \sigma^{7}$ y 2 우 0 , 14-VI-1967 (E. 

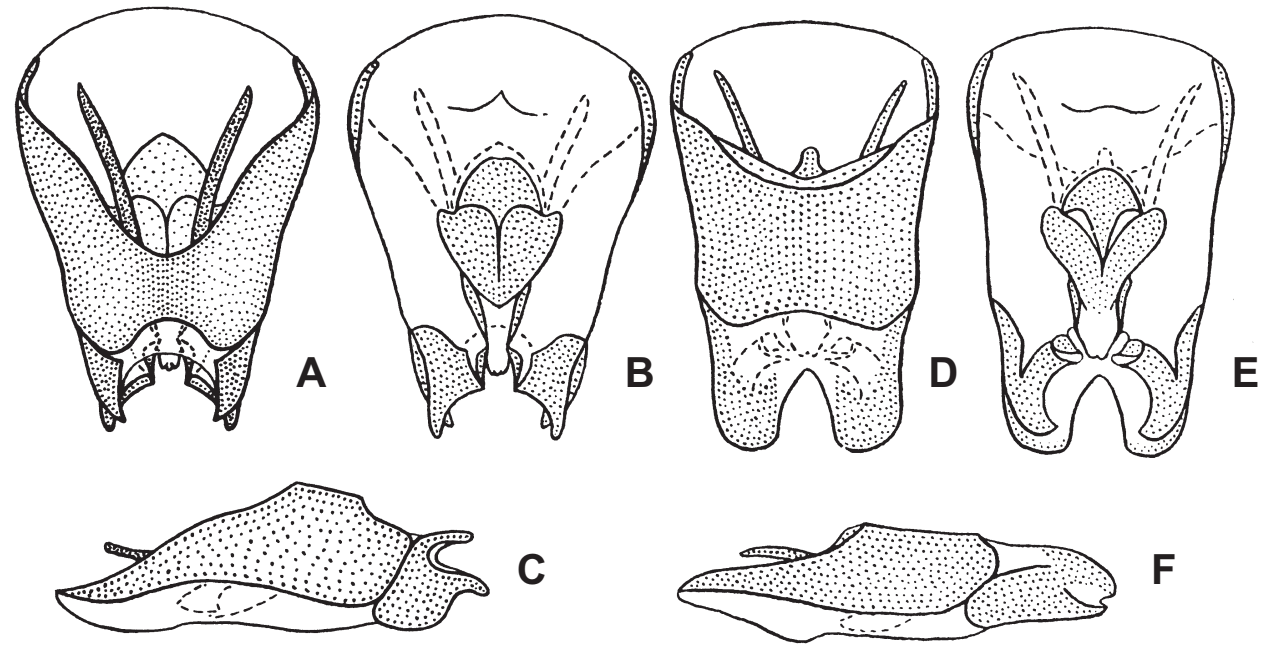

$\mathbf{F}$
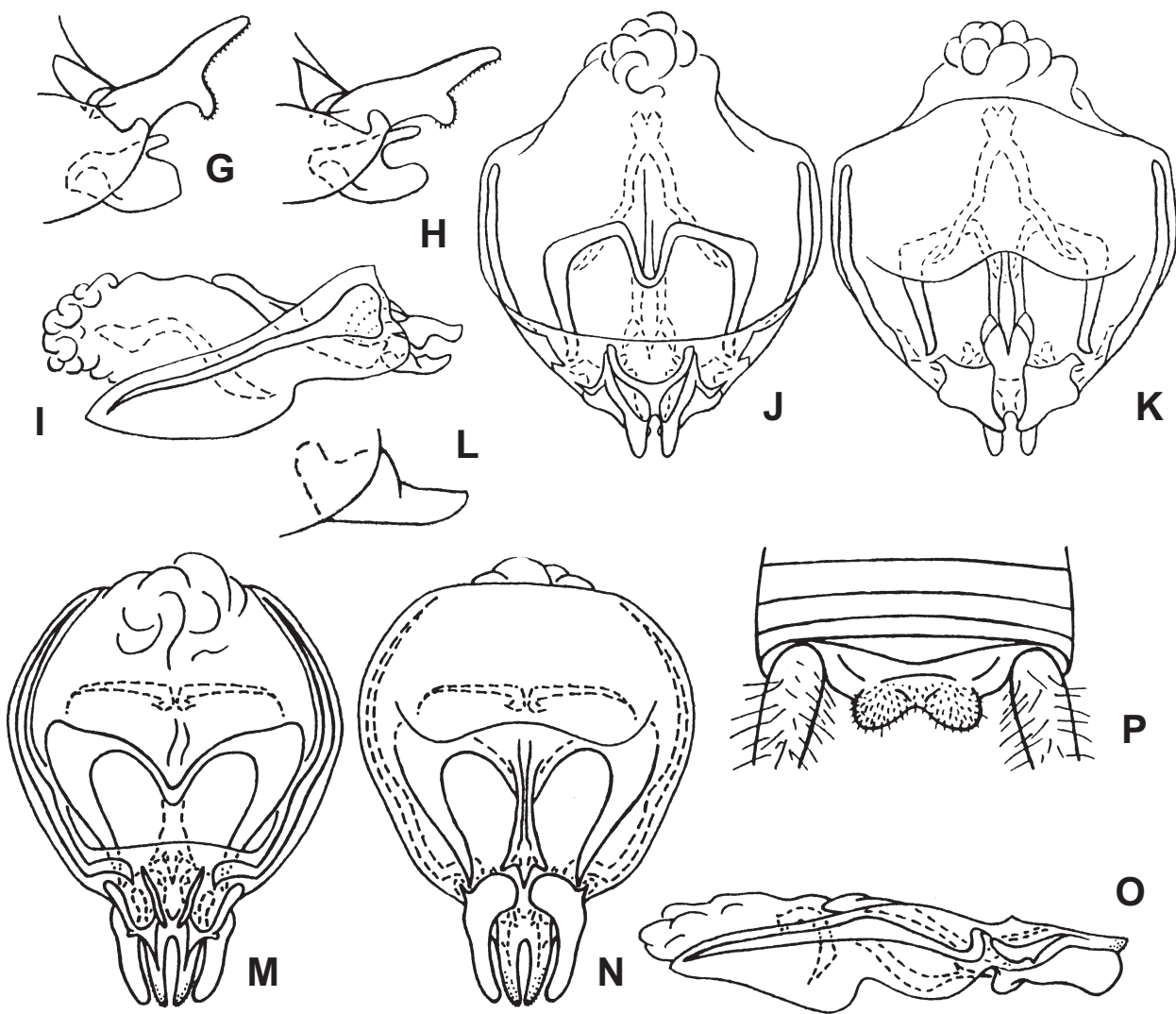

Fig. 1.- Pteronemobius y Gryllomorpha, O': A-C) Pteronemobius (Pteronemobius) heydenii tartarus; D-F) P. (Stilbonemobius) lineolatus; G) Gryllomorpha (Gryllomorpha) adspersa merobricensis; H) G. (G.) adspersa adspersa; I-L) G. (Gryllomorphella) uclensis [I-K, Barcelona; L (aumentado respecto a la figura I), Córdoba]; M-P) G. (G.) canariensis (?). Genitalia, vista dorsal (A, $\mathrm{D}, \mathrm{J}, \mathrm{M})$, vista ventral $(\mathrm{B}, \mathrm{E}, \mathrm{K}, \mathrm{N})$ y lateral $(\mathrm{C}, \mathrm{F}, \mathrm{I}, \mathrm{O})$; epifalo y ectoparámero vista lateral $(\mathrm{G}, \mathrm{H})$; ectoparámero, vista lateral (L); ápice del abdomen (sin la placa subgenital), vista dorsal (P).

Fig. 1.- Pteronemobius and Gryllomorpha, O': A-C) P. (Pteronemobius) heydenii tartarus; D-F) P. (Stilbonemobius) lineolatus; G) G. (Gryllomorpha) adspersa merobricensis; H) G. (G.) adspersa adspersa; I-L) G. (Gryllomorphella) uclensis [I-K, Barcelona; L (enlarged respect to the figure I), Córdoba]; M-P) G. (G.) canariensis (?). Genitalia, from above (A, D, J, M), from below $(\mathrm{B}, \mathrm{E}, \mathrm{K}, \mathrm{N})$ and from side $(\mathrm{C}, \mathrm{F}, \mathrm{I}, \mathrm{O})$; epiphallus and ectoparamere from side $(\mathrm{G}, \mathrm{H})$; ectoparamere from side (L); abdominal apex (without genital plate), from above (P). 
Ortiz). NAVARRA: Eugui, $30^{\pi} \sigma^{\pi}$ y 2 ㅇ $\circ$, VIII-1959 (E. Morales). SEVILLA: Sevilla, $10^{x}$ y 1 ㅇ (Mz. Escalera). TERUEL: Teruel, $935 \mathrm{~m}, 1 \sigma^{\pi}, 2 \sigma^{7} \sigma^{7} \mathrm{n}, 1$ 우 y 1 ㅇ $\mathrm{n}$ (últ. est.), 25-VIII-1934 (B. Muñoz); en el Barranco "El Regajo", 10", 10-IX-1933 (B. Muñoz). TARRAGONA: Valls, $10^{\prime \prime}$ y 2 우 우, 4-IX-1940 (F. Español). VALENCIA: Godelleta, 1 (Peris Torres) (coll. Peris) (DBUC). Valencia, 20 $\sigma^{7}$ y 1 ㅇ (Bolívar).

Encontrada adulta desde junio a diciembre y algunas ninfas, en los últimos estadios, en agosto. La forma macróptera es muy rara y fue descrita como var. fabryi Azam, 1901 (Chopard, 1951); entre el material estudiado sólo hay una hembra de esta forma de Olot. La genitalia del macho de esta especie aparece en la figura 1D-F.

Distribución. Además de estas provincias ha sido citada de las de Burgos (Cazurro, 1888), Cuenca (Pantel, 1896), Zaragoza (Navás, 1899, 1904a) y recientemente de la de Almería (Barranco y Pascual, 1991), siendo nueva para las de Cáceres, Gerona, Lérida, Navarra, Teruel y Valencia. Aunque está escasamente representada en la mitad occidental y meridional, se puede considerar que se encuentra en casi toda España peninsular; todavía no ha sido hallada ni en las Baleares ni en las Canarias. Fuera de España está citada del norte y sur de Portugal (Grosso-Silva, 2000; Fernandes, 1959a, respectivamente) y de la mitad meridional de Francia hasta Italia y Suiza.

\section{Stenonemobius (Stenonemobius) gracilis} (Jakovlev, 1871)

Material Estudiado: ALMERÍA: $19+$, 30-VIII-1963 (J Suárez). MADRID: Alcalá (de Henares), 1 우, 10-VIII-1963. Madrid, 1 우 , 18-VIII-1936 (C. Bolívar); 1 으, VII-1964 (Baxter). MURCIA: Totana, 1 ㅇ (Balaguer). TOLEDO: Talavera (de la Reina), 1 ㅇ, VIII-1960 (M. Candela).

Encontrada adulta en julio, agosto y según Blasco-Zumeta (com. pers.), también en junio. La f. braquíptera en esta especie es más rara que la macróptera; entre el material estudiado sólo hay una hembra braquíptera de Madrid. La genitalia del macho ya ha sido estudiada por Gorochov (1981: figs. 5-7).

DisTRIBUCiÓn. Además de estas provincias, este pequeño y rarísimo grillo está citado de la de Lérida (Herrera, 1982) y recientemente de Los Monegros, Zaragoza (Blasco-Zumeta, 1998), siendo nuevo para la de Madrid; por tanto, se encuentra muy localizado en el noreste, centro y sureste peninsular, lo que sugiere que su área de dispersión sea bastante más amplia. Fuera de España habita en la mitad occidental de la paleártica meridional, desde
Sicilia y África del Norte hasta Asia Central, pasando por Egipto, Sudán e Irán (Chopard, 1967).

\section{Trigonidiinae}

\section{Trigonidium (Trigonidium) cicindeloides Rambur, 1839}

Material Estudiado: AlBaCETE: Molinicos (de la Sierra), $10^{x}$ y 1 우 (Escalera). ALICANTE: Alicante, 1 우, VII1906 (J. Sanz). ALMERÍA: Sorbas, 1 오. Adra, 1 으 n (pen. est. IX-1941 (E. Morales). BARCELONA: Barcelona, 2 우 우 (Bolívar). Casa Antúnez, 10" 28-VII-1940 (E. Morales). CÁDIZ: Algeciras, $20^{7} \sigma^{7}$ y 2 우 우. Chiclana, $10^{\pi}, 2$ 우 우 y 1 우 (L. Cepero). Vejer, en La Muela, 10", 3-VIII-1995 (P. Coello). CASTELLÓN: Oropesa, 10 $10^{7}, 1$ 우 y 1 우 (macróptera), 12-25VIII-1982 (A. Compte). GRANADA: Lanjarón, $680 \mathrm{~m}, 20^{7} 0^{7}$, VII-1945 (E. Zarco). HUELVA: Coto Doñana, 10", 2-X-1967 (V. Llorente); en La Baqueta, 1 \& , 1-X-1968 (V. Llorente). MÁLAGA: Málaga, 1 \& , 16-VII-1944 (E. Morales). Marbella, $10^{7}$ y 1 ㅇ , 6-IX-1981 (M. Candela). Guadalpín, $130^{7} \sigma^{7}, 10^{7} \mathrm{n}$, 14 우 ㅇ․ MURCIA: Cartagena, 2 우, IV (Sánchez Goméz); $10^{\top}, 20^{\pi} \sigma^{7} \mathrm{n}$ y 2 우 $ᄋ$ n (s/d). SEVILLA: Sevilla, 1 o n (últ. est.) (Carrasco). VALENCIA: Puig, $2 \sigma^{\pi} \sigma^{\pi}$, 5-I-1919 (C. Bolívar). Rocafort, 10", IX-1959 (S. V. Peris) (DBUC).

BALEARES: MALLORCA: Palma, $10^{\prime \prime}$ (Moragues); $10^{\circ}$, 1-XI-1958 (Compte Sart).

CANARIAS: GRAN CANARIA: Azuaje, Baños, 10" $20^{\pi} \sigma^{\pi} \mathrm{n}$ y 1 ㅇ n (últ. est.), 16-20-X-1930 (Cabrera?). TENERIFE: Laguna, $20^{\prime \prime} \sigma^{x}$ y 1 우 (Cabrera). Sauzal, 1 으 n (últ. est.). Tacoronte, finca Pupín y Garachico (M. y J.).

Encontrada adulta desde abril a noviembre, y en enero; así como una ninfa en el penúltimo estadio en septiembre; en Canarias en febrero, junio y octubre (Gangwere et al., 1972) y ninfas últimos estadios en octubre.

Algunos autores dividen esta especie en varias subespecies, pero por ahora no se han observado diferencias constantes entre ellas. Con frecuencia la f. macróptera se considera como una subespecie aparte e incluso como otra especie humbertianum Saussure, 1878, por tener desarrollados los órganos timpanales en las tibias anteriores, mientras que faltan en la braquíptera. Entre el material estudiado sólo hay una hembra macróptera de Oropesa y dos machos con tímpanos de Guadalpín y Cartagena. La genitalia del macho aparece en Gorochov (1985a: fig. 74).

Distribución. Citada ya de la mayoría de estas provincias por varios autores (ver Herrera, 1982) y más recientemente de las de Almería (Aguirre y Pascual, 1986; Aguirre et al., 1995), Castellón (Pinedo y Llorente, 1988a) y de Sierra Nevada, Granada (Schmidt, 1999), siendo nueva para la de Albacete. Por tanto, esta especie se distribuye a lo largo de las costas oriental y meridional, así como 
en algunos puntos más al interior. También está citada de Mallorca y Menorca (Gangwere y Llorente, 1992) y de Gran Canaria y Tenerife (Bland et al., 1996). Fuera de España, desde el norte y sur de Portugal (Grosso-Silva, 2000; Fernandes, 1959a, respectivamente) y de los departamentos de la Costa Azul de Francia y Córcega, hasta Grecia, Sureste de Asia, África, Madagascar, región Indo-Malaya y parte sur de la paleártica oriental (China oriental, Japón y Corea).

\section{Natula averni (Costa, 1855), comb. n.}

Material Estudiado: CANARIAS: TENERIFE: Tenerife, $10^{x}$ (MNHU).

DisTRIBUCIÓN. Es la primera vez que se cita para las islas Canarias. Esta especie tiene al parecer una amplia distribución, desde Europa - Sur de Italia, de donde fue descrita - y África, hasta el Sureste de Asia y, Australia.

Para África y Asia es posible que averni se haya indicado bajo el nombre de Anaxipha longipennis (Audinet-Serville, 1839). Y cabe incluso la posibilidad de que ambas especies sean sinónimas y de que exista una segunda especie próxima a ella y aún por describir. Por otra parte, la presencia de averni en Australia está basada en la suposición de que Cyrtoxypha anaxiphoides Chopard, 1925, descrita de ese continente, sea también otro sinónimo de averni. Sólo el estudio de los ejemplares tipo permitirá aclarar la verdadera identidad de estas especies.

\section{Gryllomorphinae}

Este taxon fue descrito por primera vez por Saussure (1877) como "légion des Gryllomorphites"; poco después trasladó el género Gryllomorpha Fieb. (sensu Saussure) a otra "légion" y para los restantes géneros propuso un nuevo nombre "Landrevites" (Saussure, 1878: 371). Chopard (1967) sólo admitió el primer punto de vista de Saussure, considerando este taxon como tribu Gryllomorphini dentro de la subfamilia Gryllinae. Gorochov (1982 y 1984a) restituyó, en parte, el segundo punto de vista de Saussure, proponiendo considerar Landrevinae y Gryllomorphinae como subfamilias separadas y dividiendo la última en dos tribus: Gryllomorphini Sauss. y Petaloptilini Baccetti 1959, criterio que se sigue en este trabajo (inicialmente la tribu Petaloptilini fue descrita como grupo "Petaloptilae" dentro de la tribu Gryllomorphini).

De esta manera, la subfamilia Gryllomorphinae se ha convertido en un grupo bien delimitado que engloba especies que viven en la región del Antiguo Mediterráneo (desde las islas Canarias hasta el Kazajstán Oriental) y que se caracteriza por las siguientes sinapomorfías: clípeo inflado, ausencia de las alas posteriores y de los órganos de estridulación y tímpanos, así como por la estructura peculiar del ápice del oviscapto (Gorochov, 1984a: figs.11, 12, 14 y 15) y por la presencia de pequeñas espinas en las tibias posteriores, más proximales que los gruesos y desarticulados espolones (no se excluye, que este último carácter sea una plesiomorfía).

No obstante, las obras de Otte (Otte y Alexander, 1983; Otte, 1994) han introducido una notable confusión en la comprensión y límites del grupo. En el primer trabajo fueron incluidos en los Gryllomorphini los géneros australianos Eurygryllodes Chop., 1951 y Maluagryllus Otte, 1993, parecidos a Gryllomorpha únicamente por la armadura de las tibias posteriores (igual armadura también se da en otras subfamilias: Landrevinae, Itarinae). Gorochov (1990), los coloca en una tribu independiente, Eurygryllodini, dentro de la subfamilia Gryllinae. En el segundo trabajo, en el que hay algunas imprecisiones, Otte, sin ningún argumento explícito, incluye las tribus Gryllomorphini y Petaloptilini en la subfamilia Gryllinae juntamente con muchas otras tribus, la mayoría de las cuales son únicamente sinónimos de la tribu Gryllini (Gorochov, 1995a) y además incluye dentro de los Gryllomorphini no sólo los géneros australianos, más arriba mencionados, sino también representantes tan típicos de la tribu Gryllini como Gryllodinus Bol., 1927 y Eugryllodes Chop., 1927 que no comparten ningún carácter de Gryllomorphinae. Otte asimismo adjudica al género Eugryllodes, incluso la especie Gryllodes bolivari Uvarov, 1912 la cual es también representante del género Velarifictorus Randel, 1964, colocado por él mismo en otra tribu). Además coloca dentro de esta misma tribu un nuevo género, Neogryllodes, basado en una sola especie Gryllodes patagonus Sauss., 1874. Este género no está disponible al faltar una descripción o diagnosis, como exige el art. 13 del vigente Código Internacional de Nomenclatura Zoológica. Por tanto, todas estas innovaciones de Otte no se pueden tener en consideración hasta que él mismo publique los argumentos de sus decisiones y las diagnosis de los "taxones" resultantes de las mismas. 


\section{Gryllomorphini}

\section{Gryllomorpha (Gryllomorpha) dalmatina}

(Ocskay, 1832)

= Gryllomorpha dalmatina strumae Andreeva, 1982. Acta Zool. Bulg., 19: 82, syn. n.

Material Estudiado: CATAluÑA: Catalunya, $1 \sigma^{x} \mathrm{n}(1-$ os est.), 1894 (E. Traizet). BARCELONA: Barcelona, $1 \sigma^{2} \mathrm{n}$ (últs. est.) y 1 우, X-1914 (Arias); $6 \sigma^{7} \sigma^{2} \mathrm{n}$ y 3 우 우 $\mathrm{n}$ (todos 1 os est.) (E. Caballero); $20^{x} \sigma^{x}, 10-X I I-1940$ (E. Morales); $10^{x} \mathrm{n}$ (1-os est.), 27-III-1941 (E. Morales). BALEARES: MALLORCA: Comuna de Bunyola, 10", 25-IX-1993. Comuna de Caimari, Selva, $10^{\pi}$ y $10^{\pi} \mathrm{n}$ (1-os est.), 25-IX-1993. Bosc de Son Massip. Escorza, 1 on (1-os est.), 13-XI-1993. Valldemosa, Son Moragues, 1 ㅇ, 2-X-1993 (Todos C.R. Altaba). San Telm, 1 ㅇ n (1-os est.), 12-VIII-1942 (s/c).

Encontrada adulta en el nordeste de España en octubre y diciembre, y en Mallorca, desde últimos de septiembre a primeros de octubre, y en Menorca (Olmo, 1993) a mediados de julio. Las ninfas en los primeros estadios fueron halladas desde mediados de agosto hasta noviembre y marzo y en los últimos, sólo en octubre.

DistribuCión. Las citas de Málaga (Brunner, 1882; Cazurro, 1888) no las tenemos en consideración por referirse sin ninguna duda a $G$. longicau$d a$; tampoco pertenece a esta especie la de Játiva (Boscá) (Bolívar, 1878; Cazurro, 1888). Por tanto, por ahora sólo se ha encontrado en el nordeste peninsular, en Mallorca y recientemente en Menorca (Olmo, 1993). Fuera de España se encuentra desde los departamentos mediterráneos de Francia y Córcega hasta Crimea, Cáucaso y Transcáucaso, Asia Menor y Norte de África, desde Marruecos a Túnez.

Según la descripción (Andreeva, 1982), G. dalmatina strumae de Bulgaria entra dentro del margen de variabilidad de esta especie, si exceptuamos la longitud del oviscapto, que en los ejemplares búlgaros es un poco menor, pero este único carácter no es suficiente para mantenerla como subespecie independiente. La genitalia de $G$. (G.) dalmati$n a$ está publicada por Gorochov [1984a: fig. 2 (3, 7 y 11)].

\section{Gryllomorpha (Gryllomorpha) adspersa merobri- censis Fernandes, 1959, stat. $\mathbf{n}$.} (Fig. 1G, 1H)

= Gryllomorpha merobricensis Fernandes, 1959. Rev. Portug. Zool., 2: 97

Este taxon fue descrito por Fernandes (1959b) como especie independiente de la Serra de Grándola, sur de Portugal. Al examinar los ejem- plares de G. merobricensis y compararlos con los de G. adspersa Bolívar, 1914, descrita de Tánger, observamos que por varios caracteres externos ambas especies eran muy próximas. Después de estudiar las genitalias decidimos que la especie ibérica (fig. 1G) podría ser sólo una subespecie de $G$. adspersa (fig. 1H). Efectivamente, esta última se diferencia de G. merobricensis únicamente por la coloración menos oscura de la cabeza y en especial por la escotadura lateral más profunda del borde posterior de los ectoparámeros de la genitalia del macho. La genitalia de la subespecie ibérica está ilustrada casi enteramente por Fernandes (1959b: fig. 2A).

Material Estudiado: ESPAÑA: ALMERÍA: Valle, 1800

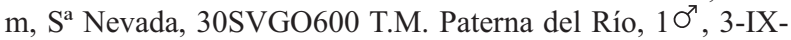
1993 (P. Barranco) [Gryllomorpha longicauda R. P. Barranco (det.) 1993]. CÁDIZ: Algeciras, 1 우 (Mz. Escalera). Sierra del Niño, 1 ㅇ , X-1989 (J.R. Miguélez) (DBUC). HUELVA: Los Marines, $10^{\pi}$ y 3 ㅇ ㅇ , 4-X-1968 (V. Llorente). JAÉN: Mancha Real, pinar de "Peña del Águila", 10", 23-III-1986 (Fco. Molino).

PORTUGAL: BAJO ALENTEJO: Grândola, Sa. Penha, $10^{x}$ y 1 ㅇ, $1-X-1959$ (A. Fernandes) (paratipos).

Encontrada adulta en la España peninsular en marzo, septiembre y octubre; en Portugal (Fernandes, 1959) en septiembre y octubre.

Los dos paratipos llevan las siguientes etiquetas: "Sa. Penha (Grândola) 1-X-1959", escrito con tinta negra, en papel cebolla; "Gryllomorpha merobricensis leg. A. Fernandes paratipo", con tinta azul (las cuatro etiquetas escritas a mano del autor); genitalia en tubo. "MNCN Cat. Tipos $\mathrm{N}^{\circ}$ 7364". Hemos considerado importante incluir los dos paratipos de Portugal, depositados en las colecciones del MNCN y donados por el autor con posterioridad a la publicación. Además, el holotipo y gran parte de la serie fueron destruidos durante el incendio del Museo Bocage de Lisboa; y como consecuencia, sólo quedan estos dos paratipos y, según Otte (1994), el neotipo macho en el NHM.

En septiembre de 1969 desde el MNCN, entonces Instituto Español de Entomología, fueron enviados al Museo Bocage de Lisboa, en préstamo al Dr. J. De A. Fernandes, ejemplares de varias especies de la subfamilia Gryllomorphinae procedentes de la Península Ibérica, Marruecos y Sidi Ifni. En este envío figuraban tipos de Discoptila fragosoi, Hymenoptila panteli Bolívar, 1914, Petaloptila aliena pallescens, así como ejemplares de Gryllomorpha longicauda, $G$. dalmatina e Hymenoptila rotundipennis (Chopard, 1938). Este material se perdió, junto con la colección de Ortópteros del Museo Bocage, en el incendio que tuvo lugar en ese Centro varios años después. Esta 
información se recoge también en el catálogo de París (1994).

Hemos comprobado que la genitalia de los machos de las provincias de Jaén y Almería, no se diferencian de la dada por Fernandes y sus medidas y las de los ejemplares de Huelva, entran dentro del margen de variabilidad de la serie tipo, aunque las del macho de Almería son un poco mayores. Sin embargo la hembra de Algeciras es más pequeña que el resto, incluida la serie tipo y sus medidas sólo coinciden con las mínimas que da Harz (1969) para $G$. merobricensis, ya que lo más probable es que se trate del mismo ejemplar.

Distribución. Citada ya de Algeciras (Harz, 1969); con el hallazgo en las provincias de Almería, Huelva y Jaén se confirma su presencia en el sur de la España peninsular. Además se conoce del sur de Portugal, de donde fue descrita y, según Harz (1969), también de Marruecos, cita que nos parece dudosa y necesitaría comprobación.

La subespecie nominotípica $G$. (G.) adspersa adspersa Bolívar, 1914, se encuentra en Marruecos; su serie tipo consta de 17 sintipos $\left(5 \sigma^{x} \sigma^{x}, 10\right.$ 우 y 2 ninfas) y depositada en MNCN. Designamos como lectotipo un macho con las siguientes etiquetas: "longicauda (tachado) tangeriana", "11", "Gryllomorpha adspersa Bol.", "Tanger, Olcese", "Gryllomorpha adspersa Bol. det. E. Morales, Agacino" y nosotros añadimos "MNCN Cat.Tipos $\mathrm{N}^{\circ} 1056$ " y genitalia en tubo. Una hembra con etiqueta: "Tanger. Olcese", 4 machos (uno con genitalia en tubo), 9 hembras y 2 ninfas $\left(\sigma^{\top}\right.$ y $\%$ ), con la etiqueta: "Tanger. M. Escalera", "MNCN Cat. Tipos $\mathrm{N}^{\mathrm{o}}$ 1057-1072" quedan como paralectotipos.

Para más información ver Catálogo de París (1994), aunque en el caso de esta especie hay algunos errores: en la $1^{\text {a }}$ etiqueta dice tanguiana, cuando en realidad es tangeriana, en la $2^{\mathrm{a}}$, " $1 \mathrm{~L}$ " y es "11" y las dos ninfas hembras registradas, son un macho y una hembra.

\section{Gryllomorpha (Gryllomorpha) longicauda} (Rambur, 1839)

Material Estudiado: GRANADA: Sierra Nevada, 1 오 1987 (C. Canella) [Gryllomorpha longicauda R. P. Barranco (det.)1993]. JAÉN: Sierra de Cazorla, E. of Nava del Espino, c.1800 m, 1 ㅇ, 30-VIII-1963 (P. M. Newman \& A. Bown) (NHM). MÁlAGA: Málaga, montañas de los alrededores, $2 \sigma^{7} \sigma^{7} \mathrm{n}$ (Rambur) (paralectotipos) y 1 우 (Rambur) (lectotipo) (NHM).

Encontrada adulta a últimos de agosto y también en abril y septiembre, según Del Cerro (1978) y Barranco y Pascual (1994), respectivamente.
Aunque Harz (1969) consideró que el tipo estaba en paradero desconocido, la serie tipo se conserva en el NHM de Londres (Otte, 1994) y ha sido estudiado por nosotros.

Designamos como lectotipo la hembra con las siguientes etiquetas: "Syntype", "Rambur coll. Pres. by R. Oberthür. Brit. Mus. 1931. 137", "Acheta longicauda", "Acheta longicauda Rambur Syntype det. John Huxley, 1972" y a los dos machos ninfas como paralectotipos.

Tanto Kirby (1906) como Harz (1969) y Otte (1994) dicen que la localidad típica es el Sur de España, sin precisar que es Málaga, en las montañas de sus alrededores, según comentarios de su descriptor.

DisTRIBUCIÓN. Ya estaba citada de las provincias de Málaga (Rambur, 1839), Jaén (Ragge, 1965; Del Cerro, 1978), siendo nueva para la de Granada. Los ejemplares de Cádiz (Chiclana, $10^{x}$ y 1 ㅇ L. Cepero leg.) mencionados por Bolívar $(1898,1900)$ y Burr (1910) y que desaparecieron en el incendio en el Museo Bocage, Lisboa, así como los de Del Cerro $(1978,1980)$ no han podido ser comprobados. Sin embargo el estudio de la genitalia de uno de los machos de Sierra Nevada (Almería) citado como $G$. longicauda (Barranco y Pascual, 1994), nos revela que no se diferencia de los de G. adspersa merobricensis por lo que lo hemos adjudicado a la subespecie anterior; mientras que el resto de estos ejemplares permanece en G. longicauda hasta que se aclare su identidad. Distintos autores la señalan también de Canarias (Kevan y Hsiung, 1992; Bland et al., 1996) y de Marruecos (Morales Agacino, 1956; Chopard, 1967), pero estas citas necesitan comprobación, ya que $G$. (G.) longicauda en especial la hembra ha sido confundida con $G$. (G.) canariensis, y en Marruecos, con $G$. (G.) adspersa. Se asemeja a estas especies por su coloración, y se diferencia de ellas por el mayor tamaño de distintas partes del cuerpo, así como por la longitud del oviscapto. En G. longicauda, la relación entre la longitud del oviscapto y la del fémur posterior es igual a 1,4 y en adspersa es 1,2. Además, como todavía no se conoce la genitalia del macho de longicauda, cabe la posibilidad de que, incluso, ésta y merobricensis sean variantes de una misma subespecie, muy variable.

\section{Gryllomorpha (Gryllomorphella) uclensis Pantel, 1890}

(Fig. 1I-L)

Material Estudiado: ALBACETE: Molinicos (de la

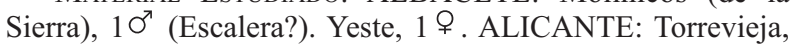


1 ㅇ , XII-1924 (M. Escalera). BARCELONA: Las Planas, 1 은, X-1940 (F. Español). San Cugat del Vallés, $10^{7}$ y 1 우, 14-X1940 (J. Mateu). Sora, $10^{7}$ y 2 우 우 (Masferrer). CANTABRIA: Santander, 10", VII-1985 (A. Blanes) (DBUC). CIUDAD REAL: Pozuelo (de Calatrava), $10^{x}$ y 1 \% (Fuente). Villahornosa, 10", 4-VIII-1986 (I. Vázquez) (DBUC). CÓRDOBA: Villanueva de Córdoba, $10^{\pi}$ (C. Bolívar). CUENCA: Uclés, $10^{\prime \prime}, \mathrm{X}$ ? (Pantel) (Gryllomorpha uclensis Pant. Bol. det.); $10^{\text {T }}$ y 1 ㅇ (G. uclensis Pant. Bol. det.) (¿Uclés, Pantel?). GRANADA: Puebla de D. Fadrique, $10^{7}$ (J. Martínez). GUADALAJARA: Humanes, río Sorbe, $10^{\pi} \mathrm{n}$ (últ. est.), 14-VII1937 (E. Morales). HUELVA: Doñana, en El Martinazo, 2 우 우, 2-3-IX-1982 (Mañez); en El Taraje, 10", 3-IX-1982 (Mañez). MADRID: El Escorial, $10^{\pi}, 1$ 우 y 1 으 $\mathrm{n}(\mathrm{s} / \mathrm{c}) ; 1$ 의 $\mathrm{n}$ (Bolívar). Madrid, 1 우, 2-VI-1982 (DBUC). MURCIA: Cartagena, $10^{7}, 10^{\prime \prime}$ n, 2 우 우 y 3 우 우 n (¿Sánchez Gómez?). TERUEL: Teruel, $10^{\circ}$ y 1 , , IX-1931; $1 \stackrel{\circ}{\circ}, 1 \mathrm{n}$ (1-os est.), 10 VII-1934; 1 ㅇ n (1-os est.), $4 \sigma^{7} \sigma^{x} \mathrm{n}$ y 1 ㅇ n (últ. est.), 20-25VIII-1934 (Todos de B. Muñoz). TOLEDO: Layos, 1 우, IX1984 (M. Menguera) (DBUC).

Encontrada adulta desde junio a octubre y en diciembre; las ninfas en los primeros y últimos estadios en julio y agosto.

DistRIBUCIÓN. También ha sido citada de las provincias de Zaragoza (Navás, 1900 y 1904a; Barranco Vega, 1998), Almería (Bolívar, 1927), Cádiz (Ragge, 1965), Granada (Pascual, 1978a, 1978b) y Navarra (Herrera y Schnidrig, 1983); siendo nueva para las de Cantabria, Córdoba, Guadalajara, Huelva, Teruel y Toledo. Por tanto, su área conocida ocupa más de la mitad oriental de la España peninsular, ya que además se ha encontrado en las provincias de Cádiz y Huelva. Fuera de España se extiende desde los departamentos mediterráneos de Francia y Córcega hasta Italia y Suiza. Su presencia en Portugal, aunque muy probable, todavía no está confirmada, ya que sólo Kirby (1906) y Chopard (1943) la dan sin mucha precisión; efectivamente años más tarde Fernandes (1960) dice que, quizás, sean citas erróneas.

Aunque distintos autores (Chopard, 1943 y 1967; Morales Agacino, 1956; Harz, 1969; Herrera, 1982) la indican para el África del Norte, estos datos necesitan comprobación, ya que en esta área habitan especies difícilmente distinguibles de ésta por sus caracteres externos. Además, creemos que es la primera vez que se estudia en profundidad la genitalia del macho de $G$. (G.) uclensis (fig. 1I-L), ya que los datos y figuras que dan Herrera y Schnidrig, no son completos.

\section{Gryllomorpha (Gryllomorphella) canariensis Chopard, 1939}

(Fig. 1M-P)

Material Estudiado: CANARIAS: TENERIFE: Agua Mansa, 1100 m, 1 ㅇ n (últ. est.), IV-1935 (C. Bolívar-F. Bonet). Guimar, Montaña Grande, $10^{7} \mathrm{n}$ (últ. est.), 22-29-I-1933.
Esperanza, pinar, en Fuente Fría, 1 \& n (últ. est.), 5-V-1921 (Gryllomorpha longicauda Ramb. Cabrera det.); en Hoya de las raíces, 1 ㅇ , 14-X-1928 (A. González) (Gryllomorpha longicauda Ramb. Cabrera det.); en Laguneta Alta, 1n (últ. est.), 24-XI-1909 (Cabrera?) (Gryllomorpha longicauda Ramb. Cabrera det.); 1 오, 2-X-1927 (Cabrera?) (Gryllomorpha longicauda Ramb. Cabrera det.) (Gryllomorpha canariensis Chop. Det. E. Morales Agacino). Icod, Chinyero (volcán en actividad), 1 ㅇ , 21-XI-1909 (Cabrera?) (Gryllomorpha longicauda Ramb. Cabrera det.). Las Cañadas del Teide, 1 ㅇ, 25-27-IX1927. Tahodio, 1n (1s. est.), 10-V-1930. Vueltas de Taganana, 700-800 m, 1 ㅇ , II-1921 (M. Escalera). LA PALMA: P.N. Calderas de Taburiente, Lomo de las Chozas. El Paso 28RBS2027, 1260 m, 10", 7-IX-1999 (Domingo-Quero).

Encontrada adulta de septiembre a noviembre y en febrero, además, según Gangwere et al. (1972), en enero y junio; ninfas en los primeros estadios en mayo y en los últimos en enero, abril, mayo $\mathrm{y}$ noviembre.

Como se puede observar en el Material estudiado y en el apartado de $G$. (G.) longicauda, estas dos especies han sido confundidas durante varios años.

Al no conocerse todavía la genitalia de G. canariensis de ejemplares de Tenerife, atribuimos con duda a esta especie el macho recientemente capturado en La Palma y cuya genitalia aparece en la figura $1 \mathrm{M}-\mathrm{P}$.

DisTRIBUCIÓN. Ya estaba citada de Tenerife, entre otros autores, por Gangwere et al. (1972), Kevan y Hsiung (1992) y Bland et al. (1996). Hasta ahora se ha considerado endémica de esta isla, citándose, con duda, por primera vez para la de La Palma.

\section{Gryllomorpha (subgénero ?) gracilipes Chopard, 1943}

No se ha dispuesto de ningún ejemplar de esta especie.

DisTRIBUCIÓN. Hasta ahora está citada sólo de la isla de Fuerteventura (Chopard, 1954 y 1967; Bland et al., 1996). Además se encuentra en Marruecos, de donde fue descrita.

La identificación correcta de esta especie, procedente de las Canarias, necesita una comprobación, ya que la genitalia del macho no ha sido todavía estudiada.

\section{Hymenoptila lanzarotensis Kevan y Hsiung, 1992}

Según estos autores encontrada adulta de marzo a mayo y noviembre y ninfas de marzo a mayo.

DISTRIBUCIÓN: Por ahora sólo encontrada en las islas de Lanzarote y Fuerteventura (Kevan y Hsiung, 1992); esta última isla fue omitida por Bland et al. (1996). 

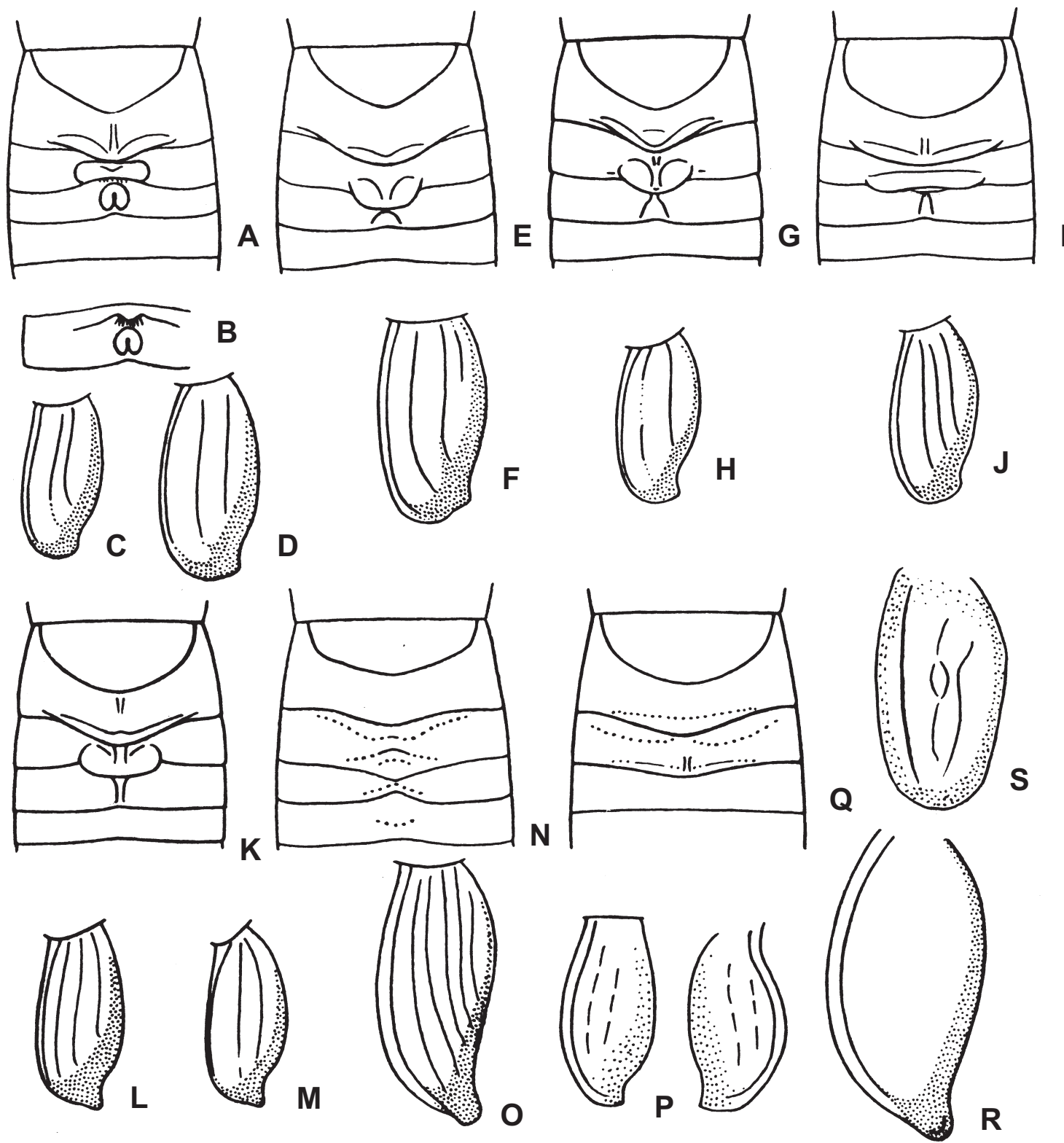

Fig. 2.-Petaloptila, $\sigma^{\nwarrow}$ : A-D) P. (Petaloptila) aliena; E-F) P. (P.) pallescens; G-H) P. (P.) fermini sp. n.; I-J) P. (P.) pyrenaea; KM) P. (P.) isabelae (K, M, holotipo); N-O) P. (Zapetaloptila) venosa sp. n.; P) P. (Z.?) bolivari (sintipo) (según Pantel, 1890); QR) P. (Z.) barrancoi sp. n. (holotipo); S) P. (Italoptila) andreinii (según Capra, 1937). Pterotorax (tegminas apartadas) y base del abdomen, vista dorsal (A, E, G, I, K, N, Q); segundo terguito abdominal, sin cubrir por delante, vista dorsal (B), tegmina izquierda (C, D, F, H, J, L, M, O, R, S); tegminas izquierda y derecha (P).

Fig. 2.-Petaloptila, $\sigma^{\top}$ : A-D) P. (Petaloptila) aliena; E-F) P. (P.) pallescens; G-H) P. (P.) fermini sp. n.; I-J) P. (P.) pyrenaea; KM) P. (P.) isabelae (K, M, holotype); N-O) P. (Zapetaloptila) venosa sp. n.; P) P. (Z.?) bolivari (sintype) (after Pantel, 1890); QR) P. (Z.) barrancoi sp. n. (holotype); S) P. (Italoptila) andreinii (after Capra, 1937). Pterothorax (without tegmina) and base of abdomen from above (A, E, G, I, K, N, Q); second tergite of abdomen, not covered at base, from above (B), left tegmen (C, D, F, H, J, L, M, O, R, S); left and right tegmina (P). 


\section{Petaloptilini \\ Petaloptila Pantel, 1890}

\section{Clave de identificación de subgéneros y especies sólo para machos}

1. Tegmina con una notable escotadura en la parte distal del borde interno (fig. $2 \mathrm{C}, 2 \mathrm{D}, 2 \mathrm{~F}, 2 \mathrm{H}, 2 \mathrm{~J}, 2 \mathrm{~L}, 2 \mathrm{M}, 2 \mathrm{O}, 2 \mathrm{P}$ y $2 \mathrm{R})$. Abdomen sólo con un pequeño lóbulo posterior del primer terguito (fig. $2 \mathrm{~A}, 2 \mathrm{E}, 2 \mathrm{G}, 2 \mathrm{I}, 2 \mathrm{~K}, 2 \mathrm{~N}$ y $2 \mathrm{Q}$ ) ........ 2

- Tegmina sin la escotadura en el borde interno (fig. 2S). Abdomen con el lóbulo posterior del primer terguito muy grande. Península Apenina [Subgénero Italoptila subgén. n. (especie tipo Petaloptila andreinii Capra, 1935)]

P. (I.) andreinii Capra

2. Tegmina pequeña (3-4 mm de longitud), con el ápice anchamente redondeado (fig. $2 \mathrm{C}, 2 \mathrm{D}, 2 \mathrm{~F}, 2 \mathrm{H}$ y $2 \mathrm{~J}$ ) o muy poco prolongado y casi puntiagudo (fig. $2 \mathrm{~L}$ y $2 \mathrm{M}$ ). Glándula dorsal bien desarrollada con unos salientes engrosados bien visibles en la parte posterior del metanoto y en los dos primeros terguitos abdominales (fig. 2A, 2E $2 \mathrm{G}, 2 \mathrm{I}$ y $2 \mathrm{~K}$ ). Genitalia con los lóbulos pares del ápice del epifalo, pequeños y pilosos; moldura de la placa de sujeción del espermatóforo larga, alcanzando el ápice de la varilla guía (figs. 3A, 3B; 4A, 4B, 4E, 4F, 4I, 4J; 5A y 5B); ápice de la varilla guía con un pequeño tubérculo bien esclerotizado (figs. 3D; 4D, 4H, 4L; 5D); parte distal del ectoparámero con una pequeña proyección no bifurcada, dirigida hacia abajo (figs. 3C; 4C, 4G, 4K; 5C). Península Ibérica [Subgén. Petaloptila s. str. (especie tipo Gryllomorphus alienus Br.-W.)] ..................................... 3

- Tegmina más grande $(4,5-5,5 \mathrm{~mm}$ de longitud) por lo general, con el ápice notablemente prolongado y estrechamente redondeado (fig. $2 \mathrm{O}$ y $2 \mathrm{R}$ ), pero a veces indistinguible de la del subgénero Petaloptila (fig. 2P). Glándula dorsal más débilmente desarrollada y formada por varias convexidades poco visibles (fig. $2 \mathrm{~N}$ y $2 \mathrm{Q}$ ). Genitalia con los lóbulos pares del ápice del epifalo más grandes y pilosos; moldura de la placa de sujeción del espermatóforo corta y separada del ápice de la varilla guía por un espacio ancho y membranoso (fig. 5F, 5G, 5I y 5J); ápice de la varilla guía membranoso; parte distal de los ectopárameros con una proyección grande y bifurcada, con ambas ramificaciones dirigidas más o menos hacia abajo (fig. $5 \mathrm{H}$ ) o dirigida hacia abajo y atrás sólo la ramificación posterior, mientras que la anterior doblada proximalmente (fig. 5K). Península Ibérica [Subgénero Zapetaloptila subgén. n.(especie tipo Petaloptila barrancoi sp. n.)] .....

3. Glándula dorsal con el saliente engrosado posterior del primer terguito abdominal débilmente ensanchado y carente de una quilla media longitudinal bien marcada y con un tubérculo bastante ancho en la parte posterior del segundo terguito abdominal (fig. 2A y 2E). Genitalia con la proyección proximal de los ectoparámeros bastante larga, pero no ensanchada o débilmente ensanchada en el ápice y dirigida hacia abajo y el medio (figs. 3B, 3C, 3E; 4B y 4C) ...... 4

- Glándula dorsal de variadas formas (fig. 2G, 2I y 2K). Genitalia con la proyección proximal de los ectoparámeros bastante corta y no ensanchada en el ápice (fig. 4F, 4G, 4J, $4 \mathrm{~K}$ y $4 \mathrm{M}) \mathrm{o}$, por el contrario, la proyección muy larga y fuertemente ensanchada en el ápice (fig. 5B, 5C y 5E) y dirigida hacia abajo y ligeramente al medio
4. Coloración parduzca, con manchas netas; cabeza por encima parda o con bandas longitudinales pardas y por delante con una mancha grande pardo oscura entre los ocelos y las partes superiores de las cavidades antenales. Glándula dorsal con un tubérculo bifurcado en la parte posterior del segundo terguito abdominal (fig. 2A y 2B). Genitalia con la escotadura central del borde posterior del epifalo estrecha y bastante profunda (fig. 3A), con la proyección proximal de los ectoparámeros débilmente ensanchada en el ápice y dirigida hacia abajo y el medio (fig. 3B y $3 \mathrm{E}$ ); el tubérculo esclerotizado del ápice de la varilla guía, puntiagudo (fig. 3D)

$\boldsymbol{P}$.(P.) aliena (Br.-W.).

- Coloración amarillo arena, con manchas más débiles; cabeza por encima con bandas longitudinales pardo claras y por delante con una mancha parduzca pequeña sólo entre los ocelos. Glándula dorsal con un tubérculo no bifurcado en la parte posterior del segundo terguito abdominal (fig. 2E). Genitalia con la escotadura central del borde posterior del epifalo más ancha y poco profunda (fig. 4A), con la proyección proximal de los ectoparámeros estrechándose hacia el ápice y dirigida hacia abajo y el medio (fig. 4B y 4C); el tubérculo esclerotizado del ápice de la varilla guía redondeado (fig. 4D) ..................... P. (P.) pallescens Bol.

5. Coloración amarillo arena, casi uniforme. Glándula dorsal con el saliente engrosado posterior del primer terguito abdominal muy ancho y con una protuberancia formada por dos tubérculos estrechos en la parte anterior y posterior del segundo terguito abdominal (fig. 2I). Genitalia con el epifalo casi desarticulado de los rami (fig. 4G), con el tubérculo esclerotizado del ápice de la varilla guía muy puntiagudo (fig. 4H) y con la proyección proximal de los ectoparámeros bastante corta y estrechándose hacia el ápice (fig. 4F y 4G) ………............... P. (P.) pyrenaea Olm.-Vid. et Hern.

- Coloración parduzca, con manchas bien delimitadas, que recuerda a la de P. aliena (ver tesa 4). Glándula dorsal con el saliente engrosado posterior del primer terguito abdominal más estrecho y con un tubérculo de distintas formas en la parte posterior del segundo terguito abdominal (figs. $2 \mathrm{G}$ y $2 \mathrm{~K}$ ). Genitalia con el epifalo no desarticulado de los rami (figs. 4K; 5C); con el tubérculo esclerotizado del ápice de la varilla guía menos puntiagudo (fig. $4 \mathrm{~L}$ ) o casi redondeado (fig. 5D) y con la proyección proximal de los ectoparámeros de distintas formas (fig. $4 \mathrm{~J}, 4 \mathrm{~K}, 4 \mathrm{M} ; 5 \mathrm{~B}, 5 \mathrm{C}$ y $5 \mathrm{E}$ )

6. Tegmina con el ápice muy poco prolongado y casi puntiagudo (fig. 2L y $2 \mathrm{M}$ ). Glándula dorsal con una quilla media longitudinal del saliente engrosado posterior del primer terguito abdominal bien patente y con un tubérculo estrecho en la parte posterior del segundo terguito abdominal (fig. 2K). Genitalia con la escotadura central del borde posterior del epifalo casi cuadrangular (fig. 4I), con el tubérculo esclerotizado del ápice de la varilla guía marcadamente puntiagudo (fig. 4L) y con la proyección proximal de los ectoparámeros corta y estrechándose hacia el ápice (fig. 4J, 4K y 4M)

P. (P.) isabelae sp.n.

- Tegmina con el ápice redondeado (fig. 2H). Glándula dorsal carente de una quilla bien patente media longidinal del saliente engrosado posterior del primer terguito abdominal y con un tubérculo más ancho en la parte posterior del segundo terguito abdominal (fig. 2G). Genitalia con la escotadura central del borde posterior del epifalo ancha, poco profunda y redondeada, en el centro de la cual apare- 
ce un saliente muy pequeño (fig. 5A); el tubérculo esclerotizado del ápice de la varilla guía casi redondeado (fig. 5D); la proyección proximal de los ectoparámeros muy larga y fuertemente ensanchada hacia el ápice (fig. 5B, 5C y $5 \mathrm{E}$ )

P. (P.) fermini sp.n.

7. Tegmina cerca de $4,5 \mathrm{~mm}$ de longitud, con el ápice casi redondeado (no prolongado) (fig. 2P)

P. (Z.?) bolivari (Caz.)

- Tegmina de 5-5,5 $\mathrm{mm}$ de longitud, con el ápice notablemente prolongado y estrechamente redondeado (fig. 20 y 2R)

8. Tegmina relativamente estrecha, con bastantes venas longitudinales (o con sus patentes huellas) (fig. 2O). Genitalia con el epifalo relativamente largo, desarticulado de los rami y provisto de una escotadura central profunda del borde posterior (fig. $5 \mathrm{~F}$ y $5 \mathrm{H}$ ); proyección distal de los ectoparámeros con la ramificación posterior grande y dirigida hacia abajo y atrás, mientras que la ramificación anterior es pequeña y dirigida casi directamente hacia abajo (fig. 5G y 5H); moldura de la placa de sujeción del espermatóforo (con las apodemas) ancha (fig. 5F y 5G) .............

P. (Z.) venosa sp.n.

- Tegmina un poco más ancha, sólo con una vena patente a lo largo del borde lateral (fig. 2R). Genitalia con el epifalo relativamente corto, unido con los rami y provisto en el borde posterior de una escotadura central pequeña, en el centro de la cual aparece un pequeño lóbulo triangular (fig 5I y $5 \mathrm{~K}$ ); proyección distal de los ectoparámeros con la ramificación posterior pequeña y dirigida ligeramente hacia abajo y atrás, mientras que la anterior es grande y dirigida hacia adelante (proximalmente) (fig. $5 \mathrm{~J}$ y $5 \mathrm{~K}$ ); moldura de la placa de sujeción del espermatóforo (con las apodemas) claramente más estrecha (fig. $5 \mathrm{I}$ y $5 \mathrm{~J}$ )

P. (Z.) barrancoi sp.n.

Petaloptila (Petaloptila) aliena (Brunner-

Wattenwyl, 1882)

(Figs. 2A-D; 3A-E)

= Discoptila eitschbergeri Harz, 1976. Nachrbl. Bayer. Entom., 25: 55, syn. n.

Material Estudiado: ALiCANTE: Cabesó, 2 우 (Boscá). Font Roja, 40 $0^{7}$ y 3 우 우, 3-X-1991 (E. Galante) (DZM). Maigno, 1 우 , 19-III-1996 (M.J. Auria) (DZM). BARCELONA: Garraf, 107 y 1 \% , 14-II-1941 (E. Morales). CUENCA: Cuenca, 1 ㅇ, 16-V-1923. GERONA: Olot, 1 ㅇ (Cazurro) (Petaloptila aliena Brunner, letra de Bolívar). TERUEL: Teruel, 10, IX-1928 (B. Muñoz); 1 ㅇ , VIII-1935 (B. Muñoz); Teruel, Sierra Alta, $10^{7} \mathrm{n}$ (últ. est.) (holotipo) (Discoptila eitschbergeri. Harz) (GNHM). VALENCIA: Calvet, 1 ? , 6VII-1888. Játiva, 2 우 우 (Boscá). Valencia, 1 우, VI (Escalera). ZARAGOZA: Zaragoza, alrededores, 10 , 16-IV-1963 (B. Cogan) (ZIAS)

Encontrada adulta de febrero a octubre y según Pardo et al. (1993), ninfas en mayo.

D. eitschbergeri fue descrita por Harz (1976) basándose en un único ejemplar. El estudio del holotipo demuestra que se trata de una ninfa macho en el último estadio, perteneciente, en realidad, a $P$. aliena, lo que evidencia la característica coloración de su cabeza. La genitalia del macho de esta especie se estudia por primera vez aquí (fig. 3A-E).

DistriBuCión. Ya estaba citada de las provincias de Gerona, Barcelona, Cuenca, Valencia (Bolívar, 1900, 1927; Navás, 1909b), Teruel (Morales Agacino, 1933) y recientemente, en gran número de la de Alicante (Hernández et al., 1998); las citas de la Serranía de Cuenca (Pardo et al., 1993) podrían pertenecer también a esta especie, siendo nueva para la de Zaragoza. Sin embargo, los ejemplares citados como $P$. aliena de la sierra de Cazorla, Jaén (Del Cerro, 1978, 1980), resultaron pertenecer a $P$. isabelae sp. n.; lo mismo podría suceder con los de Ragge (1965). Por otra parte, el ejemplar de "Panticosa (Escalera), 5-8-93" (Bolívar, 1898, 1900, 1927), citado, también, como de la provincia de Huesca (Herrera, 1982; Barranco Vega, 1998; Hernández et al., 1998) resultó pertenecer a $P$. pyrenaea. Por ahora este endemismo ibérico ocupa parte de la franja oriental de la Península desde Gerona a Alicante y algunas provincias del interior. Hasta ahora no se han podido comprobar las citas de Portugal dadas por Aires y Menano (1916) y recogidas a su vez por varios autores (Bolívar, 1927; Chopard, 1967; Herrera, 1982; Hernández et al., 1998).

\section{Petaloptila (Petaloptila) pallescens Bolívar, 1927} (Figs. 2E, 2F; 4A-D)

Material Estudiado: ÁVILA: Candeleda, 1 우 , 3-III1985 (R. Rubio) (DBUC); El Tiemblo, 1 ㅇ , 10-XI-1985 (R. C. Chillerón) (DBUC). Guisando, 1 ㅇ , 9-V-1975 (C. Eisman) (DBUC). La Adrada, 1 Ơn (últ. est.), IX-1980 (C. Iñigo Vega) (DBUC). Las Navas del Marqués, 1 ㅇ, X-1943 (L. Nájera); 1 O n (últ. est.), 6-IV-1989 (A. Aparisi) (DBUC). Piedralabes, $721 \mathrm{~m}, 1$ ㅇ , 31-III-1983 (J. Álvarez). Pto. de Castilla, $10^{\prime \prime} \mathrm{n}$ (últ. est.), 20-VII-1989 (R. Egido) (DBUC). Valle de Iruelas, Gredos, 2 우 우. CUENCA: Hoz Huécar, 1우, V-1977 (J. M. Caños) (DBUC). Priego, 1 ㅇ , 20-V-1990 (A. Cano) (DBUC). MADRID: Cadalso de los Vidrios, 1 ㅇ, V-1976 (C. Rey). Canencia, 1 ㅇ, 14-VI-1986 (R. González) (DBUC). Cercedilla, 10", IX-1916 (Bolívar) (P. aliena Brunn. var. flavescens Bol.) (lectotipo); $20^{7} \sigma^{7}$ y $10^{7} \mathrm{n}$ (F. Bonet); en la Estación Alpina, 1500 m, $30^{7} \sigma^{7}$, X-1934 (C. Bolívar);1 $\sigma^{7}, \mathrm{~V}-$ 1935; $10^{7}$ y 1 우, VI-1936; 1 오, IV-1943 (Todos J. Hernández); $10^{7} \mathrm{n}$ (últ. est.), VII-1951; 2 웅 으, IX-1951; $60^{7} \sigma^{7} \mathrm{n}$ y 7 우 우 $\mathrm{n}$ ; 1 우 n, VIII-1957; $10^{7}, 30^{7} 0^{7} \mathrm{n}, 1$ 우 y 10 우 우 n, VIII-1958; $10^{\top} \mathrm{n}$ y 3 우 으, VIII-1959 (Todas ninfas últ. est.) (Todos J. Abajo); en El Ventorrillo, $10^{7}$ y 1 ㅇ , 12-IV-1935 (E. Morales); $1480 \mathrm{~m}, 7$ 우 우 $\mathrm{n}$, VIII-1959; $10^{\text {‘n }} \mathrm{n}$ y 3 우 우 $\mathrm{n}$, VIII-1960;

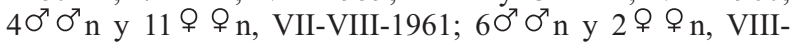
1962; $30^{7} \sigma^{7}$ y 1 우, IX-1962; $30^{7} \sigma^{\pi} \mathrm{n}$ y 4 우 우 n, VIII-1963; $30^{7} \sigma^{\prime \prime} \mathrm{n}$ y 8 우 우 n, VIII-1964; $10^{7}$ y 1 으, VIII-1965 (Todas ninfas últ. est.) (Todos J. Abajo). El Escorial, $10^{7} \mathrm{n}$ (últ. est.) (Lauffer) (paralectotipo); 1 우 IV-1930 (C. Bolívar); 1 우, 28- 

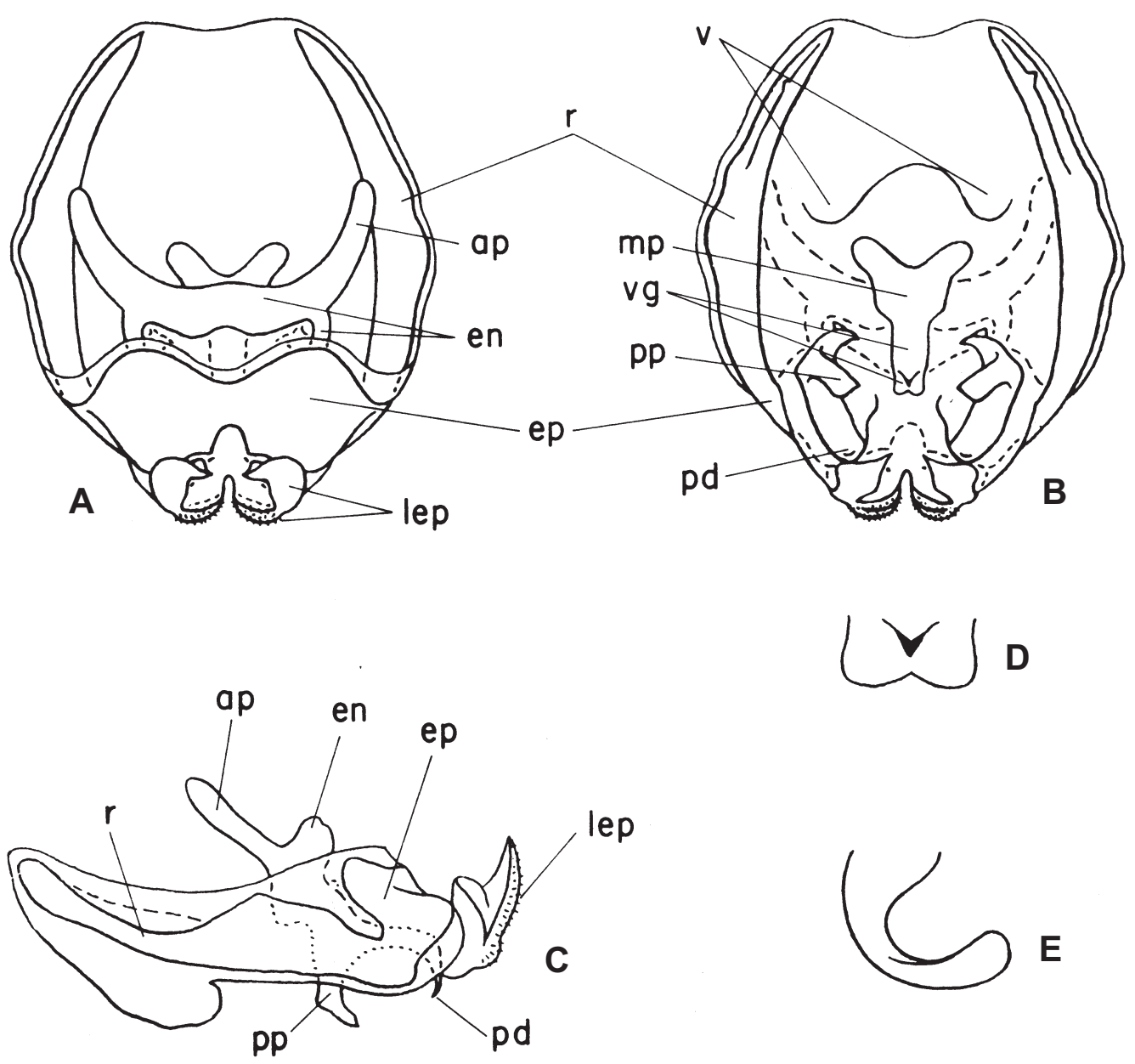

Fig. 3.- Petaloptila (Petaloptila) aliena, ơ : Genitalia, vista dorsal (A); ventral (B) y lateral (C); ápice de la varilla guía, vista ventral (tubérculo esclerotizado, pintado en negro) (D); proyección proximal inferior del ectoparámero izquierdo, por detrás (E). Abreviaturas: ap - apodema endoparameral; en - endoparámero; ep - epifalo; lep - lóbulos pilosos del ápice del epifalo; mp - moldura de la placa de sujeción del espermatóforo; pd - proyección distal del ectoparámero; pp - proyección proximal del ectoparámero; $r$ - ramus, v - valvas; vg - varilla guía.

Fig. 3.- Petaloptila (Petaloptila) aliena, $\mathrm{O}^{7}$ : Genitalia from above (A); from below (B) and from side (C); apex of guiding rod from below (sclerotized tubercle is designated by black) (D); lower proximal process of left ectoparamere from behind (E). Abreviations: ap - endoparameral apodeme; en - endoparamere; ep - epiphallus; lep -hairy lobes of apex of epiphallus; mp - mold of attachment plate of spermatophore; $\mathrm{pd}$-distal process of ectoparamere; $\mathrm{pp}$ - proximal process of ectoparamere; $\mathrm{r}$ - ramus; $\mathrm{v}$ valvae; vg - guiding rod.

IV-1978 (R. Holzado) (DBUC); en S. Lorenzo, $10^{7}$, 5-VI-1979 (E. Cercadillo) (DBUC). Madrid, 10", 4-IV-1973 (Díez), en Casa de Campo, 1 ㅇ, VI- 1972 (DBUC). Pto. Navacerrada, 1 우 y 1 ㅇ $\mathrm{n}$ (F. Bonet). Robledo, 1 ㅇ, V-1934 (E. Morales). Sta. María de la Alameda, 10", 18-X-1984 (C. M. Albadalejo y M.G. París). Siete Picos, $1650 \mathrm{~m}, 30^{7} \sigma^{7}$ y 1 \% (últ. est.), VIII-1958 (J. Abajo). Torrelodones, $10^{7} \mathrm{n}$ y 1 \& $\mathrm{n}$ (últ. est.), VII-1979 (A. Jaramillo) (DBUC). Villalba, $10^{x}$ y 1 우, 26-IV1970 (J. Ramos) (DBUC).
Encontrada adulta desde marzo a noviembre y ninfas en los últimos estadios de abril a septiembre.

La serie tipo constaba de 4 sintipos, pero uno de ellos, de Bussaco (Portugal) fue destruido en el incendio del Museo de Bocage, Lisboa. De los tres restantes designamos como lectotipo al único macho adulto, que lleva las siguientes etiquetas: "Cercedilla, IX-1916. Bolívar", "P. aliena Brunn. 
var. flavescens Bol.", "MNCN Cat. Tipos N¹356" y genitalia en tubo. Los otros dos sintipos: un macho, ninfa de "Escorial (Lauffer)" "MNCN. Cat. Tipos $\mathrm{N}^{\mathrm{o}} 1357$ " y una hembra de "Las Hurdes. Breuil. VI-1918", "MNCN Cat. Tipos No 1358", quedan como paralectotipos. Esta hembra, procedente de la provincia de Cáceres, ha resultado pertenecer a $P$. fermini sp. n. que se describe más adelante y figura, a su vez, como paratipo. Todos depositados en el MNCN.

El estudio de la genitalia del macho se realiza por primera vez y aparece en la figura 4A-D.

DistribuCión. Aunque citada por Bolívar (1927) de las provincias de Madrid y Cáceres, excluimos esta última por lo dicho más arriba; es nueva para las de Ávila y Cuenca. Su presencia en Bussaco, Portugal, queda por confirmar, aunque consideramos como más probable que sea otra especie.

Aunque Harz (1969) cambia el estatus de $P$. aliena pallescens y la eleva a especie, Heller et al. (1998) no lo tienen en cuenta y siguen considerándola como subespecie y, probablemente por esta razón, no la incluyen en su estudio como especie de la Península Ibérica.

\section{Petaloptila (Petaloptila) pyrenaea Olmo-Vidal et} Hernando, 2000

(Figs. 2I y 2J; 4E-H)

Material Estudiado: HUESCA: Oncins, Cueva del Hueso Santo, 10", 14-VI-1985 (Hernando); 1 ㅇ , 10-II-1986 (Fresneda). Panticosa, $1 \stackrel{+}{\circ}$ 5-VIII-1893 (Escalera). Pueyo de Jaca, 1200 m, 107, VII-1956 (Exp. Inst. Esp. Entomología). LÉRIDA: Llastari, Avenc Safor, $10^{\star}$ y 1 ○ , 28-XII-1982 (O. Escolá) (ZIAS).

Entre el material estudiado el único macho que no pertenece a las localidades de la serie tipo de $P$. pyrenaea es el ejemplar de Pueyo de Jaca. Este macho se parece mucho por sus dimensiones, la estructura de la glándula dorsal y la genitalia a los otros dos machos disponibles, así como a la descripción de $P$. pyrenaea, pero presenta algunas diferencias, principalmente en cuanto a su genitalia. Esta última sólo se ha podido estudiar y comparar con la del macho de Avenc Safor, ya que el otro carece de ella. Las diferencias son las siguientes: las proyecciones inferiores de la parte proximal de los ectoparámeros en el macho de Pueyo de Jaca son más cortas (esto puede ser una variabilidad intraespecífica basada en un único macho examinado por nosotros) (fig. 4F). Además el macho de Avenc Safor, de la misma procedencia que el holotipo de $P$. pyrenaea, también tiene el tubérculo del ápice de la varilla guía, pero está muy débilmente esclerotizado y poco visible, por lo que, probablemente, pasó desapercibido para los autores de este taxon $\mathrm{y}$, por consiguiente, no aparece reflejado ni en el texto ni en la figura 3 de su trabajo. Por otra parte, al no incluir dichos autores una figura de la genitalia, en visión lateral, tampoco se puede observar que el epifalo está casi desarticulado de los rami, carácter importante, ya que sirve para separar especies y que nosotros hemos incluido en la clave del género Petaloptila (fig. 4G y 4H).

Debido a la existencia de estas diferencias y a la ausencia de información sobre algunas piezas de la genitalia, hemos considerado conveniente incluir una descripción del macho de Pueyo de Jaca que resulta complementaria para $P$. pyrenaea.

Coloración amarillo arena, casi uniforme, si bien la cabeza por delante con una pequeña mancha parduzca entre los ocelos y por encima con unas franjitas oscuras longitudinales apenas visibles, antenas con un leve oscurecimiento en la parte interna del escapo, pronoto con débiles manchas oscuras y claras, algo difusas (parte inferior de los lóbulos laterales amarillo arena, a excepción de una mancha pardo oscura en el ángulo posterior), tegminas con el ápice y el borde interno oscuros casi negros, patas y abdomen con débiles manchitas parduzcas. La forma general del cuerpo, epiprocto y placa subgenital típicas del género (epiprocto por detrás con un par de salientes cortos; placa subgenital grande, en el ápice redondeada y no bifurcada). Tegminas con el ápice redondeado y 4 venas largas (fig. 2J), cubriendo por encima la glándula dorsal de forma característica: metanoto con un saliente posterior muy corto y ampliamente redondeado, el primer terguito abdominal con el saliente posterior muy ancho y corto; el segundo terguito abdominal, con una protuberancia en el medio formada por dos pequeños tubérculos, uno en la parte anterior (casi cubierto por el saliente engrosado del primer terguito abdominal) y el otro en la posterior, más estrecho (fig. 2I). Genitalia dorsalmente con la escotadura central bastante ancha y semicircular del borde posterior del epifalo y éste casi desarticulado de los rami, además los bordes laterales de los lóbulos pares del ápice del epifalo prominentes (cubiertos por una corta pilosidad en la parte distal) y con el epifalo casi desarticulado de los rami (fig. 4E y 4G); y ventralmente con el ápice corto y afilado de la proyección inferior de la parte proximal de los ectoparámeros ( bien manifiesto, lateralmente) (fig. 4G); la moldura de la placa de sujeción del espermatóforo con un par de lóbulos bastante largos en la parte proximal (fig. 4F); el tubérculo 
esclerotizado del ápice de la varilla guía muy estrecho y afilado (fig. $4 \mathrm{H}$ ).

La hembra de Panticosa es similar a las de $P$. pyrenaea y tiene las tegminas muy pequeñas, casi cubiertas por el pronoto, sólo visible $0,3 \mathrm{~mm}$. Placa subgenital en el ápice menos escotada que la de $P$. pallescens y $P$. aliena. Oviscapto largo, casi de la misma longitud que el fémur posterior.

Encontrada adulta, según Olmo-Vidal y Hernando, durante casi todo el año en cuevas de piedra caliza en las montañas de los Pirineos centrales.

DistribuCión. Ya citada de las provincias de Huesca y Lérida por los autores de esta especie recientemente descrita.

\section{Petaloptila (Petaloptila) fermini sp. $\mathrm{n}$}

(Figs. 2G y $2 \mathrm{H} ; 5 \mathrm{~A}-\mathrm{E}$ )

Material Estudiado: Holotipo: 10" "Casar de Palomero.Cáceres- Febrero-74. Fermín Martín Piera" "MNCN Cat. Tipos No 8826".

Paratipos: CÁCERES: Las Hurdes, 1 우, VI-1918 (Breuil) (Sintipo?) (paralectotipo de Petaloptila aliena pallescens Bol.) (MNCN Cat. Tipos $\mathrm{N}^{\circ}$ 1358) (MNCN Cat. Tipos $\mathrm{N}^{\circ} 8826$ ). Jarandilla, 1 우 , 10-II-1990 (Susana Schönhoth) (DBUC).

DESCRIPCión. Macho (holotipo). Por su tamaño y coloración es próxima a $P$. aliena, aunque su coloración es más contrastada: cabeza por encima del ocelo medio pardo oscura (casi negra entre los ocelos laterales) con líneas pardo claras en el occipucio y manchas detrás de los ojos, más abajo del ocelo medio de color amarillento, con manchas pardas debajo de éste y en la parte media del anticlípeo, antenas y palpos parduzcos, con espacios laterales claros y mediales oscuros del escapo, pronoto con manchas oscuras y claras (parte inferior de los lóbulos laterales pardo oscura, a excepción de una pequeña mancha amarillenta y redondeada en el ángulo anterior), tegminas pardas con el ápice y borde interno negruzcos, patas salpicadas de manchas, abdomen bastante oscuro con los esternitos y parte inferior de la placa subgenital claros, cercos pardos con la base amarillenta. Tegminas con el ápice redondeado y con 2-3 venas largas (fig. $2 \mathrm{H}$ ), cubriendo por encima la glándula dorsal, la cual se parece mucho a la de $P$. pallescens (ver fig. 2E y $2 \mathrm{G})$. Epiprocto y placa subgenital como en P. pyrenaea. Genitalia con el epifalo no desarticulado de los rami (fig. 5C). Las principales diferencias con $P$. aliena, $P$. pallescens y $P$. pyrenaea se observan en la estructura de la genitalia que se caracteriza por una escotadura central ancha y poco profunda del borde posterior del epifalo (en el centro de la cual hay un pequeño saliente) (fig. 5A) en combinación con la proyección proximal de los ectoparámeros muy grande y fuertemente ensanchada en el ápice y dirigida hacia abajo y el medio (fig. 5B, 5C y $5 \mathrm{E}$ ), así como por la forma de la varilla guía (fig. $5 \mathrm{D})$.

Hembra. Por el tamaño, forma del cuerpo y coloración parecida al macho. Tegminas muy pequeñas, longitudinalmente ovales, casi dos veces más largas que anchas (en estos dos ejemplares casi sin cubrir por el pronoto). Placa subgenital más parecida a la de $P$. pallescens, con la escotadura en el ápice más profunda que en $P$. pyrenaea. Oviscapto largo, casi de la misma longitud que el fémur posterior.

Longitud en mm: Cuerpo: $0^{7}, 11,5$; 우, 12-13. Pronoto: $0^{7}, 2,3$; 9 , 2,3-2,5. Tegmina: $0^{7}, 3,1$; $ᄋ$, 0,6-0,7. Fémur post.: $\sigma^{\circ}, 8,5$; $ᄋ, 8,5-10$. Tibia post.: $\sigma^{7}, 6,7 ; \stackrel{\circ}{\circ}, 6,7-8$. Oviscapto: 8,5-10.

OBSERVACIONES. Bolívar, cuando describe $P$. aliena pallescens, dice que el ejemplar de las Hurdes, junto con el de Bussaco, Portugal, es más oscuro y más manchado de pardo que los de Cercedilla. Efectivamente, este ejemplar, que es hembra, tiene una coloración algo distinta de los de Cercedilla y es más parecida a la del macho que aquí se describe y que también ha sido encontrado en la comarca de Las Hurdes. Por tanto, esta hembra es a la vez paralectotipo de $P$. aliena pallescens y paratipo de esta nueva especie. La hembra de Jarandilla, recolectada a unos $50 \mathrm{~km}$ de Casar de Palomero, es un poco más pequeña y con el cuerpo algo engrasado por lo que no se aprecia bien su coloración.

Esta especie se ha encontrado adulta en febrero $y$ junio.

DistribuCión. Por ahora hallada únicamente en la provincia de Cáceres.

Etimología. Dedicamos esta peculiar especie a la memoria de su colector, el Dr. Fermín Martín Piera, Científico Titular del Departamento de Biodiversidad y Biología Evolutiva del MNCN, recientemente fallecido.

\section{Petaloptila (Petaloptila) isabelae $\mathrm{sp} . \mathrm{n}$.}

(Figs. 2K-M; 4I-M)

Material Estudiado: Holotipo: 10", "Desviación de Aguamula, km 2,800 m, S de Cazorla (Jaén), 4-IV-1975 (Glez. del Tánago leg.)". "En un pinar con quejigo y lentisco" "MNCN Cat. Tipos No 8827".

Paratipos: JAÉN: Sierra de Cazorla: Arroyo Frío, 950 m, lapidícola, 1 우 (R. Outerelo) (DBUC). Camino de la Nava de 

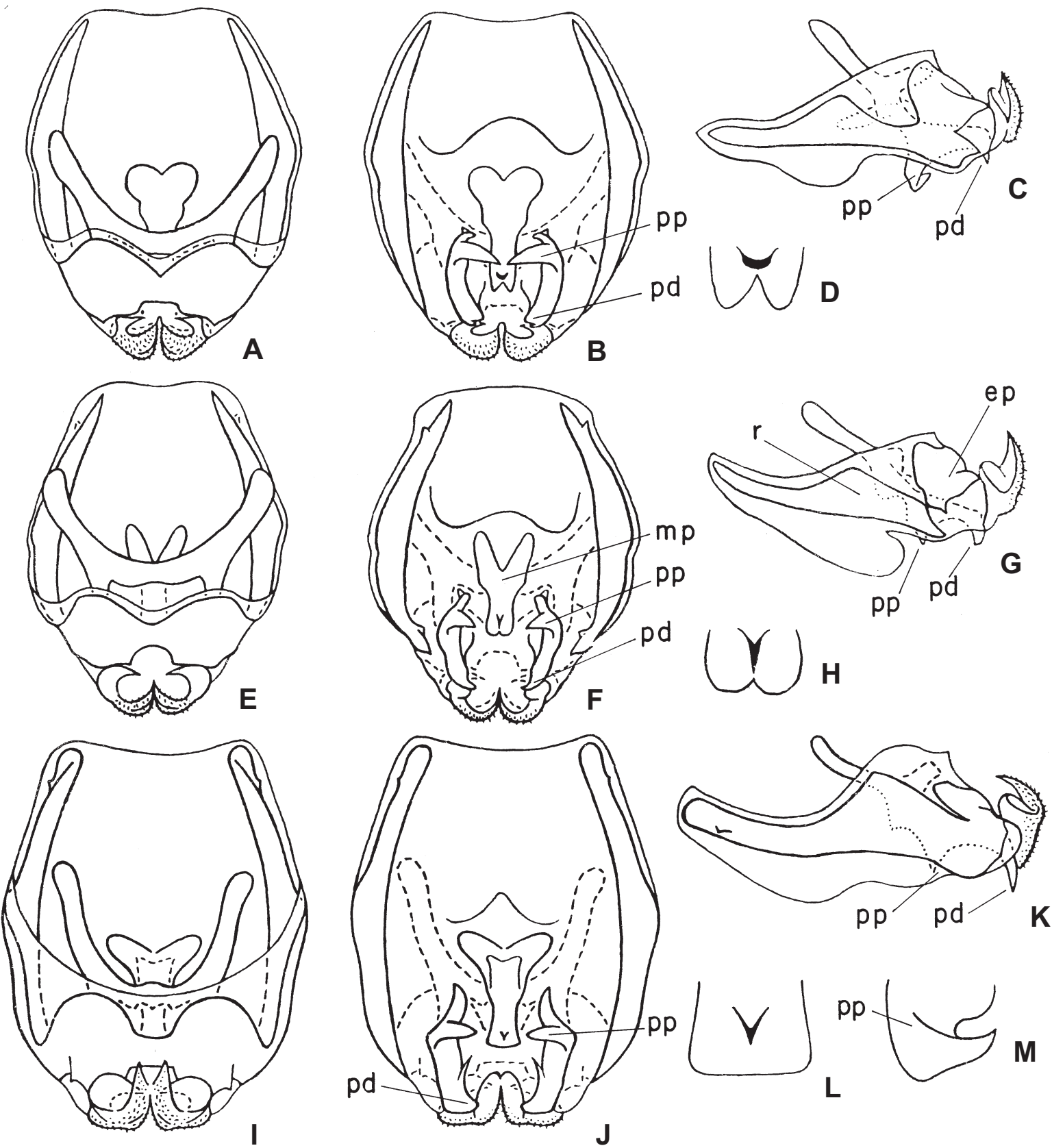

Fig. 4.- Petaloptila (Petaloptila), O': A-D) P. (P.) pallescens; E-H) P. (P.) pyrenaea; I-M) P. (P.) isabelae sp. n. (holotipo). Genitalia, vista dorsal (A, E, I), ventral (B, F, J) y lateral (C, G, K); ápice de la varilla guía, vista ventral (tubérculo esclerotizado, pintado en negro) $(\mathrm{D}, \mathrm{H}, \mathrm{L})$; proyección proximal inferior del ectoparámero izquierdo, por detrás $(\mathrm{M})$.

Fig. 4.- Petaloptila (Petaloptila), O’: A-D) P. (P.) pallescens; E-H) P. (P.) pyrenaea; I-M) P. (P.) isabelae sp. n. (holotype). Genitalia from above (A, E, I), from below (B, F, J) and from side $(\mathrm{C}, \mathrm{G}, \mathrm{K})$; apex of guiding rod from below (sclerotized tubercle is designated by black) (D, H, L); lower proximal process of left ectoparamere from behind (M). 
S. Pedro, $1300 \mathrm{~m}$, en un pinar con Juniperus oxycedrus, 1 웅 5-IV-1975 (Glez. del Tánago). Ctra. de la Nava de S. Pedro Km 31,5, en un pinar de P. laricio, encina, espino albar, Juniperus, Cytisus, 10", 5-IV-1975 (Glez. del Tánago). Ctra. Nava de S. Pedro, $1 \mathrm{~km}$ antes de la Reserva Cinegética, 1400m, $10^{7}$, 5-IV1975 (Glez. del Tánago) (ZIAS). Ctra. de El Tranco, Km 2, sobre suelo de P. halepensis, 900 m, 1 ㅇ , 3-IV-1975 (Glez. del Tánago) (Discoptila fragosoi (Bolívar)? det. B.C. Townsend, 1978). Casa Forestal de Roblehondo, 1140 m, 10"7, 23-V-1977 (A. del Cerro). Linajeros, bajo piedras, $1080 \mathrm{~m}, 1$ 우, 23-V1977 (A. del Cerro). Nacimiento del río Guadalquivir, $1400 \mathrm{~m}$, 107, 6-IV-1975 (Glez. del Tánago); Nacto. Guadalquivir, en un prado, 1 오 , 3-VII-1978 (R. Outerelo) (DBUC). Pradera del

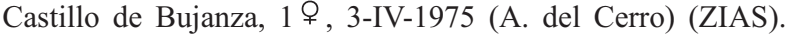
Todos los paratipos a excepción de los que tienen la siglas DBUC y ZIAS, llevan la etiqueta "MNCN Cat. Tipos $\mathrm{N}^{\circ}$ 8827 ".

DESCRIPCIÓN. Macho (holotipo). Por su tamaño y coloración prácticamente no se diferencia de $P$. aliena (un poco menos salpicado de manchas que $P$. fermini). Tegminas con el ápice ligeramente prolongado y casi puntiagudo, con 3 venas largas (fig. $2 \mathrm{M}$ ), cubriendo la glándula dorsal que es parecida a la de $P$. pallescens y $P$. fermini, pero con una quilla media baja bien marcada a lo largo del saliente engrosado posterior del primer terguito abdominal (fig. 2K). Epiprocto y placa subgenital igual que en las especies anteriores. Genitalia con la escotadura central bastante ancha y casi cuadrangular del borde posterior del epifalo y éste no desarticulado de los rami (fig. 4I y 4K); ectoparámeros con la proyección proximal corta y fuertemente ganchuda y estrechándose notablemente hacia el ápice que está dirigido hacia el medio (fig. 4J, 4K y 4M); ápice de la varilla guía como en la figura $4 \mathrm{~L}$.

Variabilidad. Tegminas de los paratipos a veces con 4 venas largas (fig. 2L) o sólo con huellas de la mayoría de ellas.

Hembra. Por el tamaño, forma del cuerpo y coloración parecida al macho y prácticamente no se diferencia de la hembra de $P$. aliena. Tegminas muy pequeñas, longitudinalmente ovales, casi cubiertas por el pronoto. Placa subgenital ligeramente escotada en el ápice. Oviscapto largo, casi de la misma longitud que el fémur posterior.

Longitud en mm: Cuerpo: $\sigma^{7}, 9,5-12,5$; $ᄋ$, $10-$ 13,5. Pronoto: $\sigma^{7}, 2,2-2,6$; $ᄋ, 2,5-2,7$. Tegmina: $\mathrm{O}^{7}, 3-3,5$; 우 $, 0,5-0,6$. Fémur post.: $\mathrm{O}^{7}, 8-8,8$; 우, 8,5-9. Tibia post.: O์, 6,7-7, , , 6,8-7. Oviscapto: $8-8,5$.

La serie tipo, excepto los ejemplares pertenecientes al DBUC, han sido donados al MNCN por el Dr. A. Notario, del Departamento de Entomología de ESI de Montes de Madrid. Años antes habían sido identificados por Del Cerro (1978 y 1980) en parte como P. aliena y en parte como Discoptila fragosoi (una de las hembras lleva la etiqueta de esta última realizada por Townsend). Según el primer autor, y las etiquetas, este grillo fue capturado a mano, bajo piedras y en el suelo, en zona de pinares con encinas, quejigos, Juniperus $o$ Cytisus, lentisco y espino albar, a una altitud comprendida entre los 800 y 1400 metros. Probablemente pertenezca también a esta nueva especie el macho de Sierra de Cazorla que cita Ragge (1965) como P. aliena.

Encontrada adulta desde primeros de abril a últimos de mayo y en julio.

DISTRIBUCIÓN. Sólo encontrada en la provincia de Jaén.

ETimología. Dedicamos esta nueva especie a la Dra. Isabel Izquierdo Moya, Conservadora de la Colección de Entomología del MNCN.

\section{Petaloptila (Zapetaloptila subgén. n.) venosa sp. n.} (Figs. $2 \mathrm{~N}$ y $2 \mathrm{O} ; 5 \mathrm{~F}-\mathrm{H}$ )

Material Estudiado: Holotipo: 10", "Teruel. 935 m. 10VIII-33. B. Muñoz" "MNCN. Cat. Tipos No 8828 "

DESCRIPCIÓN. Macho (holotipo). Tamaño bastante grande. Coloración casi uniforme, amarillento-arena, muy parecida a la de P. pallescens (con un ligero oscurecimiento entre los ocelos, ápice y borde interno de las tegminas oscuros, así como unas manchas pardas muy débiles en los fémures posteriores). Tegminas relativamente largas y estrechas con bastantes venas longitudinales (5-6) y con el ápice fuertemente prolongado y estrecho (fig. 2O). Glándula dorsal débilmente desarrollada (fig. $2 \mathrm{~N})$. Epiprocto y placa subgenital parecidos a los del subgénero Petaloptila. Genitalia con el epifalo desarticulado de los rami y con el borde posterior de éste profundamente escotado en el medio (fig. $5 \mathrm{~F}$ y $5 \mathrm{H}$ ); ectoparámeros con la proyección distal muy gruesa, la ramificación posterior de la cual es grande y dirigida hacia abajo y atrás, mientras que la ramificación anterior es pequeña y dirigida hacia abajo; la proyección proximal de los ectoparámeros relativamente grande y dirigida hacia abajo y el medio (fig. 5G y 5H); moldura de la placa de sujeción del espermatóforo ancha (fig. 5F y 5G).

Hembra desconocida.

Longitud en mm: Cuerpo: 17,2. Pronoto: 3,1. Tegmina: 5,5. Fémur post.: 11,7. Tibia post.: 10.

OBSERVACIONES. Al parecer, según la figura que da Harz (1969: fig. 2273), esta especie pudo ser citada en la bibliografía bajo el nombre de $P$. bolivari. Sin embargo las tegminas de $P$. bolivari son 
más cortas y con una forma un poco distinta (fig. $2 \mathrm{O}$ y $2 \mathrm{P}$ ); para más detalles ver el apartado de $P$. bolivari.

Encontrada adulta en agosto.

DisTRIBUCIÓN: Por ahora hallada sólo en la provincia de Teruel.

Etimología. Del adjetivo latino venosus, aludiendo al mayor número de venas que presentan las tegminas en los machos.

\section{Petaloptila (Zapetaloptila) barrancoi $\mathrm{sp} . \mathrm{n}$.} (Figs. 2Q y 2R; 5I-K)

Material Estudiado: Holotipo:10", "Cueva Nueva. Sierra de Gádor, Almería (España). P. Barranco- J. Amate leg. 21-10-1992". "MNCN Cat. Tipos No 8829".

Paratipos: ALMERÍA: Los mismos datos que el holotipo: $50^{7} 0^{7}$ y 5 우 $(\mathrm{MNCN}) ; 10^{71}$ y 1 우 (ZIAS); $10^{71}$ y 1 우 (Colección Barranco). Covanova, Sa Gádor, 30 SWF 3880. T. M. Enix, $10^{\pi}$ y 2 우 ㅇ , 21-X-1992 (P. Barranco leg.) [Petaloptila bolivari (Cazurro 1888) P. Barranco det. 1993]. Mina 7 Mineros, S ${ }^{a}$ Gádor, 30 SWF 3689 T. M. Alhama, $10^{7}$, 1-XII-1992 (P. Barranco leg.) (MNCN). Todos identificados por P. Barranco como P. bolivari; los ejemplares pertenecientes al MNCN llevan además la etiqueta "MNCN Cat. Tipos N" $8829 "$.

DESCRIPCIÓN. Macho (holotipo). Parecido a $P$. venosa, pero casi completamente de color uniforme, amarillento, con la parte superior de la cabeza y manchas en el disco del pronoto pardo claras, el ápice y el borde interno de las tegminas negruzcos. Estas últimas un poco más anchas que en $P$. veno$s a$, con el ápice notablemente prolongado y estrecho y sólo con una vena lateral (fig. 2R). Glándula dorsal (fig. 2Q) apenas desarrollada. Epiprocto y placa subgenital como en otras especies del género. Genitalia con el epifalo no desarticulado de los rami y con una pequeña escotadura del borde posterior del epifalo, en el centro de la cual hay un pequeño lóbulo triangular (fig. 5I y 5K); ectoparámeros con la proyección distal no muy grande y la ramificación posterior relativamente pequeña y dirigida hacia atrás, mientras que la ramificación anterior es grande y proximal (dirigida hacia adelante); la proyección proximal de los ectoparámeros pequeña y dirigida hacia abajo (fig. $5 \mathrm{~J}$ y $5 \mathrm{~K}$ ); moldura de la placa de sujeción del espermatóforo estrecha (fig. 5I y 5J).

Variabilidad. Los paratipos presentan los fémures posteriores con unas manchas pardas muy suaves.

Hembra. Similar al macho, pero con las tegminas muy pequeñas, longitudinalmente ovales, casi por completo cubiertas por el pronoto. El color también parecido al del macho, aunque en este sexo destaca más una franja transversal más clara situada en el tercio apical de cada terguito del abdomen; fémures posteriores con manchas pardas, apenas visibles. Placa subgenital parecida a la de $P$. isabelae. Oviscapto un poco más corto que el fémur posterior.

Longitud en mm: Cuerpo: $\sigma^{\pi}, 16,5-19$; $ᄋ$, 1720. Pronoto: $\sigma^{x}, 2,7-3$; $ᄋ, 2,8-3,3$. Tegminas: $\sigma^{7}$, 5,1-5,4; ㅇ , 0,5-0,8. Fémur post.: $\sigma^{7}, 11,5-13,5$; 우, 12-14,5. Tibia post.: O์, 11,3-12,7; ᄋ , 11,7-13. Oviscapto: 11,2-13

Estos ejemplares, donados al MNCN por el Dr. P. Barranco, así como otros de la misma procedencia y depositados en la colección del autor, fueron citados por Barranco y Pascual (1995) como $P$. bolivari. Según estos autores, este grillo se desarrolla óptimamente en cuevas con total oscuridad, habiéndolo capturado en ellas, mediante trampas.

Esta nueva especie ha sido encontrada adulta en octubre y diciembre; según Barranco y Pascual, todos los estadios ninfales aparecen durante todo el año.

DisTRIBUCIÓN. Por ahora hallada sólo en la provincia de Almería.

ETIMOLOGíA. Dedicamos esta petaloptila de hermosa apariencia a su colector, el ortopterólogo Dr. Pablo Barranco, Profesor del Departamento de Biología Aplicada de la Escuela Politécnica Superior de la Universidad de Almería.

\section{Petaloptila (Zapetaloptila?) bolivari (Cazurro, 1888)} (Fig. 2P)

Aunque, según Pantel (1890), la serie tipo estaba depositada en el MNCN, ya Harz (1969) la consideró en paradero desconocido; nosotros hemos intentado localizarla en las colecciones de Entomología del Museo, pero sin éxito.

La breve descripción de $P$. bolivari e incluso la redescripción más detallada de esta especie basada en la serie tipo $\left(10^{\prime \prime}\right.$ y 2 ㅇ $\odot$ ninfas $)$ y realizada por Pantel (1890: lám. III. fig. 2), no permite atribuirla con seguridad al súbgénero Zapetaloptila, pero según las figuras publicadas por este autor, la glándula dorsal del único macho sintipo, está débilmente desarrollada, lo que la aproxima más a Zapetaloptila que a Petaloptila, aunque la forma de sus tegminas está más próxima a este último (fig. 2P). El tamaño de las tegminas del macho sintipo es intermedio entre las de las auténticas Zapetaloptila y las Petaloptila s. str.; con una longitud del pronoto prácticamente igual (cerca de $3 \mathrm{~mm}$ ), la longitud de las tegminas de $P$. venosa y $P$. barrancoi es de 

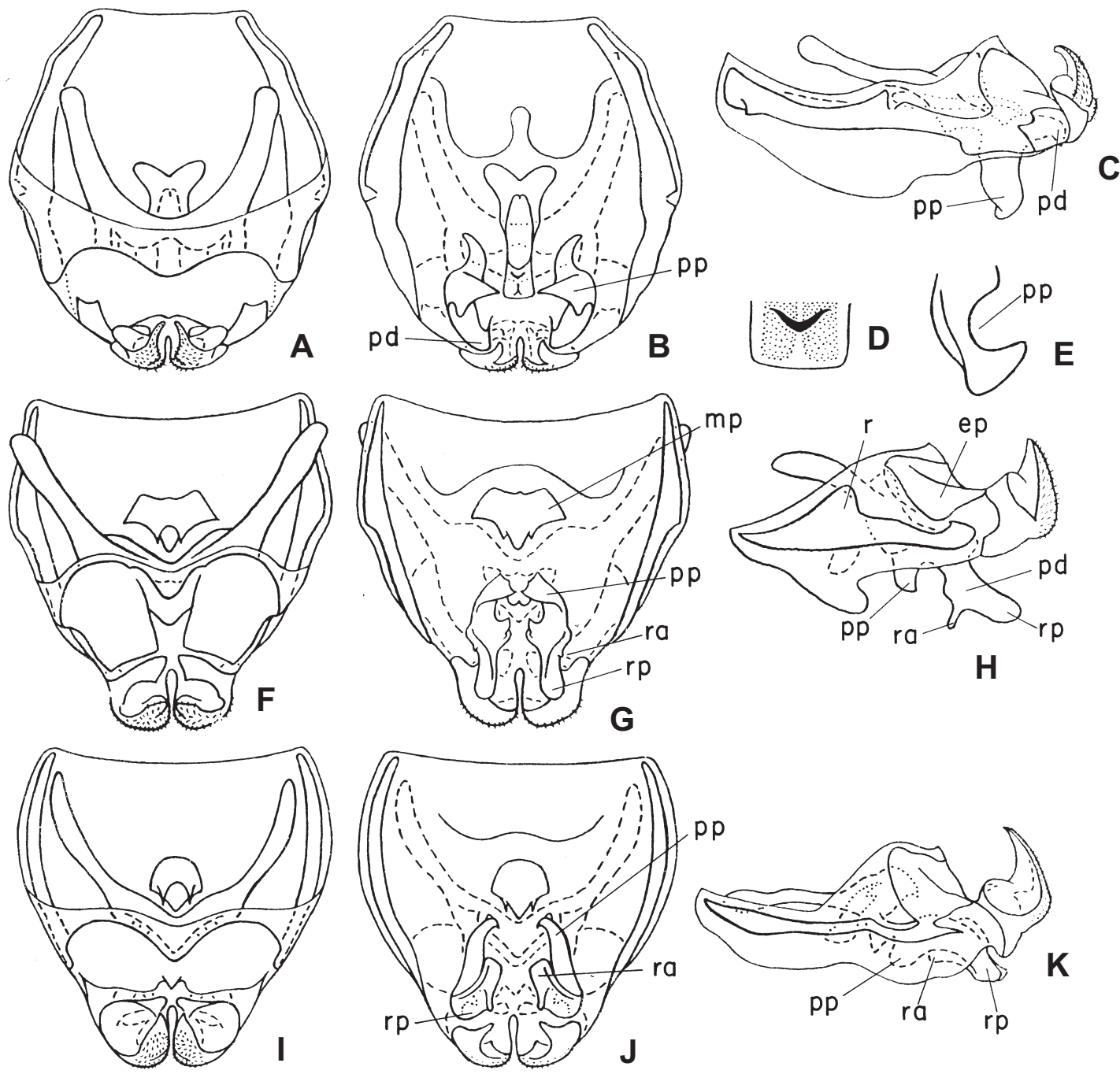

Fig. 5.- Petaloptila, O': A-E) P. (Petaloptila) fermini sp. n.; F-H) P. (Zapetaloptila) venosa sp. n.; I-K) P. (Z.) barrancoi sp. n. (holotipo). Genitalia, vista dorsal (A, F, I), ventral (B, G, J) y lateral (C, H, K); ápice de la varilla guía, vista ventral (D); proyección proximal inferior del ectoparámero izquierdo, por detrás $(\mathrm{E})$. Abreviaturas: ra- ramificación anterior de la proyección distal del ectoparámero; rp- ramificación posterior de la proyección distal del ectoparámero.

Fig. 5.- Petaloptila, O $^{n}$ : A-E) P. (Petaloptila) fermini sp. n.; F-H) P. (Zapetaloptila) venosa sp. n.; I-K) P. (Z.) barrancoi sp. n. (holotype). Genitalia, from above (A, F, I), from below (B, G, J) and from side (C, H, K); apex of guiding rod from below (D); lower proximal process of left ectoparamere from behind (E). Abbreviations: ra - anterior branching of distal process of ectoparamere; rp -posterior branching of distal process of ectoparamere.

5,1-5,5, mientras que la de $P$. bolivari es de $4,5 \mathrm{~mm}$ (según Cazurro y Pantel); en los distintos representantes del subgénero nominativo la longitud de las tegminas no sobrepasa los $4 \mathrm{~mm}$ (generalmente 3$3,5)$. La información sobre esta especie (incluidas las medidas) fue, seguramente, incorporada por
Harz (1969), junto con los datos de $P$. venosa, y la descripción así obtenida la adjudicó a $P$. bolivari . Por tanto, las citas de esta especie para otros puntos de la Península necesitan comprobación, ya que aquí también son posibles los errores; así por ejemplo, Bolívar (1927), Morales Agacino (1933) y 
Harz la dieron para "Cartagena" basándose, probablemente en hembras ninfas, algunas de las cuales se conservan en el MNCN y actualmente no dan la posibilidad de identificarlas a nivel de especie. También fue citada de Teruel y alrededores (Morales Agacino, 1933), así como de la provincia de Almería (Barranco y Pascual, 1995) y más recientemente de L'Atzuvia, Alicante (Olmo-Vidal y Hernando, 2000). La cita de Almería, como ya indicamos más arriba, ha resultado ser la nueva especie P.(Z.) barrancoi .

DisTRIBUCIÓn. Por todo lo expuesto, las únicas localidades seguras para esta especie son las de la perdida serie tipo:"Cabesó"(Alicante) y "Tabernes" (Valencia).

\section{Discoptila fragosoi (Bolívar, 1885)}

Esta interesante especie fue descrita por un único macho de Dos Hermanas (Sevilla; R. González Fragoso leg.); años más tarde Cazurro (1888) y Bolívar (1900) la citan además de Sevilla capital (Calderón leg.), diciendo el segundo de ellos y Burr (1910) que había sido encontrada en mayo y julio, dato que no recoge ningún autor posterior.

El tipo macho, junto con el otro ejemplar de Sevilla se consideran destruidos por el incendio que tuvo lugar en el Museo Bocage, Lisboa (París, 1994).

DISTRIBUCIÓN. Por ahora sólo encontrada en la provincia de Sevilla. Nosotros no hemos encontrado ningún ejemplar en la Península perteneciente al género Discoptila, ya que los citados por Del Cerro $(1978,1980)$ de la provincia de Jaén y, en parte, estudiados por nosotros, resultaron ser Petaloptila isabelae sp. $\mathrm{n}$. La atribución por distintos autores (Chopard, 1967; Harz, 1969 y Heller et al., 1998) a esta especie de ejemplares de otros territorios fuera de nuestras fronteras necesita comprobación.

\section{Gryllinae$$
\text { Gryllini }
$$ \\ Gryllus campestris Linnaeus, 1758}

Por tratarse de una especie ampliamente repartida en la Península, no incluimos el material estudiado.

Encontrada adulta de abril a noviembre y como ninfa, en los primeros y últimos estadios, en estos mismos meses y en febrero y marzo (Gómez et. al., 1991; Pardo et al., 1993; y nuestros propios datos).
DisTRIBUCIÓN. Ha sido hallada en casi toda España peninsular a excepción de las provincias de Alicante, Ávila, Badajoz, Cáceres, León, Lugo, Málaga, y Zamora, donde es más que probable su presencia, estando mucho mejor representada en la mitad septentrional. Citada también de las Baleares (Gangwere y Llorente, 1992), ausente de las Canarias (Kevan y Hsiung, 1992). Fuera de España se encuentra en la mitad meridional de Europa desde el sur de la Gran Bretaña, Portugal, Francia hasta Letonia, Suroeste de Rusia y Cáucaso, Transcaucasia, Asia Menor, Marruecos, Argelia y Túnez.

\section{Gryllus bimaculatus De Geer, 1773}

$\mathrm{Al}$ igual que en la especie anterior no incluimos el material estudiado.

Encontrada adulta en la Península y Baleares de abril a noviembre (Pardo et al., 1993 y nuestros datos) y ninfas en los primeros estadios de marzo a noviembre y en los últimos de abril a agosto. En el archipiélago canario se ha encontrado adulta durante todo el año y ninfas en los primeros estadios sólo en septiembre, mientras que en los últimos, de marzo a julio y en diciembre; además, según Johnsen (1974), también en enero en distintos estadios.

DistribuCión. Es más meridional que G. campestris, extendiéndose por las provincias del litoral desde Barcelona hasta Huelva, incluyendo las de Jaén y Sevilla y llegando a algunas provincias del centro como las de Zaragoza, Teruel, Cuenca, Ávila, Madrid, Cáceres y Albacete, pero en éstas siempre en muy bajo número; es nueva para las de Cáceres, Ávila, Tarragona y Murcia. Además está citada de las Baleares (Gangwere y Llorente, 1992) y de todas las islas Canarias (Bland et al., 1996). Fuera del territorio español se encuentra en la mitad meridional de la región paleártica, desde el sur de Portugal, departamentos mediterráneos de Francia, y África del Norte hasta Asia central; y en las regiones Etiópica, de Madagascar y en la Indo-Malaya.

\section{Melanogryllus desertus (Pallas, 1771)}

Material estudiado: BARCELONA: Barcelona, $20^{7} 0^{77} \mathrm{y}$ 1 ㅇ (Caballero). CIUDAD REAL: Manzanares, en Herrera, $20^{7} 0^{7}$ y 2 ㅇ ㅇ , VI-1909 (Exp. Mus.). Ruidera (Lagunas), $10^{\prime \prime}$ y 9 우 우 (C. Bolívar). Valdepeñas, 1 우, 11-VI-1980 (DBUC). GERONA: Ampurdán, $10^{7}$ y 1 ㅇ (Masferrer). GUADALAJARA: Bolarque, $10^{7}$ y 3 우 웅 VI-1928 (M. Escalera). Yela, $10^{\pi}$ y 1 ㅇ , 13-VI-1963 (A. Álvarez) (DBUC). Zorita de los Canes, 1 ㅇ (I. Izquierdo). HUELVA: Doñana, 30 $0^{\pi}, 24-V-1967$ (E. 
Ortiz); Palacio, 2 우 우 n (últs. est.), 28-29-IX-1968; dunas de Sta. Olalla, 2 우 우 n (últs. est.), 5-V-1969 (todos V. Llorente). MADRID: Aranjuez, 1 \% (últ. est.), IV (E. Morales); $30^{x} 0^{x}$ y 1 우, 9-V-1954 (E. Ortiz); 1 오 $\mathrm{n}$ (últs. est.) $10-\mathrm{V}-1971$ (C. Aranaiz) (DBUC), 1 \& (últ. est.) 20-X-1971 (J. Mamolar) (DBUC). Boadilla, 1 ㅇ , 2-VI-1979 (T. Cuerda) (DBUC). Buitrago de Lozoya, 1 o n (últ. est.) 15-V-1990 (J. L. del Barrio) (DBUC). Castillejo, $10^{7} \mathrm{n}$ (últ. est.), III-1932 (E. Morales). Cienvallejos, 1 우 (F. Bonet); $10^{x}$ y 3 우 오, VI-1927 (C. Bolívar). Galapagar, 1 ㅇ , VI-1936 (D. Peláez). La Poveda, $10^{\pi} \mathrm{n}$ (últ. est.), IV-1934 (I. Bolívar). Madrid, $20^{x} \sigma^{x}$ y 1 우 (Cazurro); $20^{\top} \sigma^{x}$ y 1 ㅇ (Bolívar); en El Canal, $10^{x} \mathrm{n}$ (últs est.), 14-III-1906 (Arias). Miraflores de la Sierra, 2 우 우 (Exp. Museo). Montarco, 10", VI-1908 (Bolívar). Pozuelo, 10", 2-V1990 (J. Zamora) (DBUC). Valdemoro, $10^{7}, 27-\mathrm{V}-1973$ (L. F. Moreno) (DBUC). Villaverde, $50^{x} \sigma^{x}$ y 1 ㅇ (Arias). NAVARRA: Monteagudo, $10^{\pi}$ y 2 우, VI-1940 (E. Morales). RIOJA: Navarrete, $10^{\pi}, \mathrm{V}-1958$ (s/c). TERUEL: Teruel, 1 \% (A. Sanz); $10^{\pi}, 29-\mathrm{V}-1932$ (B. Muñoz). TOLEDO: Quero, $10^{7}$ y 1 오, V-1908 (J. Sanz); $20^{x} \sigma^{x}$, 12-VI-1905. Toledo, 1 오 $\mathrm{n}$ (últ.est.), 10-IV-1990 (M. A. Bartolomé) (DBUC). Urda, 1 우, VII-1888 (Bolívar ?). ZARAGOZA: Alhama de Aragón, 10", 22-V-1929.

Encontrada adulta desde mayo a julio y, según Cazurro (1888), Gómez et al. (1991) y Pardo et al. (1993), también en septiembre; las ninfas en los últimos estadios de marzo a mayo y en septiembre (Del Cerro, 1978; Llorente, 1980).

DisTRIBUCión. Está citada de las provincias de Granada (Rambur, 1839), Zaragoza (Navás, 1900, 1904a), Teruel (Morales Agacino, 1933), Cuenca (Pantel, 1886; Pardo et al.1993), Murcia (Bolívar, 1927), Jaén (Del Cerro, 1980), Almería (Barranco y Pascual, 1991), Albacete (Gómez et al., $1991 \mathrm{y}$ Pardo et al., 1993), así como de Mallorca (Moragues, 1894; Ebner, 1931). Por tanto, su área conocida ocupa más de la mitad oriental de la Península y Baleares; no habiéndose encontrado todavía en Canarias (Kevan y Hsiung, 1992; Bland et al., 1996). La distribución general abarca la mitad meridional de la paleártica, desde los departamentos mediterráneos de Francia, y África del Norte hasta el Asia Central.

A veces esta especie se divide en subespecies, formas o variedades; a menudo esta división está relacionada con la $\mathrm{f}$. braquíptera o macróptera. Sin embargo, todavía no se han observado, en nuestra opinión, caracteres lo suficientemente sólidos como para dividirla en subespecies.

\section{Acheta domesticus (Linnaeus, 1758)}

Material Estudiado: ESPAÑA: GUIPÚZCOA: Irún, 1 ㅇ (Aguinaga). MADRID: Alcalá de Henares, $20^{\top} \sigma^{\top}, 1$, $\mathrm{n}$ (últ.est.) y 1 o n ( $1^{\circ}$ s est.) 26-X-1970 (Cuadra, De Juana, Elena y Llorente) (DBUC). Los Peñascales, $1 \stackrel{9}{ }$, VIII-1982 (Ga.
Torrent); 1 ㅇ, V-1983 (A. Llobet) (DBUC). Madrid, 60 $60^{\pi}$, $10^{7} \mathrm{n}$ y 5 우 우 (Cazurro); 1 우 (Bolívar?); en la Casa de Campo, 1 ㅇ n (1s est.?), IV-1972 (L. de Ceballos) (DBUC). Ribatejada, $10^{7}$, VI-1941 (E. Pons). Villalba, 1 오, 5-IX-1978 (N. Oñate) (DBUC). PONTEVEDRA: Villagarcía, 1 은 IX-1933 (E. Morales).

Encontrada adulta de mayo a septiembre; ninfas en abril, mayo, septiembre y octubre (Aguirre et al., 1995; Del Cerro, 1978 y nuestros datos).

Distribución. Citada de las provincias de Granada (Rambur, 1839), Coruña, Navarra (Bolívar, 1878), Sevilla, Baleares (Cazurro, 1888), Jaén (Ragge, 1965; Del Cerro,1980), La Rioja (Burgos y Herrera, 1986), Almería (Aguirre et al., 1995) y Huesca (Torralba, 1995); siendo nueva para la de Pontevedra. Aunque disponemos de poquísimo material podría encontrarse en casi toda la Península, islas Baleares (Gangwere y Llorente, 1992) y con duda en las Canarias (Kevan y Hsiung, 1992).

Es una especie sinántropa que generalmente vive en las casas y que ha sido transportada por el hombre incluso hasta regiones polares. El área primitiva de esta especie se encontraba, probablemente, en los límites del área actual de otras especies del género Acheta F., es decir, desde las regiones áridas del África Septentrional y Oriental y del mediterráneo europeo hasta el Uzbequistán y las regiones áridas de la India (el centro de la diversidad es la Península Arábiga).

\section{Acheta hispanicus Rambur, 1839} (Fig. 6A-F)

$=$ Gryllus erythrospilus Walker, 1869. Cat. Derm. Saltat. Brit. Mus.1: 49, syn. n.

$=$ Gryllus hispanicus var. fusculus Bolívar, 1927. Bol. R. Soc. Hist. Nat., 27: 99, syn. n.

Material Estudiado: ALICANTE: Alicante, $0^{7}, 20$-VII1974 (P. Sanz) (DBUC). Cabo Huertas, 10", 27-V-1996. (L. Brugada) (DZM). Benidorm, $3 \sigma^{7} \sigma^{7}$ y 7 우 우 (F. Bonet). Orihuela, $10^{7}$ y 1 웅 (J. Andreu). Torrevieja, 1 오 , 7-VIII-1962 (Pujol). ALMERÍA: Almería, 19 (J. G. Menor); 1 오 , 2-IX1946. El Palmer, 1 ㅇ , 20-VI-1950 (Cobos Sánchez). Fondón, $10^{\pi}$. Garrucha, 1 우, 5-IV-1985 (G. García) (DBUC). Vera, 1 우 (paralectotipo de G. h. var. fusculus). CÁDIZ: Cádiz, $10^{7}$ (Smith); 1 은 VIII-1978 (B. Macazaga) (DBUC). Chiclana, Est. servicio, 2 우 은 6-IX-1962 (V. Llorente). CIUDAD REAL: Torre de Juan Abad, 1 \% , 5-V-1982 (J.J. González) (DBUC). CÓRDOBA: Alcurrucen, 10, 5-IX-1981 (D. Senén) (DBUC). GRANADA: Almuñecar, 10 , 18-IX-1984 (Llamazares) (DBUC). MADRID: Los Negrales, 1 우, XI-1979 (A. Núñez) (DBUC). MÁLAGA: Benalmádena, 10", 10-IX1983 (F. R. Dorado) (DBUC). Fuengirola, $20^{x} \sigma^{x}$ y 6 우 우, 20VIII-1979 (V. Llorente); $10^{7}$ y 2 우 운, 23-VIII-1982 (V. Llorente). MURCIA: Calasparra, F.C.,107, 3-X-1978 (R. 
Outerelo) (DBUC). Cartagena, 1 ( 9 (paralectotipo de G. $h$. var. fusculus). Cartagena, 1 우 (Sánchez Gómez) (Gr. hispanicus? Bol. det.). Murcia, 10" VIII-1971 (C.Ureña) (DBUC). Santiago de la Ribera, 1 ó, 21-VIII-1974 (J. L. Rodríguez) (DBUC). SEVILLA: Lora del Río. 10", 13-IV-1986 (M. Ramírez) (DBUC). Osuna, 1 웅 24-VII-1974 (R. Puro) (DBUC). Sevilla, 10", 26-IX-1967 (E. Mingo). TOLEDO: Quero, 1 오 (paralectotipo de G. $h$. var. fusculus).

CANARIAS: GOMERA: Lomada de Tesina, 19 ㅇ , 10-IX1919 (Cabrera). GRAN CANARIA: Barranco Doramas, $10^{7}$, 19-III-1952 (Mateu). TENERIFE: Bajamar, $10^{7}$ y 1 우 , 10-XI1900/09 (Cabrera); 10", 12-X-1911 (Cabrera); $10^{\pi}$ y 1 ㅇ , 1021-III-1918 (A. Cabrera); $10^{7}$ y 3 우 우, II-1921 (Cabrera?); 1 우 , IV-1921 (M. Escalera); 600 m, $20^{7} 0^{7}$ y 4 우 우, IV-1921 (M. Escalera); $50 \mathrm{~m}, 1$ \% , IV-1935 (C. Bolívar). Barranco Tahodio, 1 ㅇ , 13-III-1927. La Laguna, $10^{7}, 10$-VII-1917; $10^{7}$, 14-III-1918 (Cabrera); 1 우, IV-1919; $10^{\nearrow}, 10-$ VIII-1919; 1 우, 6-V-1920; $10^{\pi}$ y 1 ㅇ , IX-1914/21 (todos Cabrera). 10", 27-IX1921; 2 우 우, VII-1928/31; 4 우 오, VIII-1927/31/32; 10", 10 VII-1931; 1 ㅇ , 2-II-1933 (todos Cabrera?). Laguneta Alta, 10", 2-II-1927. Médano, 2 우 우, 19-VIII-1931 (Cabrera). Montaña Bermeja, 1 ㅇ , 19-IV-1952 (J. Mateu). Monte Aguirre, 1 오 , 24-VIII-1898 (P. Oramas). Punta de Hidalgo, litoral, $10^{7}$, 16-II-1925 (Cabrera?). Tacoronte, $10^{7}$ y 2 \% $\$$, IV-1921. Tenerife, 1 ㅇ , VIII-1873 (Ch. All.Coll.); 1 우 (Cabrera).

Encontrada adulta en la España peninsular desde abril a noviembre $\mathrm{y}$, según Aguirre et al. (1995), también en diciembre; en las Canarias, de febrero a diciembre (Gangwere et al., 1972 y nuestros datos).

DiSTRIBUCIÓN. Ha sido citada de las provincias de Jaén (Del Cerro, 1980), Almería (Aguirre y Pascual, 1986), Albacete (Gómez et al., 1991; Pardo et al., 1993) y Zaragoza (Blasco-Zumeta, 1998); siendo nueva para las de Ciudad Real, Córdoba, Madrid y Sevilla. Por tanto, su área de dispersión ocupa provincias del centro, sur y sureste peninsular; en Canarias está representada en las islas de La Gomera, Gran Canaria y Tenerife, así como en Hierro, según Chopard (1954) y Bland et al. (1996); todavía no se ha encontrado en las Baleares. Recientemente se ha encontrado en el sur de Portugal (Lock, 1999) y en Sicilia (La Greca, 1994). Además se distribuye desde África del Norte hasta la península de Indostán.

Esta especie es muy variable en su coloración (desde relativamente clara, que recuerda a la de $A$. domesticus, hasta casi completamente negra) y además, los ejemplares oscuros y claros habitan en los más diversos lugares del área de dispersión de la especie, por lo que no es posible conservar el nombre de fusculus, ni siquiera incluso como subespecífico. La serie tipo de Gryllus h. var. fusculus se conserva en el MNCN y consta de 5 sintipos ( $10^{\top}$ y 4 우 우), procedentes de la España peninsular y Marruecos (París, 1994). Después de estudiar la serie y en especial la genitalia del macho, designamos como lectotipo a este último, que lleva las etiquetas: "Mogador. Escal.", "Gryllulus hispanicus var. fusculus (Bol.) Det. E. Morales Agacino", "MNCN Cat. Tipos $\mathrm{N}^{\mathrm{o}} 857$ " y genitalia en tubo, quedando como paralectotipos: 1 우 "Quero", 1 우 "Cartagena" y 1 ㅇ "Vera"; 1 우 "Mogador. Escalera”, MNCN Cat. Tipos No 854-856 y 858 (más información en París, 1994). Por cierto, Otte (1994) da como localidad típica sólo "Quero en Ciudad Real", lo que no es correcto, ya que al no haber designado él mismo el lectotipo no puede reducir las localidades típicas. Ahora, al ser designado el lectotipo, queda limitada a: "Mogador. Marruecos".

Existe también cierta variabilidad en la estructura del ápice de los ectoparámeros en la genitalia del macho (fig. 6D-F), pero ésta no permite la separación en subespecies. La genitalia del holotipo macho de $G$. erythrospilus, que se conserva en el NHM y cuyo origen se desconoce, también ha sido estudiada y coincide plenamente con la de $A$. hispanicus.

\section{Acheta meridionalis (Uvarov, 1921)}

$$
\text { (Fig. 6G-I) }
$$

Material Estudiado: CANARIAS: TENERIFE: Bajamar, 1 우, 18-X-1898; 10, 10-X-1911; 1 우, 10-III-1918; 2 우 ㅇ, 1921 (Gr. Guanchicus Kr. Letra de Bolívar) (Gryllulus canariensis Chopard. Det. E. Morales Agacino); 10" , 14-IX1927; 50 m, 3 우 ㅇ․ IV-1935 (C. Bolívar). Barranco de San Andrés, 10", IV-1921 (M. Escalera). Esperanza, Hoya de las raíces, 1 , 22-II-1928. La Cuesta, Montaña Guerra, 1 , 15I-1909. Laguna, 1 क , 2-II-1933; 10", 2-II-1934. Santa Cruz, 300 m, 1 우, XII-1920 (M. Escalera). Tacoronte, $30^{7} 0^{7}$ y 1 우, 18-IV-1952 (Mateu coll.). Tahodio, Barranco, 10", 24-IX1927; 10", 10-V-1930. Tejina, 10", 26-XI-1927.

Encontrada adulta de enero a mayo y de septiembre a diciembre, según Gangwere et al. (1972) y nuestros datos.

DistRIBUCiÓN. Ya está citada de las islas de Tenerife, Gran Canaria y Gomera por varios autores (entre ellos Gangwere et al., 1972; Johnsen, 1974; Bland et al., 1996 y Hochkirch, 1997). Fuera de las Canarias se encuentra en África del Norte, suroeste de Asia hasta Irán.

La genitalia de un macho de la isla de Tenerife aparece en la figura $6 \mathrm{G}-\mathrm{I}$.

\section{Acheta gossypii (Costa, 1855)}

En la colección del MNCN se conserva una hembra de la provincia de Murcia con cuatro eti- 

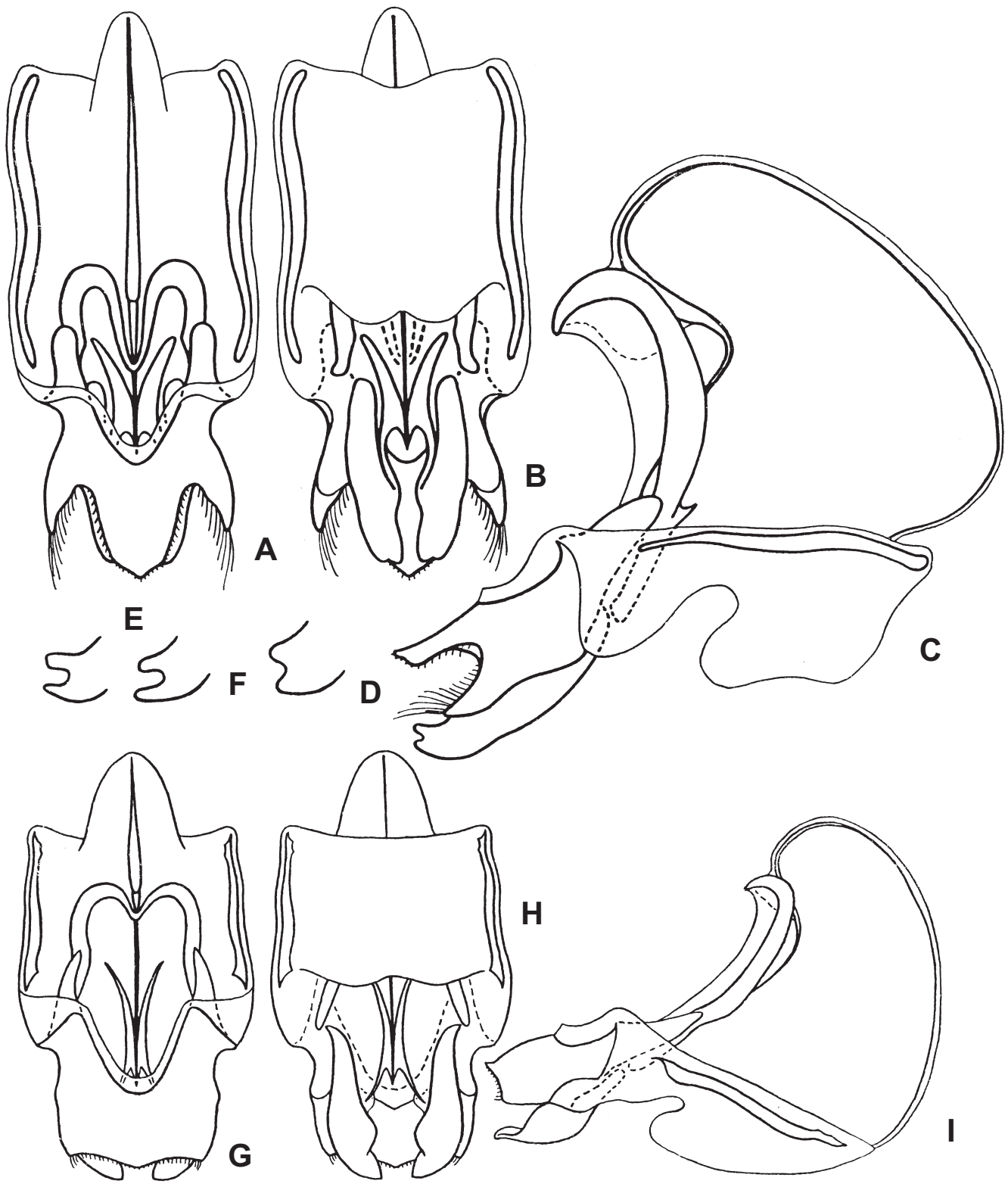

Fig. 6.-Acheta, $\mathrm{O}^{7}$ : A-F) A. hispanicus (A-C. Irán; D, Marruecos; E, España; F, holotipo de G. erythrospilus); G-I) A. meridionalis. Genitalia, vista dorsal (A, G), ventral (B, H) y lateral (C, I); ápice del ectoparámero, vista lateral (D-F).

Fig. 6.-Acheta, Ơ : A-F) A. hispanicus (A-C. Irán; D, Morocco; E, Spain; F, holotype of G. erythrospilus); G-I) A. meridionalis. Genitalia, from above $(\mathrm{A}, \mathrm{G})$, from below $(\mathrm{B}, \mathrm{H})$ and from side $(\mathrm{C}, \mathrm{I})$; apex of ectoparamere from side (D-F).

quetas: la $1^{\mathrm{a}}$ lleva "Cartagena (Sánchez Gómez)” y las tres restantes son de identificación, dos escritas a mano por Bolívar: "Gryllus Gossypii Costa" (en una de ellas, además figura "Cartagena") y la 4a: "Gr. gossypii Costa. Det. E. Morales Agacino".
Este ejemplar, aunque identificado por estos dos ortopterólogos como G. gossypii, posiblemente no pertenezca a esta especie, ya que no coincide con las figuras ni las dimensiones que da Harz (1969), basadas en los datos de Costa (1855). Burr (1910) 
dice que esta hembra, junto con otra desaparecida de Garrucha (Almería), pertenecen a una variedad de G. bordigalensis. Sin embargo Bolívar (1927) considera que estas hembras son de mayor tamaño y, si no pertenecen a G. gossypii, habría que adjudicarlas a $A$. hispanicus. Nosotros también consideramos que esta hembra no pertenece a $E$. bordigalensis, ya que la sutura clípeo-frontal no es tan aguda como en ella, y apenas alcanza la mitad de las cavidades antenales. Después de haberla comparado con las hembras de varias especies cercanas como A. meridionalis, A. domesticus y A. hispanicus, concluimos, como Bolívar, que es muy próxima a la última de ellas.

No obstante hemos creído conveniente seguir considerando esta hembra como A. gossypii por no disponer de ningún macho y ser, precisamente, este sexo el más característico de la especie. Por otra parte, los ejemplares de la provincia de Albacete citados como gossypii por Gómez et al. (1991) correponden a $E$. bordigalensis, al menos los estudiados por nosotros, pero, pese a ello, el hecho de no haber podido revisar los ejemplares a que se refieren las citas de Pardo et al. (1993) y de Burgos Ramírez y Herrera Mesa (1986) de las provincias de Albacete y La Rioja, respectivamente, nos obliga a mantener por el momento a gossypii entre las especies ibéricas.

DistRiBUCIÓn. Por tanto, la presencia de esta especie en la Península Ibérica queda pendiente de ser confirmada. Su distribución fuera de la España peninsular se reduce a Italia, de donde fue descrita y, según Chopard (1967), a Kenia.

\section{Modicogryllus (Modicogryllus) algirius (Saussure, 1877)}

(Fig. 7A-D)

La inclusión de esta especie en el presente estudio se basa tan sólo en un comentario de Bolívar (1927), según el cual se considera perteneciente a M. algirius un ejemplar de Valencia, citado por López Seoane (1878) como Gryllus frontalis (Fieber, 1845).

DisTRIBUCIÓN. Se ha encontrado en el sur de Francia ["Var Bagnols-en-Foret, 5-5-90. V. Aellen", $10^{7}$ y 1 \% (GNHM); estos ejemplares fueron identificados erróneamente por Gorochov como $M$. frontalis (Fieb.)(Aellen y Thorens, 1997)] y en Italia [ Sicilia (La Greca, 1994 y nuestros datos: "Italia", 1 ○ (ZIAS)], además de Âfrica del Norte y parte occidental del suroeste de Asia.

Respecto a Gryllulus algirius var. finoti descrita de Argelia por Chopard en 1943, es muy probable que se trate de otra especie, aunque la genitalia del macho (fig. 7D) la aproxima mucho a la especie que nos ocupa (fig. 7A-C).

\section{Modicogryllus (Modicogryllus) guanchicus}

(Krauss, 1892)

(Fig. 7E-7G)

Material Estudiado: CANARIAS: [GRAN] CANARIA: $10^{7}$ y 1 ㅇ (Ch. Alluaud, 1890). TENERIFE: Bajamar, 1 울 $2-$ X-1915. La Laguna, $10^{\circ}$ (Cabrera); 1 우, 30-VIII-1934. Tacoronte, $10^{\prime}, 1921 ; 1$ ㅇ , IV-1921 (Cabrera?). Tahodio, $10^{\top}$, 10-VII-1941.

Encontrada adulta desde abril a octubre y según Johnsen (1974), también en enero.

DisTRIBUCIÓN. Citada ya de estas dos islas y de La Gomera (Kevan y Hsiung, 1992; Bland et al., 1996). También se encuentra en la parte occidental de África del Norte.

La genitalia del macho de esta especie (fig. 7E7G) es muy parecida a la de M. (M.) zolotarewskyi (Chop., 1954) del Chad, Mali y Etiopía. Cabe la posibilidad de que estos dos nombres sean sinónimos.

\section{Svercus palmetorum palmetorum (Krauss, 1902)}

(Fig. 7H y 7I)

Material Estudiado: MÁlaGA: Benalmádena, $10^{7} \mathrm{y}$ 2 우 우, 22-VIII-1982 (V. Llorente). El Chaparral, en Mijas Costa, $10^{7}, 2-I X-2000$ (Ma.L. Hinojosa). Málaga, $10^{x}$ (NHM).

CANARIAS: GOMERA: San Sebastián, 1 ㅇ , IV-1935 (C. Bolívar y F. Bonet). GRAN CANARIA: Agaëte, Barr. Berrazales, 10", 10-IX-1930. Azuaje, 10" 5-V-1934 (Cabrera?). Canaria, 10", (Ch. Alluaud, 1890). TENERIFE: Charco Tahodio, 7 우 우, 20-22-IV-1952 (J. Mateu).

Los ejemplares de Benalmádena y Mijas Costa tienen las alas posteriores caudiformes, alcanzando el ápice del oviscapto, siendo más frecuentes los individuos de alas más cortas como es el caso de los de Canarias.

Encontrada adulta en España peninsular en agosto y septiembre; en Canarias en abril, mayo y septiembre.

DistriBución. Aunque Lock (1999) dice que Bolívar (1927) ya citó para España peninsular $S$. palmetorum bajo el nombre de Gryllus chinensis var. intermedia, esto no es cierto, ya que el ortopterólogo español sólo sugería que se comparara con $S$. palmetorum. Por tanto, es la primera vez que se cita para la España peninsular, mientras que de las tres islas Canarias ya se conocía (Gangwere et al., 1972; Bland et al., 1996). Recientemente se ha encontrado en el sur de Portugal (Lock, 1999) y en Sicilia [La 
Greca, 1994 y nuestros datos: "Sicilia. Mizam", 1 우 (ZIAS)], en la mitad septentrional de África, Suroeste de Asia y Chipre. En la mitad meridional de África y quizás, en la región de Madagascar se encuentre $S$. palmetorum geonomes (Otte et Cade, 1984), stat. n., que se diferencia de la subespecie nominada por tener más delgado el ápice de los ectoparámeros de la genitalia del macho (fig. $7 \mathrm{H}$ y 7I). La genitalia del macho de la subespecie sureña aparece en Gorochov (1988, Figs. 63-65).

Eumodicogryllus bordigalensis (Latreille, 1802)

$=$ Gryllodes ferdinandi Bolívar, 1899. Ann. Soc. ent. Belg., 43: 606, syn. n.

$=$ Gryllus chinensis var. intermedia Bolívar, 1927. Bol. R. Soc. Esp. Hist. Nat. 27(1): 100-101, syn. n.

Por tratarse de una especie muy abundante, no mencionamos el material estudiado.

Encontrada adulta en la España peninsular y Baleares de abril a octubre y en Tenerife, en julio y enero (Gangwere et al., 1972; Johnsen, 1974, respectivamente).

DistRIBUCIÓN. Prácticamente se encuentra en toda la España peninsular e islas Baleares; de Canarias está citada sólo de la isla de Tenerife, por dos únicas hembras (Gangwere et al., 1972; Johnsen, 1974; Kevan y Hsiung, 1992) y según Bland et al., 1996, también de Lanzarote, aunque con duda, ya que el único ejemplar se conserva en mal estado. La distribución general abarca desde Portugal, Francia, Europa Central y África del Norte hasta Asia Central e India.

Distintos autores dividen esta especie en subespecies, formas de color y variedades relacionadas con la longitud de las alas. Por ahora es difícil dividir una especie tan variable y de fácil difusión, en subespecies sólidas. Además, conviene indicar que en casi todas partes este taxon se presenta sólo como forma macróptera, aunque en raras ocasiones también aparece la $\mathrm{f}$. braquíptera; como por ejemplo, el lectotipo hembra de Gryllodes ferdinandi de Turquía - depositado en el MNCN y estudiado por nosotros- (ver París, 1994). Hay que tener en cuenta que se aceptaba como variante de alas cortas a ejemplares de la f. macróptera, que tras el período de vuelo habían sufrido la pérdida completa o autoeliminación de las alas posteriores.

Después de estudiar la serie tipo de G. chinensis var. intermedia, llegamos a la conclusión que el nombre intermedia fue dado por Bolívar a ejemplares muy claros de E. bordigalensis. Designamos como lectotipo la hembra sintipo con las siguientes etiquetas: "Valencia. C. Bolívar", " Gryllus chinenesis var. intermedia Bol." y "MNCN Cat. Tipos N865"; quedan como paralectotipos las 11 우 우 sintipo que aparecen en París (1994) con sus respectivas etiquetas a las que hay que añadir "MNCN. Cat. Tipos No 859-870".

\section{Eumodicogryllus theryi (Chopard, 1943)}

(Fig. 7J-L)

Material Estudiado: MÁlaGA: Málaga, $10^{7}$ (Rambur) (paralectotipo de Acheta arvensis Rambur) (NHM). PALENCIA: Fuentes de Nava, Laguna "La Nava", Trampa "Pitfall", $50^{7} \sigma^{7}$ y 15 우 0 10-VII-1996 (U. Stengele); Trampa No E, $20^{7} \sigma^{\pi}$ y 5 ㅇ ㅇ , 26-VII-1996 (U. Stengele); Trampa No 6 , $180^{7} \sigma^{7}, 10^{x} \mathrm{n}$ (últ.est.) y 10 우, $26-\mathrm{VII}-1996$ (U. Stengele) (Todos del MNCN); $20^{7} \sigma^{x}$ y 2 우 우, los mismos datos (ZIAS).

Encontrada adulta únicamente durante el mes de julio, así como una ninfa en el último estadio a finales del mismo mes.

Acheta arvensis Rambur, 1838 fue descrita basándose en un macho de Granada, otro de Málaga y, según Uvarov (1948), en una hembra sin localidad. Uvarov, al estudiar estos ejemplares de la colección Rambur, designa el macho de Granada como tipo (lectotipo) de A. arvensis, que ya entonces estaba considerada como sinonimia de E. bordigalensis. Además considera que el otro macho de Málaga es una especie distinta, hecho que ningún autor posterior tiene en cuenta. Nosotros, después de estudiar y comparar este sintipo macho de Acheta arvensis procedente de Málaga y los ejemplares de Palencia con el tipo hembra de E. theryi y los ejemplares estudiados por Morales Agacino (1956), llegamos a la conclusión que todos pertenecen a una misma especie $E$. theryi. Esta última fue descrita de Sebou (Marruecos), basándose en una sola hembra, que se conserva en el MNHN de París, y estudiada por nosotros; el macho (allotipo) y 15 ejemplares más, también de Marruecos, los dio a conocer Morales Agacino y se conservan en el MNCN de Madrid.

E. theryi se diferencia de E. bordigalensis por varios caracteres bien definidos que se mencionan en Chopard (1943), así como por la genitalia del macho (fig. 7J-L); los ectoparámeros en la primera especie están más fuertemente esclerotizados. Designamos como paralectotipo de A. arvensis el macho sintipo del NHM que lleva las siguientes etiquetas: "Syntype", "Málaga", "Rambur coll. Pres. by R. Oberthur. Brit. Mus. 1931, 137”, "Gryllus arvensis Rambur Syntype det. John Huxley, 1970" y nosotros añadimos: "Eumodicogryllus theryi (Chop.) A. Gorochov det.”. 

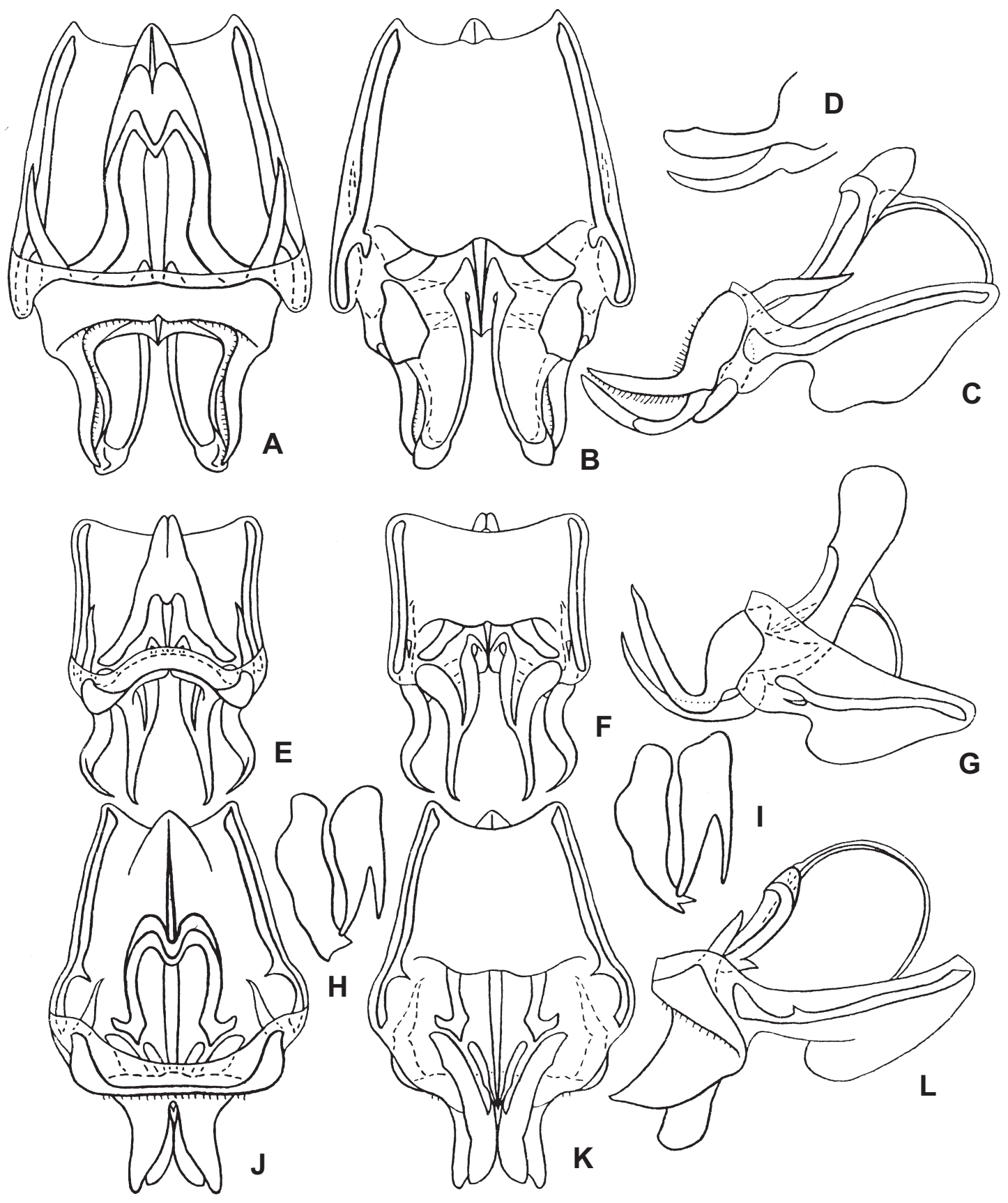

Fig. 7.- Modicogryllus (Modicogryllus), Svercus y Eumodicogryllus, O': A-C) M. (M.) algirius; D) M. (M.) algirius var. finoti; E-G) M. (M.) guanchicus; H) S. palmetorum palmetorum; I) S. palmetorum geonomes; J-L) E. theryi. Genitalia, vista dorsal (A, E, J), ventral $(\mathrm{B}, \mathrm{F}, \mathrm{K})$ y lateral $(\mathrm{C}, \mathrm{G}, \mathrm{L})$; mitad distal del epifalo y del ectoparámero, vista lateral (D); ectoparámero junto con el lóbulo central $(\mathrm{H}, \mathrm{I})$.

Fig. 7.- Modicogryllus (Modicogryllus), Svercus y Eumodicogryllus, O': A-C) M. (M.) algirius; D) M. (M.) algirius var. finoti; E-G) M. (M.) guanchicus; H) S. palmetorum palmetorum; I) S. palmetorum geonomes; J-L) E. theryi. Genitalia, from above (A, E, J), from below $(B, F, K)$ and from side $(C, G, L)$; distal half of epiphallus and ectoparamere, from side (D); ectoparamere with mesal lobe $(\mathrm{H}, \mathrm{I})$. 
DisTRIBUCIÓN. Por ahora sólo hallada en las provincias de Málaga y Palencia, siendo nueva para la Península Ibérica y Europa. El reciente hallazgo en gran número en Fuentes de Nava, en una provincia tan alejada como Palencia, nos sugiere que su distribución sea mucho más amplia. También se encuentra en Marruecos.

Las citas de $A$. arvensis como variedad o subespecies de E. bordigalensis (Bolívar, 1878, 1900; Pantel, 1886, 1890; Morales Agacino, 1933) pertenecen casi todas a ejemplares de E. bordigalensis de color más oscuro, con las tegminas más cortas y alas vestigiales.

\section{Gryllodes supplicans (Walker, 1859)}

Material Estudiado: CANARIAS: TENERIFE: Sta. Cruz, 1 ㅇ , 28-XI-1941; en el maíz, $4 \sigma^{\top} \sigma^{7}, 4 \sigma^{7} \sigma^{7} \mathrm{n}$ (ults.est.), 3 우 우 y 3 우 우 n (ults. est.) (todos A. de la Cruz).

Encontrada adulta en noviembre y diciembre, y ninfas en los tres últimos estadios en diciembre.

DistriBución. Por ahora sólo citada de la isla de Tenerife (Gangwere et al., 1972; Kevan y Hsiung, 1992 y Bland et al., 1996). En los trópicos se encuentra muy extendida, y en el este de Asia pasa también a la zona templada (hasta el río Amur).

Es una especie sinántropa, que vive en las casas y ha sido transportada por el hombre incluso hasta las alejadas islas oceánicas. Se desconoce el área inicial (primitiva) de esta especie, ya que el género Gryllodes Saussure, 1874 tiene una sola especie, pero lo más probable es que esta área se encontrara en los límites de la parte tropical de Asia y África, donde se distribuye la mayoría de especies de los géneros más o menos cercanos a él (Velarifictorus Randell, 1964 y Tugainus Gorochov, 1986). G. supplicans aparece a menudo bajo el nombre de $G$. sigillatus (Walker, 1869), que es en realidad su sinonimia más reciente. Creemos que debe utilizarse el nombre de supplicans y no el de sigillatus como proponen Otte (1994) y Bland et al. (1996), basándonos en el CINZ y especialmente tras conocerse que el tipo de supplicans, que se creía perdido, se conserva en el NHM (Kevan y Kevan, 1995; G.B. Popov, com. pers., 1997).

\section{Gryllodinus kerkennensis (Finot, 1893)}

Material Estudiado: CiUdAd REAL: Pozuelo de Calatrava, $10^{x}$ y 1 우 (Fuente!) (Gr. macropterus) (lectotipo y paralectotipo) (MNCN Cat. Tipos $\mathrm{N}^{\circ}$ 8728). TOLEDO: Quero, $4 \sigma^{7} \sigma^{x}$ y 6 우 우, 15-V; 3GG, 12-VI-1905; $20^{7} \sigma^{7}$ y 1 우, V-1908 (J. Sanz); 1 오, (C. Bolívar). Villacañas, $20^{7} \sigma^{7}, 1$ 우 y 1 积 (últ.est), 21-V-1934 (C. Bolívar); 1 \& , VI-1936 (E. Morales).
Algunos de los ejemplares citados por Fernandes (1967) llevan su etiqueta de identificación.

Encontrada adulta en mayo y junio, así como una ninfa hembra en el último estadio a mediados de mayo.

Distribución: Citada ya de las provincias de Ciudad Real (Fuente, 1894a; Bolívar, 1927), Toledo y Cuenca (Fernandes, 1967), por tanto, por ahora sólo se ha encontrado en la zona centro de la España peninsular. Fuera de España se distribuye, por la parte meridional de la mitad occidental de la paleártica, desde África del Norte hasta Asia Central.

Este grillo está relacionado con salinares (o con suelos salinos cerca de reservorios de agua) en lugares áridos; es capaz de excavar galerías, pero está relacionado en menor grado con ellas que Gryllus campestris, aunque las ninfas de los primeros estadios viven en la madriguera materna (es posible que esta especie muestre cuidados maternales hacia sus crías ). La genitalia del macho ha sido estudiada por Fernandes (1967: fig. 1A-C) y Gorochov (1979: Figs. 4-6).

Bolívar ya sinonimizó en 1927 G. macropterus Fuente, 1894 con $G$. kerkennensis, dato que incluimos en este estudio, ya que Otte (1994) sigue considerando como autor a Chopard (1967).

Por esta razón, el hallazgo entre el material estudiado de $1 \sigma^{\top}$ y 1 ㅇ con las etiquetas: "Gr. macropterus" y "Ciudad Real. Fuente!" nos hizo pensar que podría tratarse de parte de los ejemplares pertenecientes a la serie tipo que se consideraba en paradero desconocido. Efectivamente, según se desprende de las medidas que da De la Fuente (1893 y publicado el 31 de enero de 1894) al realizar la descripción de $G$. macropterus, la serie tipo podría estar compuesta, al menos, de dos machos y dos hembras. Bolívar (1894) en su trabajo sobre el género Gryllodes Saussure, 1874, también estudia esta especie, basándose en $10^{7}$ y 1 ㅇ de "Ciudad Real", sin decir expresamente que se los hubiera enviado De la Fuente, aunque, por las medidas que da de ellos, podemos suponer que así fue, ya que coinciden bastante bien con las de la serie tipo y además ambos ejemplares llevan la etiqueta de "Ciudad Real. Fuente!", como veremos más adelante. Por consiguiente, creemos, al igual que Chopard (1943), que los tipos están en el Museo de Madrid, aunque consideramos que son sólo parte de la serie tipo y estando el resto en paradero desconocido, ya que, en la colección de De la Fuente, en Ciudad Real, no hay ningún ejemplar perteneciente a esta especie.

Con relación a la localidad típica de Gryllodes macropterus, hay que decir que es Pozuelo de 
Calatrava (Ciudad Real), como bien señala De la Fuente (1894: 138) y no únicamente Ciudad Real como apunta Bolívar (1894: 48); por esta razón, creemos conveniente añadir a los dos ejemplares de la serie tipo una etiqueta con la mencionada localidad.

Por todo lo expuesto, designamos como lectotipo de G. macropterus el macho con las etiquetas: "Ciudad Real. Fuente!", a mano; "Gryllodinus kerkennensis (Finot). Det. J. de A. Fernandes - 1968”, y genitalia en tubo. El macho carece de antenas, patas II y el tarso III dcha. y 2 artejos y uñas pata III izda. A la hembra con las etiquetas: "Ciudad Real. Fuente!" y "Gr. macropterus", ambas a mano de I. Bolívar, la designamos paralectotipo; ésta carece de antena izda. y pata III izda. A ambos ejemplares les añadimos las nuevas etiquetas: "Pozuelo de Calatrava (ref. Fuente, 1994a)" y "MNCN Cat. Tipos No 8728".

\section{Eugryllodes pipiens (Dufour, 1820)}

(Fig. 8A)

$=$ Gryllodes pipiens var. provincialis Finot, 1901. In Azam. Misc. Ent. 9: 101, syn. n.

Fernandes (1967) consideró como sinónimos de esta especie los siguientes nombres: Gryllodes ibericus Brunner - Wattenwyl, 1882, G. panteli Cazurro, 1888, G. pipiens var. castellanus Bolívar, 1894, G. pipiens var. valentinus Bolívar, 1894, G. boscai Bolívar, 1898 y G. carrascoi Bolívar, 1902. A excepción de panteli y valentinus, el resto de los nombres se dieron a ejemplares morfológicamente muy parecidos que se diferencian entre sí sólo por detalles de coloración.

Después de haber estudiado los tipos de la mayoría de estos taxones, designamos los lectotipos siguientes:

Lectotipo de $G$. ibericus, un macho sintipo de NHMW con las siguientes etiquetas: "13.956", "Coll. Br. v. W. Castroceniza (Salamanca), Bolívar", "det. Br.v. W.Gryllodes ibericus G", "Ectolandrevus Iberus, Brun. n.sp.", "Syntype", "Coll. Nat.-Mus. Wien”, "Eugryllodes ibericus (Br. v. W.)". La localidad de Castroceniza pertenece realmente a la provincia de Burgos, aunque se menciona Salamanca no sólo en la etiqueta del ejemplar sino también en Brunner (1882); el error se mantiene en Harz (1969), Herrera (1982) y Otte (1994).

Lectotipo de G. boscai, una hembra sintipo del MNCN con las siguientes etiquetas: "pipiens, Boscá, Játiva", "Gryllodes Boscai Bol.” y "MNCN Cat. Tipos $\mathrm{N}^{\mathrm{o}} 1281$ ". La segunda hembra como paralectotipo, con las etiquetas: "M. Escalera.
Valencia", "Eugryllodes pipiens (Duf.) f. boscai. Det. J. de A. Fernandes - 1968" y "MNCN Cat. Tipos No 1282 ".

Lectotipo de G. carrascoi, un macho sintipo del MNCN con las etiquetas: "Santiago de la Espada, Escalera", "Carrascoi Bol.", "Gryllodes carrascoi Bol." y "MNCN Cat. Tipos No 1283". Los restantes sintipos $\left(10^{7}\right.$ y 2 우 우 ) los designamos paralectotipos: $10^{7}$ y 1 O llevan las etiquetas: "Santiago de la Espada. Escalera", "Eugryllodes pipiens (Duf.) f. carrascoi (Bol.). Det. J.de A.Fernandes 1968", O", genitalia en tubo; la segunda hembra sólo lleva: "Santiago de la Espada. Escalera" y "MNCN Cat. Tipos No 1284 a 1286"; a los cuatro ejemplares añadimos la etiqueta: "15-30-VII (ref. Bol. 1902)".

Por último, designamos como lectotipo de $G$. pipiens var. castellanus un macho sintipo del MNCN con las siguientes etiquetas: "Oña", "Eugryllodes pipiens (Duf.) f. ibericus (Brunn.). Det. J. de A. Fernandes-1968", "var. castellanus Bol. Sintipo" y "MNCN Cat. Tipos No 1278"; genitalia en tubo (a este ejemplar se le pegó la pata III dcha. en 1997, Llorente). Los restantes sintipos los designamos paralectotipos: $10^{\top}$ con las etiquetas : "Oña", "Gryllodes ibericus Brunn.", "var. Castellanus" ( a este ejemplar se le pegó la pata III izda. en 1997, Llorente) y 2 우 우 con “Oña” y una de ellas lleva: "Eugryllodes pipiens (Duf.) f. ibericus (Brunn.) Det. J. de A. Fernandes-1968" y "MNCN Cat. Tipos No 1277, 1279 y 1280".

Creemos que probablemente todas ellas sean sólo variantes de una misma especie muy variable en su coloración. Igual variante de color resulta ser G. pipiens var. provincialis de Francia. La genitalia del macho de E. pipiens está representada en el trabajo de Fernandes, más arriba mencionado (fig. 3: A y B; fig. 4: A).

MATERIAL Estudiado: ALMERÍA: Fiñana, 1 ㅇ n (últ. est.) (Escalera). Sierra María, 3 우, XI (Escalera). BARCELONA: Collsespina, 10", 8-IX-1932 (A. Villarrubia) (Eugryllodes pipiens (Duf.). Det. J. de A. Frenandes-1968) (MZB). Montseny, 1 은 20-VII-1941 (J. Mateu); 1 ㅇ n (Gryllodes pipiens Duf. Navás det.?). Mura, 1 우, 12-XII-1932 (Español) (Eugryllodes pipiens (Duf.) Det. J. de A. Fernandes-1968). BURGOS: Castroceniza, 10" (Bolívar) (lectotipo de Gryllodes ibericus Br. v. W.) (NHMW). Oña, $10^{\prime \prime}$ (lectotipo de Gryllodes ibericus var. castellanus); $10^{7}$ y 2 우 우 (paralectotipos de esta última). CASTELLÓN: Morella, 10" (J. Rojo) (Eugryllodes boscai Bol. det. V. Llorente, 1988). CUENCA: Altomira, $110^{7} \sigma^{7}$ y 1 우, VII-1932 (M. Pujol). Uclés, $10^{\pi}$ (Pantel!) (Gr. pipiens Duf. letra de Bolívar) (Eugryllodes pipiens (Duf.) Det. J. de A. Fernandes-1968). GERONA: Camprodón, $10^{7}$ (Masferrer); $10^{7}$ y 3 우 으, VIII (Martorell?); 950 m, 1 우, 25IX-1940 (J. Mateu); 2 우 ơ, 1945 (J. Mateu). Espinelvas, $10^{7}$ y 1 오 (Masferrer). Holtalroig, $10^{x}$ (Montsech). Olot, 10", 4-IX- 
1915 (ex col. Codina) (Eugryllodes pipiens (Duf.) Det. J. de A. Fernandes-1968) (MZB). GRANADA: Puebla de D. Fadrique, $10^{7}$ (J. Martínez). HUESCA: Naval, 10", 28-VII-1934 (C. Bolívar). JAÉN: El Puntal, 1200 m, sierra de Cazorla, 10", 2030-X-1986 (Bouillie) (Eugryllodes pipiens (Duf.) det. V. Llorente, 1989). Santiago de la Espada, 10", 15-30-VII (Escalera) (lectotipo de G. carrascoi Bol.), $10^{7}$ y 2 우 우, los mismos datos, paralectotipos). Sierra de Cazorla, E. of Nava del Espino, $1800 \mathrm{~m}, 10^{\text {, }}$, 30-VIII-1963 (P. Newman y A. Brown) (Gryllodes pipiens (Dufour) det. P. M. Newman, 1964), $10^{\prime \prime}$, los mismos datos (Eugryllodes pipiens (Duf.). Det. J. de A. Fernandes-1968). LÉRIDA: Viu de Llevata, Llastarri, $10^{7}$ (C. Bolívar). TARRAGONA: La Juncosa, 10", VIII-1934 (Museu) (MZB). Port Tortosa, 1 온 VII-1934 (MZB). Valls, $10^{\pi}$, 22-IX-1931 (F. Español) (Los tres ejemplares con etiqueta Eugryllodes pipiens (Duf.) Det. J. de A. Fernandes-1968) TERUEL: Gea, $10^{x}$ y 2 우 $ᄋ$ (Escalera). Manzanera, $10^{x}$ y 1 우 (F. Beltrán). Teruel, 935 m, 10'n (penúlt. est.), VIII-1931 (B. Muñoz); 1 ㅇ , 20-VIII-1934 (B. Muñoz). VALENCIA: Játiva, 1 우 (Boscá) (lectotipo de Gryllodes boscai, Bol.). Valencia, 1 으 (M. Escalera) (paralectotipo de la misma especie).

Encontrada adulta desde mediados de julio hasta últimos de diciembre y ninfas en los últimos estadios en agosto y, según Del Cerro (1978), también en septiembre.

DISTRIBUCIÓN. Este grillo fue descrito de Aragón y Cataluña; además está citado del Moncayo (Zaragoza), de Brihuega (Guadalajara) (Navás, $1900,1904 \mathrm{a}$ y 1928) y de Navarra (Fernandes, 1967; Herrera 1982). También pertenecen a esta especie los grillos identificados como E. ibericus, boscai, carrascoi y castellanus que se relacionan en el apartado de Material Estudiado, a los que hay que añadir los ejemplares de Albacete, considerados como E. carrascoi por Gómez et al. (1991) y Pardo et al. (1993). Según Fernandes (1967), el macho de Mijas, Málaga (Ragge, 1965) podría pertenecer a E. escalerae. Por tanto, la distribución conocida hasta ahora ocupa la mitad oriental de la Península, como dice Fernandes, a la derecha de una línea imaginaria trazada desde Burgos a Granada; no habiéndose encontrado ni en las islas Baleares ni en Canarias. Fuera de España sólo se conoce del sureste de Francia.

\section{Eugryllodes panteli (Cazurro, 1888)}

\section{(Fig. 8B)}

Material Estudiado: CUENCA: Uclés, 10", 19-IX-1886 (Pantel) (lectotipo de Gr. panteli Caz.) y 3 우 (R. P. Pantel) (paralectotipos). TERUEL: Teruel, 10 y 1 우 우, IX-1931 (B. Muñoz). VALENCIA: Manises, $60^{7} 0^{x}$ y 1 (우 (Boscá) (paralectotipos de G. valentinus Bol.). Valencia, $10^{\pi}$ (Boscá) (Gr. valentinus B.) (lectotipo de G. valentinus); $10^{x}, 10^{7} \mathrm{n}$ (últs. est.) y 2 우 (1 sin oviscapto) (Boscá); 10 , VI (Escalera) (todos paralectotipos de G. valentinus).
Encontrada adulta en junio y septiembre.

Distribución. Citada como $G$. panteli de las provincias de Cuenca, Teruel y Álava (Cazurro, 1888; Morales Agacino, 1933; Herrera, 1985) у como G. valentinus de la de Valencia (Bolívar, $1894,1927)$. Por ahora restringida a estas tres provincias del centro y levante.

Es muy probable que G. pipiens var. valentinus Bolívar, 1894, como dice Fernandes (1967), sea sinónima de esta especie. Para establecer esta sinonimia sería necesario un estudio adicional de la morfología de esta especie y de E. pipiens. Habría que contar el número de dientecillos que lleva la vena estriduladora de los tipos o de los topotipos de E. panteli y valentinus y compararlos con los de pipiens, o hacer un estudio acústico. Este interesante asunto se deja para investigaciones futuras.

Después de examinar las series tipo de estos dos taxones, depositadas en el MNCN, pasamos a designar sus respectivos lecto y paralectotipos.

Designamos como lectotipo de la var. valentinus un macho sintipo con las etiquetas: "Valencia, Boscá", "Gr. valentinus B.", "MNCN Cat. Tipos No 1343". Genitalia pegada en etiqueta. Los restantes sintipos $\left(90^{7} \sigma^{7}\right.$ y 3 ᄋ \% ) los designamos paralectotipos: 10 " con etiqueta "Eugryllodes pipiens (Duf.) f. valentinus Bol. Det. J. de A. Fernandes-1968", $10^{7} \mathrm{n}$ y 2 ㅇ $ᄋ$ (una de ellas sin oviscapto), todos con la etiqueta de "Valencia. Boscá" y $10^{\text {" }}$ "Valencia. Junio. Escalera". Además $60^{\circ} \sigma^{7}$ con la etiqueta de "Manises. Boscá" y 1 \% de la misma procedencia con una etiqueta más: "Eugryllodes pipiens (Duf.) f. valentinus Bol. Det. J. de A. Fernandes-1968" "MNCN Cat. Tipos No 1344 a 1355". Aunque esta información aparece en el Catálogo de París (1994), corregimos aquí el sexo de un ejemplar, mencionado como $10^{7}$ ninfa, y que, en realidad es una hembra adulta a la que le falta el oviscapto; además se ha omitido la localidad de Valencia en las líneas $6^{\mathrm{a}}$ y $10^{\mathrm{a}}$.

Designamos como lectotipo de panteli un macho sintipo con las etiquetas: "19-9-86", "Uclés. G. Panteli Caz.", "Gryllodes Panteli Caz.", con letra de I. Bolívar, "Eugryllodes pipiens (Duf.) f. panteli (Caz.) Det. J. de A. Fernandes - 1968" "MNCN Cat. Tipos No 7433". A este ejemplar le faltan las antenas, pata II dcha. y los últimos artejos de los tarsos de las patas III, así como el tarso entero de la pata I dcha. Los restantes sintipos (3우 $)$, quedan como paralectotipos, 2 $\odot$ llevan la etiqueta: "Uclés R. P. Pantel" a mano y una de ellas además "Eugryllodes pipiens (Duf.) $f$. panteli, Det. J. de A. Fernandes-1968"; la $3^{\text {a }}$ hembra lleva la etiqueta "Uclés. R. P. Pantel" a mano de I. Bolívar; 


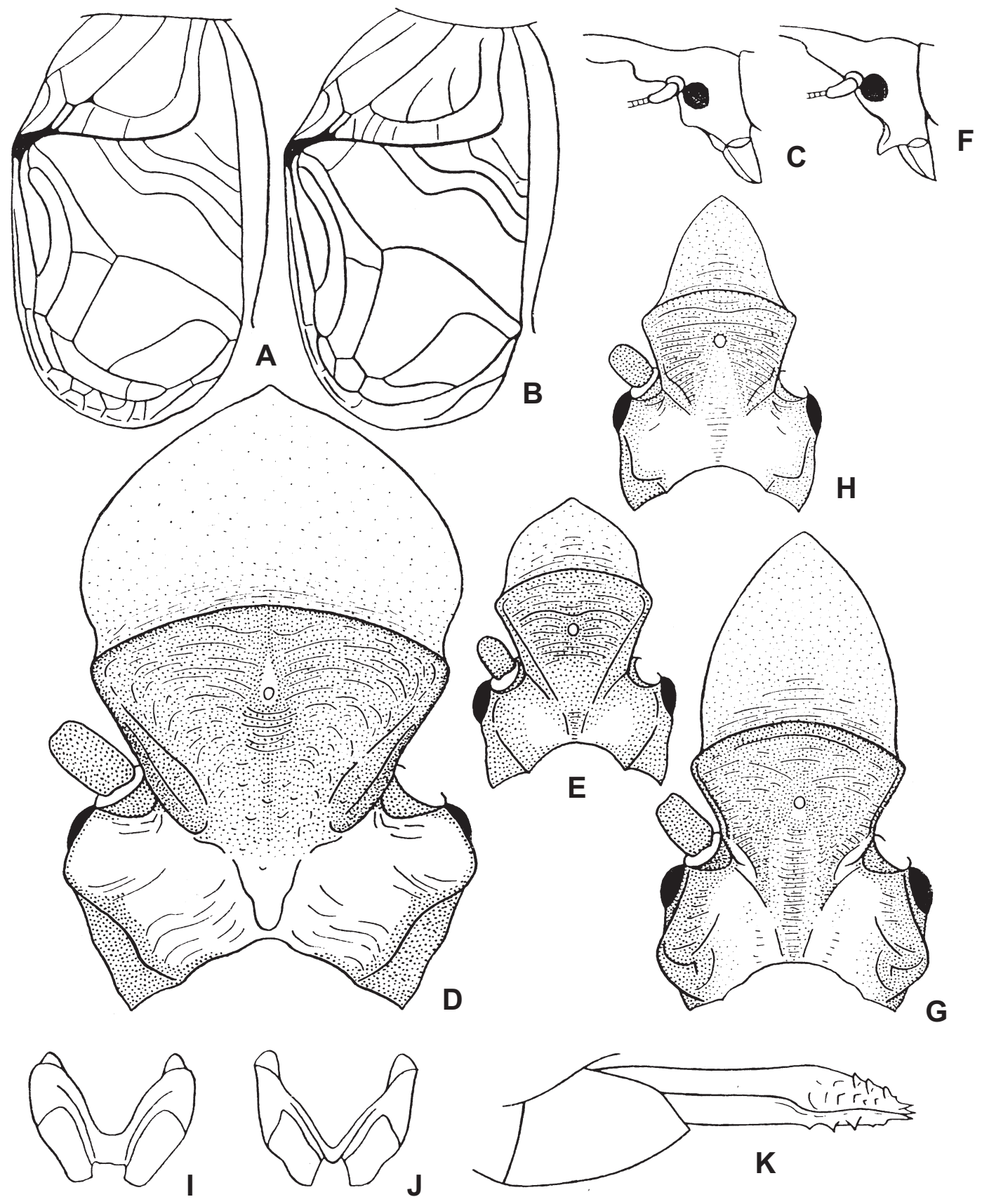

Fig. 8.- Eugryllodes, Sciobia (Sciobia), Oecanthus y Paramogoplistes. A) E. pipiens; B) E. panteli; C-E) S. (S.) boscai (C, D, macho grande; E, macho pequeño); F-H) S. (S.) lusitanica (F, G, macho grande; H, macho pequeño); I) $O$. pellucens; J) $O$. dulcisonans; K) P. dentatus sp. n. Campo dorsal de la tegmina izquierda del macho (A, B); representación esquemática de la cabeza ( $\sin$ el ápice de la proyección membranosa del vertex), vista lateral (C, F); escudo facial con la proyección membranosa del vértex, vista ventral y ligeramente por delante (D, E, G, H); epifalo, vista dorsal (I, J); oviscapto, vista lateral (K).

Fig. 8.- Eugryllodes, Sciobia (Sciobia), Oecanthus y Paramogoplistes. A) E. pipiens; B) E. panteli; C-E) S. (S.) boscai (C, D, large male; E, small male); F-H) S. (S.) lusitanica (F, G, large male; H, small male); I) O. pellucens; J) O. dulcisonans; K) P. dentatus sp. n. Dorsal part of male tegmen (A, B); head (without apex of lamellar rostral process) from side (C, F); frontal shield with lamellar rostral process from below and slightly in front (D, E, G, H); epiphallus from above (I, J); ovipositor from side (K). 
además le falta el oviscapto, ya que tiene deteriorado el extremo del abdomen.

E. panteli se parece mucho a E. pipiens, incluso también por la estructura de la genitalia del macho y del oviscapto, pero se diferencia bien por la longitud de la vena estriduladora de las tegminas del macho, ya que en panteli es 1,9-2,1 veces más larga que la distancia entre la vena estriduladora y el espejo, mientras que en pipiens la vena estriduladora es más larga que esta distancia sólo en 1,5-1,6 veces (para comparar ver la figura $8 \mathrm{~A}$ y $8 \mathrm{~B}$ ).

\section{Eugryllodes escalerae (Bolívar, 1894)}

Material Estudiado: ÁVILA: Hoyo de Pinares, 10", $23-$ VI-1985 (E. González) (DBUC). Piedralabes, en Pto. Serradillos, 1 o n (últ. est.), 30-V-1929. Sierra de Gredos, en Garganta de las Pozas, $2100 \mathrm{~m}, 10^{7}$ (holotipo de G. uvarovi Bol.) ("MNCN Cat. Tipos $\mathrm{N}^{\mathrm{o}} 1360$ ) y $20^{\top} \sigma^{7}$ (paratipos de la misma especie) (MNCN Cat. Tipos No 1361 y 1362), VIII-1926 (C. Bolívar); en Puerto del Pico, 10n, (últ. est.), VI-1909 (Exp. Mus); en Valle de Iruelas, $10^{x} \mathrm{n}$ (últ. est.). CÁCERES: El Torno, $950 \mathrm{~m}, 20^{x} \mathrm{O}^{x}, 25$-VIII1980 (M. A. Marcos) (Eugryllodes carrascoi (Bolívar) 1902. E. Clemente det. Nov. 1995) (DZM). Yuste, 1 우 y 1 ㅇ n (últ. est.), 28-XII-1966 (E. Ortiz). MADRID: Brunete, en Cienvallejos, 1 온, VII-1927 (C. Bolívar). Cercedilla, $10^{2} \mathrm{n}$ (últ. est.), VI (F. Bonet); Estación Alpina, 1500 m, $80^{\top} \sigma^{\pi}$, VIII-1930 (J. Abajo); $10^{\pi}$, VIII (E. Morales); $1480 \mathrm{~m}, 10^{\pi}$, VIII-1958 (J. Abajo) (Eugryllodes escalerae (Bol.) Det. J. de A. Fernandes-1968), $64 \sigma^{2} \sigma^{\prime \prime}$ y 1 \% , VIII-1958 (J. Abajo); $7 \sigma^{7} \sigma^{7}$, VIII-1959; en El Ventorrillo, $1480 \mathrm{~m}, 80^{\pi} \sigma^{\pi}$, VII-VIII-1960-62; $30^{\top} \sigma^{\prime \prime}$, VIII-1964 (todos J. Abajo). El Escorial, $10^{7}$ (Cardiel); $10^{7} \mathrm{n}$ (últ. est.), 2VII-1891; $10^{x}$ y 1 우 (Lauffer); $30^{x} 0^{x}$ y 1 우; $10^{x}$ y 1 우 (C.

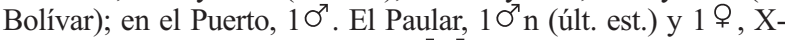
1908 (C. Bolívar). Fuencarral, 30 $\sigma^{\pi}$ (M. Pujol). Guadarrama, Puerto de Cotos, 1830 m, 1 ᄋ , 22-X-1971 (V. Llorente). Madrid, $20^{7} \sigma^{7}$ (I. Selgas); $10^{7}$; en El Pardo, $10^{\pi}$ y 1 ㅇ , 2-XI-1931 (C. Bolívar); $30^{7} \sigma^{\pi}$, 18-X-1932 (D. Peláez); 10", VI-1983 (M. A. Blanco) (DBUC). Soto del Real, 10", 16-IX-1979 (V. Llorente). Villaviciosa de Odón, 10" 1891 (Escalera) (lectotipo de G. escalerae), $30^{x} 0^{x}, 10^{x} \mathrm{n}$ y 2 우 우 (Escalera) (paralectotipos de esta especie). ORENSE: Celanova, 10", VIII-1927 (L. Iglesias). SALAMANCA: Cerralbo, $20^{x} \sigma^{x}$ y 2 우 ㅇ․ Sequeros, $950 \mathrm{~m}$, $1 \sigma^{\top} \mathrm{n}$ (últ. est.), VII-1954 (Exp. IEE). SEGOVIA: El Espinar, $20^{77} \sigma^{7}$ y 1 \% , VIII-1894 (Bolívar). Muñopedro, $50^{7} \sigma^{\prime \prime}$, IX-1956 (Vaquero). San Rafael, $10^{\pi}$ (C. Bolívar) (Eugryllodes escalerae (Bol.) Det. J. de A. Fernandes-1968); $280^{\prime \prime} \sigma^{\prime}, 2$ 우 우 y 1 우 $\mathrm{n}$ (C. Bolívar). Valsaín, 10", VI-1944 (J. Abajo). TOLEDO: Sierra de S. Vicente, Coto Piélago, $10^{7}$ (Lauffer). Talavera de la Reina, $20^{7} \sigma^{\prime \prime}$ (G. Planchuelo). VALLADOLID: Valladolid, $40^{\prime \prime} \sigma^{\prime \prime}$ (Rioja); $10^{7}$.

PORTUGAL: Guarda: Sierra Estrella, 10", IX-1885 (lectotipo de G. lusitanicus Bol.) (MNCN Cat. Tipos No 1287).

Encontrada adulta desde junio a diciembre y como ninfas en el último estadio, de mayo a diciembre.

DISTRIBUCIÓN. Ya estaba citada de las provincias de Madrid, Segovia y Valladolid (Bolívar, 1894,
1900 y 1927), Ávila y Málaga? (Fernandes, 1967), así como de las de Guadalajara, en Altollano (Pardo et al., 1993) y de Zaragoza, en Los Monegros (Blasco-Zumeta, 1998); siendo nueva para las de Cáceres, Orense, Salamanca y Toledo. También se encuentra en gran parte de Portugal (Fernandes, 1967), por tanto su distribución abarca aproximadamente la mitad occidental de la Península Ibérica.

Fernandes (1967) consideró a Gryllodes pipiens var. lusitanicus Bolívar, 1894 y Gryllodes uvarovi Bolívar, 1927 como sinónimos de esta especie. Estos nombres fueron dados a ejemplares que se diferencian entre sí solamente por la intensidad de su coloración.

Al estudiar las series tipo de estos taxones, hemos constatado que Bolívar ya designó el tipo y paratipos de G. uvarovi en el momento de su descripción y que aparecen como tales en el material estudiado; el lectotipo de Gryllodes pipiens var. lusitanicus lo designó París (1994) en base al único ejemplar de la serie. Nosotros designamos como lectotipo de G. escalerae el macho sintipo con las etiquetas: "Villaviciosa de Odón. 1891", "Gryllodes Escalerai Bol.", "MNCN Cat. Tipos. No 1336"; quedando como paralectotipos los $40^{7} 0^{7} \mathrm{y}$ 2 우 $ᄋ$ de la misma procedencia "MNCN Cat. Tipos $\mathrm{N}^{\circ} 1337-1342$, así como 4 ejemplares de la serie tipo que se conservan en otros centros (París, 1994).

Como ya indicamos en el apartado de $E$. pipiens, Fernandes (1967: Carte II) adjudicó con duda "?" a G. escalerae un macho de Sierra de Mijas, Málaga (Ragge, 1965); duda justificada ya que para identificar con seguridad las especies de este género es necesaria la presencia de la hembra. Con respecto a la cita de Cantabria que da Fernandes (1967: Carte II) y que corresponde al macho con la etiqueta: "Coto Piélago. Lauffer leg." (Bolívar, 1900), podemos afirmar que se refiere en realidad a una zona llamada El Piélago y situada en la sierra de San Vicente, entre los ríos Guadyerbas y Tiétar, en la provincia de Toledo. En el caso de la cita de "Montseny, fin junio (Navás)" que Bolívar (1927) consideró como perteneciente a G. escalerae, nosotros, por su distribución, estamos más de acuerdo con Navás $(1899,1904 a$ y 1928) que en varias ocasiones la identificó como pipiens.

E. escalerae es muy parecida a las dos especies anteriores incluso por la estructura de la genitalia del macho, pero la vena estriduladora de la tegmina en este sexo es más o menos de una longitud intermedia y además el oviscapto está fuertemente abreviado (probablemente, en relación con la exca- 
vación de galerías), siendo 4-5 veces más corto que el fémur posterior, mientras que en $E$. pipiens y $E$. panteli es sólo 1,4-1,5 veces más corto que este fémur.

\section{Eugryllodes littoreus (Bolívar, 1885)}

Material Estudiado: TOLEDO: Talavera de la Reina, $10^{x}$ (Gryllodes littoreus Bol.) (Rioja!) (lectotipo), $10^{x}$ y 2 우 우 (Rioja) (paralectotipos); 40 $\sigma^{\pi}, 2 \sigma^{\prime} \mathrm{n}$ (últ.est.) y $1 \stackrel{\circ}{\circ} 8$-X1885 (paralectotipos); $120^{\top} \sigma^{\top}$ y 3 우 우 (G. Planchuelo).

Encontrada adulta sólo en octubre, al igual que las ninfas en los últimos estadios.

DistribuCión. Según Fernandes (1967), lo más probable es que el macho de la Serra da Estrela, Portugal, identificado por Ragge (1965) como $E$. littoreus, pertenezca a $E$. escalerae. Por tanto, este grillo por ahora es endémico de la España peninsular y solamente hallado en las orillas del río Tajo, en Talavera de la Reina. Por esta razón hay que excluirlo de Portugal (Harz, 1969; Herrera, 1982) y, además tener en cuenta la errata en el Catálogo de Chopard (1967), donde dice: "Portugal: bords du Tage", en lugar de: "Espagne: Talavera de la Reina, bords du Tage".

Este grillo es muy parecido a E. escalerae, incluso por la estructura de la genitalia y la tegmina del macho, pero se diferencia por tener el espolón supero-interno de las tibias posteriores más largo, sobrepasando la mitad de la longitud del metatarso y además, el oviscapto es 2-2,5 veces más corto que el fémur posterior, es decir la longitud intermedia entre E. escalerae y las otras dos especies (E. pipiens y E. panteli).

Designamos como lectotipo de G. littoreus un macho sintipo con las etiquetas: "Talavera de la Reina. Rioja!", "Gryllodes littoreus Bol.”con letra de Bolívar, "MNCN. Cat. Tipos No 1288" y genitalia en tubo; y como paralectotipos, $10^{\prime \prime}$ y 2 \% $\%$ con etiqueta "Talavera de la Reina. Rioja" a mano, no del autor, y $40^{x} \sigma^{x}, 1 \%$ y 2 ninfas con etiqueta "Talavera. 8.oct.85" a mano, no del autor y "MNCN Cat. Tipos No 1289-1298", así como 10 ejemplares de la serie tipo que se conservan en otros centros (para más detalle, ver París, 1994).

\section{Sciobia (Sciobia) lusitanica (Rambur, 1839)} (Fig. $8 \mathrm{~F}-8 \mathrm{H}$ )

Material Estudiado: ÁVILA: Candeleda, 1 \& n (últ. est.), 26-IV-1970 (A. Fdez. García) (DBUC). BADAJOZ: Badajoz, $20^{7} \sigma^{7}, \mathrm{~V}-1880$ (Uhagón, ref. Gogorza, 1881). Bótoa, $10^{7} \mathrm{n}$ (últ. est.) y 1 으, IV-1976 (F. Sánchez) (DBUC). Las Vegas, 1 i $\mathrm{n}$ (últ. est.), X-1971 (S. Delgado) (DBUC). CÁCERES:
Membrio, 10", 18-IV-1983 (E. Galante) (Sciobia lusitanica, E. Clememte det. 1995) (DZM). Plasencia, $10^{7} \mathrm{n}$ (últ. est.), 26-III1986 (M. Mayo) (DBUC). Poblado Ciñara, 10", V-1982 (E. Lizama) (DBUC). Santiago de Alcántara, 1 오 , 13-V-1978 (L. Domínguez) (DBUC). CÁDIZ: Grazalema, 10", 26-IV-1995 (S. Bordera) (Scionica lusitanica Rambur. E. Clemente det.1995) (DZM). CÓRDOBA: Pozoblanco, 1 오, IV-1990 (J. Saiz) (DBUC). CUENCA: Altomira, $50^{7} \sigma^{7}$ y 3 우 우, VI-1932 (M. Pujol); $160^{\pi} \sigma^{\pi}, 12$ 우 우 y 1 으 n (últ. est.), VII-1932 (M. Pujol). Uclés, $20^{\top} \sigma^{\prime \prime}$ y 1 우 (Pantel) (f. armata). GUADALAJARA: Mondéjar, alr. 1n (últ. est.), 8-II-1976 (J. A. Argumosa). HUELVA: Tarsis, 10", V-1909 (Exp. Mus.). JAÉN: Jaén, $10^{7}$ (Balguerías); 1 ㅇ n (últ. est.), VI-1984 (F. Alonso) (DBUC). MADRID: Alcalá de Henares, 1 오 (Escalera); $20^{7} \sigma^{\prime \prime}$ (últ. est.), 26-X-1970 (C. Diez y Mamolar) (DBUC). Arganda, en La Poveda, 10 , 4-V-1967 (J. Álvarez). Brunete, 2 우 우; en Cienvallejos, $20^{\top} \sigma^{\pi}$ y 2 우, VI-1927 (C. Bolívar). Coslada, $10^{7}$ y 1 ㅇ , 6-VI-1980 (Calvo). El Escorial, $10^{\pi} \mathrm{n}$ (últ. est.), 20VI-1982 (R. Caldar) (DBUC). Madrid, $10^{7}$ n (últ. est.), 12-V1943 (J. Abajo); 1 ㅇ n (últ. est.), 1-VI-1971 (C. Diez) (DBUC); $10^{7} \mathrm{n}$ (últ. est.), 1-IV-1973 (J. L. Miranda) (DBUC); $10^{7} \mathrm{n}$ (últ. est.), 1-V-1974 (I. Allo) (DBUC); en la Moncloa, 10", VI-1942 (M. Pujol); en el Pardo, $10^{\prime} \mathrm{n}$ (últ. est.), 5-XI-1944 (Peris Torres) (DBUC); $3 \sigma^{7} \sigma^{x}$ y $10^{7} \mathrm{n}$ (últ. est.), 31-V-1969 (E. Ortiz). Rivas de Jarama, $2 \sigma^{x} \sigma^{x}$ y 1 ㅇ, 21-V-1916 (Dusmet) (Platyblemmus lusitanicus Serv.); en Montarco, $10^{\pi}$ (Bolívar); $2 \sigma^{7} \sigma^{2}$ y 1 \% , VI-1908 (Bolívar); $2 \sigma^{7} \sigma^{7}$ (Lauffer); $2 \sigma^{7} \sigma^{7}$ y 2 우 우, 8-VI-1923; $10^{x}$ (C. Bolívar); $20^{x} 0^{x}$ y 1 ㅇ (Dr. Martin); 1 오 n (1s est.), 26-III-1933 (E. Morales); 1 오 n (últ. est.), V1934 (E. Morales). Nuevo Baztán, 1 ㅇ, 10-VI-1928; $10^{\prime}$, 24VI-1973 (C. Sequeira y Marena) (DBUC). Paracuellos de Jarama, $10^{\circ}$ (J. Dusmet); 1 9 , 12-V-1984 (M. Alcántara) (DBUC). Pelayos de la Presa, 2 ơ 우, 2-VI-1927 (Mazarredo). Villaviciosa de Odón, $10^{7}$. MÁLAGA: Málaga, $40^{7} \sigma^{7}$ y 1 O (E. Gros); 10" , 16-IV-1905 (Fco. Navarro) (Sciobia lusitanica Serv. Bol. det.); $20^{7} 0^{7}$ y 1 ㅇ 9-V-1948 (Cobos Sánchez). SALAMANCA: Cepeda, 2 우 ơ (Sanz). SEVILLA: Osuna, $10^{7} \mathrm{n}$ (últ. est.), IV-1909 (Exp. Mus.). Sevilla, 10", 15-IV-1940 (W. Marten). Venta de los Ángeles, Cazalla de la Sierra, 1 오 $\mathrm{n}$ (1-os est.), 21-III-1978 (P. Gamarra) (DBUC). TOLEDO: Buenavista, 10", 30-IV-1933 (J. Royo). Illescas, 10", 16-V1965 (M. Ortego). Navalcán, $10^{7}$ y 1 ㅇ , 13-V-1973 (J. Lafora) (DBUC). Polán, 10", 15-IV-1978 (C. R. Vigal) (DBUC). Talavera de la Reina, $10^{7}$ (Capelle). VALENCIA: Valencia?, 1 ㅇ n (Boscá).

Encontrada adulta desde abril a julio y, según Pardo et al. (1993), también en septiembre y octubre; las ninfas en los primeros estadios en marzo y en los últimos de febrero a julio y en octubre y noviembre.

Distribución. Está citada de las provincias de Málaga, Granada (Rambur, 1839, Pascual, 1978a), Badajoz (Gogorza, 1881), Cuenca, Madrid, Valencia (Bolívar, 1878; Cazurro, 1888), Huelva, Jaén Salamanca, Sevilla, (Bolívar,1927), Albacete (Pulido, 1990), Ciudad Real y Toledo (Pardo et al., 1993); siendo nueva para las de Avila, Guadalajara, Cáceres y Córdoba. Por tanto, su distribución abarca más de la mitad meridional de la 
Península, incluyendo el norte y sur de Portugal (Grosso-Silva, 2000); también se encuentra en Marruecos.

Posiblemente el nombre de Platyblemmus ramburi Audinet-Serville, 1839 se adjudicó a tres pequeños machos de esta especie, como los de Altomira, Montarco y Talavera de la Reina. En estos ejemplares los tubérculos sexuales secundarios de la cabeza son sustancialmente más pequeños, en relación con la allometría, que en los machos de mayor talla (fig. $8 \mathrm{G}$ y $8 \mathrm{H}$ ).

Sciobia (Sciobia) boscai Bolívar, 1925, stat. n. (Fig. 8C-E)

= Scibia (s. str.) lusitanica f. boscai Bolívar, 1925. Eos, 1: 440

= Sciobia lusitanica boscai Otte, 1994. Crickets (Grylloidea). Orth. Sp. File, 1: 18

Material Estudiado: AlBACETE: Molinicos de la Sierra, $10^{\top}$ (Escalera). CIUDAD REAL: Almadén, 1 ㅇ n (últ est.), 13-V-1975 (Vieitez). Almadenejos, $10^{7}$ (holotipo) y 1 우 (Boscá). Ciudad Real, 10", V-1980 (G. Velasco), 1 ㅇ , V-1980 (Caballero). Fuenllana, $10^{-1}$ n (últ. est.), III-1973 (M. García) (DBUC). JAÉN: Cazorla, $10^{7}$ y 1 우 (Escalera).

Los ejemplares de "Cazorla (Escalera)" están citados por Bolívar (1927) como pertenecientes a $S$. lusitanica y además el macho lleva una etiqueta con letra de Bolívar: "v. Ramburi Serv. f. inermis “.

Encontrada adulta en mayo y ninfas en el último estadio en marzo y mayo.

DisTRIBUCIÓN. Sólo se conocía de Almadenejos, Ciudad Real (Bolívar, 1927), siendo nueva para las provincias de Albacete y Jaén.

El holotipo macho lleva dos etiquetas manuscritas de Bolívar: "Almadenejos 11 (Boscá)" y "Ejemplar extraordinario por la frente" y se añade "MNCN Cat. Tipos No 1911". Este autor (1925) sólo menciona un único ejemplar, cuyo sexo $\left(\sigma^{7}\right)$ se deduce de los caracteres y de las figuras que acompañan su descripción, sin referirse en ningún momento a la hembra de idénticos datos, que se conserva todavía en el MNCN; esta hembra, por lo tanto, no puede considerarse como paratipo. Este taxon ha venido considerándose como forma o variedad de $S$. (S.) lusitanica por Chopard (1943, 1967) y Harz (1969) hasta que Otte (1994) lo menciona como subespecie. Nosotros la elevamos a nivel de especie, estimándola distinta de $S$. (S.) lusitanica, con la que tiene un gran parecido en la forma del cuerpo, coloración, tamaño y, en especial, en la venación de las tegminas. Estas dos especies se diferencian perfectamente por los siguientes caracteres: a) la proyección membranosa del rostro en $S$. (S.) boscai es claramente más ancha y más corta (fig. 8D y 8E) que en $S$. (S.) lusitanica (fig. 8G y $8 \mathrm{H})$.

b) el escudo facial en $S$. (S.) boscai se estrecha claramente hacia abajo y no lleva en la parte inferior ningún tubérculo o diente grueso (en ejemplares grandes pueden desarrollarse unos salientes aplanados al nivel de los ojos) (fig. 8C-E); en $S$. (S.) lusitanica sin embargo, el escudo facial no se estrecha hacia abajo, incluso se ensancha y lleva en la parte inferior salientes dirigidos hacia adelante en forma de conos o por lo menos unos tubérculos redondeados (nunca se desarrollan unos salientes al nivel de los ojos) (fig. 8F-8H).

\section{Sciobia (Thliptoblemmus) caliendrum caliendrum} (Fischer, 1853)

Material Estudiado: CÁDIZ: Algeciras, $80^{\circ} 0^{\pi}$ y 2 우 우 (Mz. Escalera), 10 $\mathrm{n}$ (Arias). Almoraima, 10'. Chiclana /de la Frontera/, $20^{7} \sigma^{7}$ y $10^{7} \mathrm{n}$ (L. Cepero). Tarifa, $10^{7}$ y 1 \% , 6-VI1977 (C. A. López).

Encontrada adulta sólo en junio.

DisTRIBUCIÓN. Por ahora sólo se ha capturado en la provincia de Cádiz. Aunque indicada para Portugal por Kirby (1906) y recogida por autores posteriores (Bolívar, 1912; Herrera, 1982; Chopard, 1967), Fernandes (1960) considera que esta cita bibliográfica sea probablemente errónea.

La otra subespecie $S$. (Th.) caliendrum ambigua, Bolívar, 1925, stat. n. - hasta ahora especie independiente - se encuentra en Marruecos y se diferencia de la subespecie nominada por la presencia en los machos grandes de un par de salientes o tubérculos en la parte inferior del escudo facial. El holotipo macho, ha sido estudiado y está depositado, junto con los 9 paratipos en el MNCN (París, 1994).

Sciobia (Thliptoblemmus) natalia Gorochov, 1985.

Material Estudiado: CÁDIZ: Algeciras, $10^{x}$ y 1 ㅇ (Mz. Escalera).

Distribución. Citada ya de Algeciras, Cádiz como S. (Platyblemmus) barbara Sauss., 1877, por Bolívar $(1925,1927)$ y Harz (1969). Por tanto, es la primera vez que se cita para la España peninsular como $S$. (Th.) natalia. Fuera de España sólo se encuentra en Marruecos, de donde fue descrita.

Las diferencias entre $S$. natalia y $S$. barbara ya están enumeradas en Gorochov (1985b: fig. 1-5). 
En Marruecos los machos de talla grande pertenecientes a $S$. (Th.) natalia tienen un par de protuberancias o tubérculos en la parte inferior del escudo facial -al igual que $S$. (Th.) caliendrum ambigua -, mientras que los machos de talla grande de $S$. ( Th.) barbara no los tienen. No obstante, para resolver el estatus subespecífico de los ejemplares ibéricos no disponemos de suficiente material (el escudo facial del único macho de talla menor de "Algeciras" no tiene salientes o tubérculos en la parte inferior).

\section{Acanthogryllus acus Gorochov, 1988}

Material EstUdiado: CANARIAS: GOMERA: Hermigua, 107, 28-VI-1909; 1 , 8-VII-1909. San Sebastián, 2 우 익 IV-1935 (C. Bolívar - F. Bonet). GRAN CANARIA: Azuaje, 1 ㅇ , 2-VI-1934. Canaria, 1 ㅇ , 1890 (Ch. Alluaud). G. Canaria, $20^{\prime \prime} \sigma^{x}$ y 1 ㅇ (Quiroga). Las Palmas, 2 우 (Quiroga); 10, 25-V-1975 (DBUC). Mogán, 10, 6-IX-1943 (Naranjo). Puerto de la Luz, 10", IV-1935 (C. Bolívar - F. Bonet). TENERIFE: Bco. Tahodio, 500 m., 1 오, III-1921 (M. Escalera); 4 우, 24-IV-1927; 10", 26-IV-1927 (Cabrera ?). Charco Tahodio, 1 ㅇ , 20-IV-1957 (J. Mateu).

Encontrada adulta de marzo a julio y septiembre y, según Johnsen (1974), también en enero.

Lo más probable es que sea esta especie la indicada con anterioridad para las Islas Canarias bajo el nombre de Platygryllus brunneri (Saussure, 1877) por varios autores (entre ellos Chopard, 1967; Gangwere et al., 1972; Kevan y Hsiung, 1992 y Bland et al., 1996). Efectivamente, el material estudiado aquí, perteneciente al MNCN y, a su vez, utilizado por Gangwere et al. (1972) y Bland et al. (1996), estaba identificado como Gryllulus brunneri (Sauss); no obstante la sinonimia con A. acus no se puede asegurar, puesto que hoy día se conservan sólo dos sintipos de Massaua, que según Otte y Cade (1984) son hembras y en la mayoría de especies de este género las hembras son indistinguibles. La genitalia del macho aparece en Gorochov (1988: figs. 88 y 103).

DisTRIBUCIÓN. Ya citada de las tres islas canarias como P. brunneri (Kevan y Hsiung; Bland et al. 1996). Fuera del archipiélago se encuentra en África del Norte y Etiopía.

\section{Grylloderes Bolívar, 1894}

= Platygryllus Chopard, 1961. Eos, 37: 276, syn. dist.

Otte (1994) no está de acuerdo con esta sinonimia; él dice: "Gorochov synonymizes Platygryllus with Grylloderes without sufficient justification.
He did not compare and illustrate the type of Grylloderes brunneri Riggio, the type species of Grylloderes. The genitalia he does figure belong to species congeneric with Chopard's Platygryllus species". Probablemente, Otte no ha tenido en cuenta el trabajo de Goidanich (1959) en el que se designa el neotipo de G. brunneri (Riggio, 1888) y se da una muy detallada descripción acompañada de fotografías y figuras (entre ellas el dibujo de la genitalia del macho) que permiten identificar fácilmente también otros ejemplares de Sicilia pertenecientes a esta misma especie.

\section{Grylloderes orlovskajae adventicius subsp. n.}

Material Estudiado: Holotipo: 10", España: Islas Canarias, "En el buque "Akademik Fiodorov", que navegaba entre las Islas Canarias, II-1990" (ZIAS).

Paratipo, 1 ㅇ los mismos datos que el holotipo (ZIAS). Este buque hacía el itinerario desde el puerto de Odesa (Ucrania) hasta Cuba, haciendo escala en una de las islas Canarias.

DESCRIPCIÓN. Macho (holotipo). Muy parecido a G. orlovskajae orlovskajae Gor. de Mali y BurkinaFaso, incluyendo los detalles de la genitalia (Gorochov, 1988: figs. 86, 95, 101, 106, 112 y 113). El par de bandas claras, mediales y longitudinales en el occipucio notablemente más cortas y sin alcanzar el borde posterior del occipucio, y además el clípeo casi enteramente oscuro.

Hembra. Parecida al macho por su coloración; oviscapto muy largo, 1,8 veces más largo que el fémur posterior (el oviscapto de la subespecie nominada es 1,4-1,5 veces más largo que el fémur posterior).

Longitud en mm: Cuerpo: $\sigma^{\pi}, 20$; $\odot, 18$. Cuerpo incluidas alas: $\sigma^{\pi}, 28$; $ᄋ$, 27. Pronoto: $\sigma^{7}$,

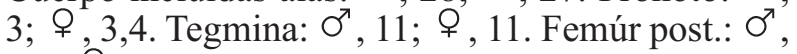
9,8; + , 10,9. Oviscapto: 19,6.

Encontrada adulta en febrero.

Etimología. Del adjetivo latino adventicius, extranjero, inesperado, debido a la captura de los ejemplares en un barco.

\section{Oecanthinae \\ Oecanthini}

\section{Oecanthus pellucens (Scopoli, 1763)}

(Fig. 8I)

Por tratarse de una especie muy abundante no incluimos el material estudiado.

Encontrada adulta de mayo a octubre. 
DISTRIBUCIÓN. Aunque citada por varios autores (Bolívar, 1927; Gangwere y Morales Agacino, 1970, etc.) de toda la Península, todavía no ha sido hallada en 15 provincias, la mayoría de las cuales están situadas en la mitad occidental, pero no se descarta su presencia; también está citada de las Baleares y Canarias (Gangwere y Llorente, 1992 y Bland et al., 1996, respectivamente). Fuera de España se encuentra en la mitad meridional de Europa desde Portugal, Francia, Bélgica hasta Polonia, el suroeste de Rusia y el Cáucaso, parte suroccidental de Asia, del sur del Ural, Transcaucasia y Asia Menor hasta Asia Central y África del Norte (las indicaciones para los territorios meridionales del Asia suroccidental y África del Norte necesitan comprobación).

Esta especie suele dividirse en subespecies, pero todavía no se han observado diferencias lo suficientemente constantes (fig. 8I).

\section{Oecanthus dulcisonans Gorochov, 1993}

$$
\text { (Fig. 8J) }
$$

Material Estudiado: CÁdiZ: San Roque, 10"1 19-X1996 y 1 ㅇ , 8-XI-1996 (J. Ramírez). HUELVA: Doñana, en el Pinar del Fraile, 10", 28-IX-1968 (V. Llorente) [Oecanthus pellucens (Scop.) V. Llorente det. 1980].

CANARIAS: TENERIFE: "Teneriffa. P. Hinhs", $10^{\text {" }}$ (Holotipo) (ZIAS).

Encontrada adulta en la España peninsular de septiembre a noviembre.

DISTRIBUCIÓN. Este grillo se cita por primera vez de la Península; de Tenerife ya se conocía (Gorochov, 1993), aunque fue omitido por Bland et al. (1996). Fuera de España ha sido citado de Italia, Grecia, Chipre y la Península Arábiga.

Es muy probable que esta especie haya sido confundida con la anterior, hecho que se confirma con el ejemplar de Doñana citado anteriormente como O. pellucens (Llorente, 1980). Parece una especie muy poco frecuente, ya que entre el material estudiado de la Península y Canarias sólo hemos encontrado estos ejemplares.

Las principales diferencias entre $O$. dulcisonans y $O$. pellucens consisten en pequeñas peculiaridades en la forma de los lóbulos distales del epifalo [en especial en la forma del corto lóbulo central (fig. 8I y 8J)] y en el mayor tamaño de los ejemplares, en particular de sus tegminas. Para más detalles sobre la genitalia del macho ver Gorochov (1993: Figs. 48 y 49).

\section{Mogoplistidae. \\ Mogoplistini}

\section{Mogoplistes brunneus Audinet-Serville, 1839}

Material Estudiado: BARCELONA: Barcelona, 1 우 (Masferrer). Manresa, 2 우 $ᄋ$ 14-VII-1889 (Capelle). MÁLAGA: Ojén, El Juanar, 1 ㅇ, 22-IX-1984 (M. A. Alonso Z.) (ex Col. A. Zarazaga). SEVILLA: Sevilla, 1 오 , IX(Calderón).

BALEARES: MALLORCA: Son Moragues, 1n (1-os. est.), 2-X-1993 (C. R. Altaba). Bosc Son Massip Escorca, 1n (1-os. est.), 13-XI-1993 (C. R. Altaba).

Encontrada adulta en julio y septiembre, así como en agosto en Mallorca (Navás, 1909a) y ninfas en los primeros estadios en octubre y noviembre.

DistriBuCión. Además está citada de la provincia de Tarragona (Navás, 1923), siendo nueva para la de Málaga. La cita de Bolívar (1927) de Guadalajara: "Brihuega (Navás)", basada, al parecer, sólo en dos ejemplares, ha resultado ser la nueva especie que se describe a continuación. A pesar de que disponemos de muy pocas capturas, ocupa parte del nordeste y sur de la España peninsular y Mallorca. Recientemente ha sido citada por primera vez para Portugal de Seia, Parque Natural da Serra da Estrela (Grosso-Silva, 2000), ampliando considerablemente su distribución en la Península Ibérica. Se conoce además de los departamentos mediterráneos de Francia, Córcega, Italia hasta la ex Yugoslavia y Grecia, y vive también en la mitad occidental de Africa del Norte.

La genitalia del macho aparece en Gorochov (1984b: fig. 8).

\section{Paramogoplistes dentatus sp. n. (Fig. 8K)}

Material Estudiado: Holotipo: ESPAÑA: GUADALAJARA: 1 ○ "Navás (Brihuega). Julio 1900" "MNCN Cat. Tipos $\mathrm{N}^{\mathrm{o}} 8830$ ".

Paratipo: $10^{\pi}$, los mismos datos que el holotipo.

DESCRIPCIÓN. Hembra (holotipo). De dimensiones y forma del cuerpo parecidas a las otras dos especies del género: $P$. novaki (Krauss, 1894) y $P$. kinzelbachi (Harz, 1971). Coloración general pardo oscura con el clípeo, piezas bucales (salvo los palpos bastante oscuros) y antenas un poco más rojizo claros, con la placa subgenital y base de los cercos pardo claras, así como con el oviscapto amarillento muy claro. La máxima anchura del clípeo casi 4 veces la anchura del escapo. La longitud del pronoto casi 1,2 veces menor que su anchura. Carece de alas y órganos timpanales.. Placa subgenital muy 
grande y larga, más o menos triangular, pero con el ápice casi truncado, cubriendo más de $1 / 3$ del oviscapto. Este último, corto, aproximadamente casi 2 veces más corto que el fémur posterior; su ápice casi en forma de cono y armado de numerosos dientes agudos (fig. 8K).

Macho. Parecido a la hembra, también carece de alas y órganos timpanales, pero de tamaño algo menor, con la placa subgenital más oscura y con el pronoto un poco más estrecho (su longitud alrededor de 1,1 veces menor que su anchura). Epiprocto, paraproctos y la base de la placa subgenital similares a los de otras especies del género; el ápice de la placa subgenital y la misma genitalia están dañados.

Longitud en mm: Cuerpo: $0^{\top}, 6$; $ᄋ$, 7. Pronoto:

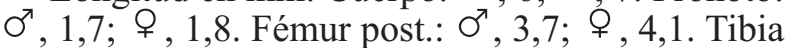
post.: $\sigma^{\pi}, 2,5$; $ᄋ$, 2,7; Oviscapto: 2 .

$P$. dentatus se diferencia claramente de las otras dos especies del género por la coloración y por el ápice dentado del oviscapto. Además, este nuevo taxon se distingue bien de M. brunneus - la especie externamente más parecida que habita en España - por la plena ausencia de tegminas y por el pronoto no alargado del macho (como en otras especies del género Paramogoplistes Gorochov, 1984b), así como por el oviscapto dentado.

Encontrada adulta en julio.

DisTRIBUCIÓn. Por el momento sólo conocida de la localidad típica: Brihuega (Guadalajara).

Etimología. Del adjetivo latino dentatus que hace referencia a este pequeño grillo que tiene el ápice del oviscapto cubierto de agudos dientes.

\section{Arachnocephalini}

\section{Arachnocephalus vestitus Costa, 1855}

MATERIAL Estudiado: BARCELONA: Barcelona, 1 우 (Masferrer); alrededores, Carmelo, 10 $0^{\pi}$, 1-IX-1913; en el Tibidabo 1n (últ. est.), 1-IX-1913. Las Planas, $10^{7} \mathrm{n}$ (últ. est.), 20-IX-1931; $10^{2}$ n (últ. est.), 15-IX-1940 (F. Español). Tiana, $10^{\pi}$, IX-1941 (J. Mateu); en el ex Monasterio Conrería, 1 오, 4X-1931. CÁDIZ: Alcalá de los Gazules, 1 ㅇ , 1-VIII-1995 (P. Coello); Sanlúcar de Barrameda, en la Algaida, 2 우 우, 10-IX1962 (V. Llorente). HUELVA: Doñana, en la Porquera del Fraile, 1 ㅇ , 29-IX-1968 (V. Llorente). MADRID: Madrid, en la Casa de Campo, $10^{x}$ y 1 $~, 23-$ VIII (I. Bolívar). MÁLAGA: Guadalpín, 1 ㅇ , 5-IX-1981 (M. Candela). Marbella, 1 ㅇ , 1-IX1981 (M. Candela). TARRAGONA: Fontscaldetes, 1 옹 IX1934 (F. Español ?). VALENCIA: Paterna, $10^{2} \mathrm{n}$ y 1 우 n (últ. est.), 11-VIII-1961 (Peris Torres) (DBUC). Portacoeli, 1 우, 7IX-1941 (Peris Torres) (coll. Peris) (DBUC).

Encontrada adulta de agosto a octubre y, según Navás (1921), también en julio; ninfas en los últimos estadios en agosto y septiembre.
DistRiBUCión. Citada de Mallorca (Navás, 1909a; Ebner, 1931; Herrera, 1993), así como de las provincias de Albacete (Gómez et al., 1991; Pardo et al., 1993) y de Almería (Barranco y Pascual, 1994), siendo nueva para las de Tarragona y Valencia. Por ahora sólo se ha encontrado en el centro, este y sur peninsular, así como en Baleares faltando en Canarias. Fuera de España se conoce de Europa meridional desde el centro y sur de Portugal (Grosso-Silva, 2000; Fernandes, 1959a, respectivamente) los departamentos mediterráneos de Francia y Córcega hasta Rumanía, Crimea, Cáucaso y Transcáucaso, Asia Menor y la mitad occidental de África del Norte.

La genitalia del macho aparece en Gorochov (1984b: figs. 18 y 19).

\section{Pseudomogoplistes squamiger (Fischer, 1853).}

Material Estudiado: ALICANTE: Mascarat, 1 i $\mathrm{n}$ (Boscá). CASTELLÓN: islas Columbretes, 1 ㅇ n (Boscá). Oropesa del Mar, 10", 2-VIII-1982 (A. Compte).

Encontrada adulta sólo en agosto.

DisTRIBUCIÓn. Citada ya de estas dos provincias (Bolívar, 1898; Pinedo y Llorente, 1988a), así como de la de Valencia (López Seoane, 1878; Bolívar, 1900; Harz, 1969). Además se encuentra en Italia y la ex Yugoslavia y posiblemente en el litoral mediterráneo de Francia (Kruseman, 1988). Lo más probable es que las indicaciones para Portugal (Fernandes, 1959a; Harz, 1969) pertenezcan a la especie siguiente, ya que uno de los machos es un paratipo de P. vicentae; lo mismo podría suceder con las de las Canarias (Bland et al., 1996); sin embargo las citas de Grecia, así como las de otras regiones más orientales correspondan posiblemente a P. bysantius Gor. y P. turcicus Gor.

La genitalia del macho de $P$. squamiger está dada por Gorochov (1995b: figs. 1-4).

\section{Pseudomogoplistes vicentae Gorochov, 1996}

Material Estudiado: ESPAÑA. GRAN CANARIA: Maspalomas, 1 ᄋ , 20-XI-1992 (Leg. D. Werner) (MNHU).

PORTUGAL: ALGARVE: Praia de Castelejo, 10" $13-\mathrm{X}-$ 1958. ESTREMADURA: Lisboa, Cabo Raso, 1 ㅇ, 25-IX1963 (ambos paratipos de P. vicentae) (MNCN Cat. Tipos $\mathrm{N}^{\circ}$ 12206).

ARGELIA: "Habibas Is., W. of Oran, 10", 12-IX-1953. J. A. Ducrot. B. M. 1954-140” (NHM).

Al disponer de tan poco material, hemos creído interesante incluir el de Portugal y Argelia.

Encontrada adulta en las Canarias en noviembre, y en Portugal y Argelia, en septiembre y octubre. 
DisTRIBUCIÓn. Se cita por primera vez de las Canarias. Ya citada de Portugal y Marruecos; se ha encontrado además en el litoral atlántico de Francia y en el sur de Inglaterra, siendo nueva para Argelia.

Como hemos indicado más arriba, uno de los ejemplares citados como Mogoplistes squamiger de Portugal (Fernandes, 1959a), así como los de Marruecos: "Tanger, Escalera" (Bolívar, 1914) sirvieron a Gorochov para describir $P$. vicentae. Posiblemente correspondan también a esta especie las citas de $P$. squamiger de Tenerife, La Palma y Hierro (Kevan y Hsiung, 1992; Bland et al., 1996).

La genitalia del macho aparece en Gorochov (1996: figs. 1, 2, 5 y 6).

\section{Cycloptiloides canariensis (Bolívar, 1914)}

Material Estudiado: CANARIAS: Canarias, 1 오 TENERIFE: Laguna, $10^{\top}$ (Cabrera) (Ectatoderus canariensis Bol. Tipo) (Ectatoderus canariensis Bol.) (lectotipo); $10^{7}, 1$ 우 y 1 으 n (Cabrera) (paralectotipos); 1 우 (Cabrera). Santa Cruz, 10", 31-XII-1909 (B. Ramos); 1 우, 7-XII-1910; $20^{7} 0^{7}, 2$ 우 우 y 1 Q $\mathrm{n}$ (últ. est.), 10-XII-1910; en casa Verdo, $10^{7} \mathrm{n}$ (últ. est.), 2-I-1917.

Encontrada adulta sólo en diciembre y ninfas en el último estadio en diciembre y enero.

DISTRIBUCIÓN. Este diminuto grillo es por ahora endémico de la isla de Tenerife (Gangwere et al., 1972; Bland et al., 1996).

La genitalia del macho aparece en Gorochov (1984b: figs. 20, 21).

La serie tipo, que se incluye en el Material estudiado, está compuesta de cuatro sintipos $\left(20^{7} \sigma^{7}\right.$ y 2 우 ㅇ ) y como dice París (1994): "Aunque uno de los ejemplares está etiquetado como tipo no por el autor, al no haberse mencionado en la publicación original, se han de considerar todos Sintipos, ...". Por esta razón, designamos como lectotipo el primer sintipo macho que aparece en este catálogo con sus respectivas etiquetas a las que añadimos: "MNCN Cat. Tipos N $\mathrm{N}^{\circ} 1332$ " y al que le falta la pata III dcha. y no la izda., esta última sin uñas; los restantes ejemplares quedan como paralectotipos (una de las hembras es una ninfa en el último estadio) "MNCN. Cat. Tipos No 1333-1335".

\section{Myrmecophilidae}

Myrmecophilinae

\section{Myrmecophilus (Myrmecophilus) myrmecophilus}

(Savi, 1819)

Según Baccetti (1966), la mayoría de las citas de M. (M.) acervorum (Panzer, 1799) del sur de
Europa corresponde a esta especie; sin embargo todos los ejemplares estudiados por nosotros pertenecen a la siguiente, $M$. (M.) ochraceus.

DISTRIBUCIÓN. Por ahora, no se ha encontrado en España peninsular ni en las Baleares; su distribución general, según Baccetti (1966) y Kruseman (1988) ocupa los departamentos franceses que bordean el Mediterráneo, Córcega, Italia y Grecia.

\section{Myrmecophilus (Myrmophilina) ochraceus Fischer, 1853}

Material Estudiado: AliCANTE: Alicante, 5 우 오, IV1881 (Bolívar?); 1 우 (E. Morales). ALMERÍA: Almería, alred., $10^{\prime \prime}$ y 1 운,13-XI-1949. Berja, 1 우, 12-IV-1949. El Ejido, 1 오, 3-IV-1949 (todos Mateu-Cobos). CÁDIZ: Algeciras, $60^{\pi} \sigma^{7}$ y $3 \mathrm{n}$ (Arias); 5 우 우 (C. Bolívar); 1 우, 10-III1976 (J. de Ferrer). MURCIA: Cartagena, 30 $0^{7}$ y 6n (Sánchez Gómez). Totana, $2 \sigma^{\top} \sigma^{\top}$ y 1 \& (Balaguer).

BALEARES: MALLORCA: Esporlas, 10" 19-X-1962 (A. Compte).

Encontrada adulta en marzo, abril y, según Baccetti (1966), también en mayo, así como en octubre y noviembre.

Cazurro (1888), Bolívar (1878, 1898 y 1900) y Burr (1910) la citaron de las provincias de Alicante, Cádiz, Murcia y Valencia como M. (M.) acervorum (Panzer, 1799). Años más tarde Bolívar (1927) consideró que todas estas citas, así como la de Mallorca, se referían a $M$. (M.) ochraceus. Datos que tuvieron en cuenta Baccetti (1966), Gangwere y Morales Agacino (1970) al citarla como única especie de este género encontrada por ahora en España peninsular y Baleares.

DistriBuCión. Además de las provincias anteriormente indicadas, está citada también de la de Almería (Aguirre et al., 1995); por tanto, por ahora se encuentra en el sur, sureste y este peninsular, así como en Baleares. Fuera de nuestro territorio está presente en Italia, Grecia, Asia Menor, Siria y en el norte de la mitad occidental de África del Norte.

Las poblaciones de localidades alejadas de su área se diferencian un poco entre sí morfológicamente y no se excluye que representen distintas subespecies; esta cuestión requiere un estudio especial.

Gryllotalpidae Gryllotalpini

\section{Gryllotalpa gryllotalpa (Linnaeus, 1758)}

Al ser una especie muy común y bien repartida por la Península e islas Baleares hemos prescindido de la relación del material estudiado. 
Encontrada adulta en enero y de marzo a octubre; ninfas en los primeros estadios en febrero, marzo, julio y agosto y en los últimos, de abril a agosto.

DistribUCión. Se encuentra en toda la Península y Baleares a excepción de Canarias. No se descarta que bajo algunas citas de G. gryllotalpa se oculte en algunos casos la especie siguiente (Llorente del Moral, 1980). Fuera de España, la frontera septentrional pasa por Gran Bretaña, el sur de Escandinavia, litoral báltico y Rusia central hasta Siberia occidental; la frontera meridional va desde Portugal, Francia y norte de Italia hasta Moldavia, sur de Ucrania, sur de Rusia europea y Kazajstán; es muy probable que se encuentre también en la parte noroccidental de África del Norte.

\section{Gryllotalpa septemdecimchromosomica Ortiz, 1958}

El material que sirvió a Ortiz (1951 y 1958) para el estudio y descripción de esta especie, procedía principalmente de Abarán (Murcia, España), de la albufera de Canet (Perpiñán, Francia), así como de Alcira (Valencia) y Castellón.

En la colección de insectos del MNCN hemos encontrado ejemplares, conservados en alcohol, de todas las localidades mencionadas, a excepción de la última.

Un frasco $\left(n^{\circ} 3\right)$ contiene tres ejemplares hembras y tres etiquetas, escritas a mano: la 1a "Alcira, 14-V-54. Muerto 19 julio"; la 2a "Alcira, 14-V-54. Muerto 21 julio, menor y con ácaros" y la $3^{\mathrm{a}}$, "Alcira. 14-V-54. Muerto el 22 jul. le falta la $2^{\mathrm{a}}$ pata derecha", en realidad es la izquierda. Esta fecha entra dentro de los años en que se realizó y publicó el estudio, aunque Ortiz no da ninguna fecha. Los tres ejemplares son hembras, como dice el autor, y están bastante bien conservadas, aunque una tiene la tegmina dcha. suelta y la cabeza junto con el pronoto desprendidos del cuerpo; la $2^{\mathrm{a}}$, que es menor, carece de la tegmina izda., tibia y tarso de la pata III dcha.; a la $3^{\mathrm{a}}$ le faltan la tegmina izda., pata II izda. y la III dcha. Todas carecen parcial o totalmente de antenas y algunos artejos de los tarsos.

Otro frasco $\left(n^{\circ} 4\right)$ contiene los restos de cuatro machos (mal conservados y en trozos sueltos, faltando una tegmina de un ejemplar, además de algunas patas); lleva una sola etiqueta, escrita a mano, en una cara: "Abarán. VI-1954" (probablemente recolectado por J. Templado, según Ortiz, 1951, 1958) y en la otra: “우 $ᄋ$ "; la fecha coincide con la dada por Ortiz (1958), aunque falta el día de captura que menciona el autor. El sexo no coincide con el de la etiqueta, aunque sí con parte del material de esta fecha estudiado $\left(60^{x} \sigma^{x}\right.$ y 2 $Q$ \% $)$ por Ortiz.

Los ejemplares anteriormente mencionados son los únicos que corresponden a la serie tipo. Entre ellos designamos como lectotipo una de las hembras de "Alcira. 14-V-1954" [recolectado por I. Docavo, según Ortiz (1958)] por estar mejor conservada y coincidir con los datos del autor, aunque como se ha dicho más arriba tiene la cabeza junto con el pronoto desprendidos del cuerpo. Colocamos este ejemplar en un frasco aparte con el $n^{\circ} 3 a$. Las otras dos hembras, de la misma procedencia que la anterior y los cuatro machos fragmentados de "Abarán. VI-1954", son paralectotipos; añadimos las etiquetas de identificación, las de tipos correspondientes y "MNCN Cat. Tipos $\mathrm{N}^{\circ} 8831$ "

Hay dos frascos más que merecen un comentario. El $\mathrm{n}^{\mathrm{o}} 2$ tiene dos etiquetas: la $1^{\mathrm{a}}$ lleva escrito a mano: “ᄋ Q Gryllotalpa gryllotalpa. Abarán. 17V-1950". Esta fecha coincide en día y mes, pero no en año, con el material estudiado por el autor (1958). La $2^{\mathrm{a}}$ etiqueta, en una cara: " $\sigma^{\top} \sigma^{\top}$. Gryllotalpa gryllotalpa. Abarán. 2-VI-1950" y en la otra: "el individuo adulto es $Q$ ". En el frasco hay 2 $\odot$ $\odot$ adultas, un adulto sin tegminas, 4 ninfas en los primeros estadios y 2 en los últimos. Estos ejemplares debieron formar parte del material utilizado por Ortiz, aunque no se mencione.

El frasco $\mathrm{n}^{\circ} 6$ con una sola etiqueta, a mano: "Albufera de Canet (Francia), VIII-1957. Ortiz", fecha que no coincide con la de Ortiz (1958), 21IX-1955.

Como dato importante queremos indicar que en ninguna etiqueta figura el nombre de G. septemdecimchromosomica; este nombre sólo aparece en Ortiz (1958) como "Gryllotalpa 17-chromosomi$c a$ ". La ausencia de un etiquetado correcto ha sido la causa de que este material permaneciera hasta ahora inadvertido.

Según Ortiz (1958), G. septemdecimchromosomica se diferencia de G. gryllotalpa por los siguientes caracteres: número de cromosomas, longitud de las alas posteriores; relaciones de longitud: tegminas/pronoto, alas/tegminas, así como por la relación de longitud de ciertas celdas pertenecientes o adyacentes, al área cubito-anal de las tegminas. A nuestro parecer, los dos primeros caracteres son los más determinantes, mientras que en los restantes el rango de variabilidad puede solaparse entre ambas especies.

Esta especie se ha encontrado adulta, según Ortiz (1958) y el material del MNCN, en enero, de abril a junio y en septiembre y octubre; ninfas en los primeros y últimos estadios en mayo y junio. 
DiSTRIBUCIÓN. Por ahora sólo se ha encontrado en el sureste y este peninsular. Fuera de España se conoce del sur de Francia e Italia (Baccetti y Capra, 1978).

\section{Gryllotalpa africana Palisot-Beauvois, 1805}

Material Estudiado: ALMERÍA: Almería, $30^{7} 0^{7}$, XI1950 (J. Mateu). CÁDIZ: Cádiz, $10^{x}$ y 1 ㅇ , V-1932 (Benítez). HUELVA: Coto Doñana, en El Martinazo, $10^{7}$ y $10^{7} \mathrm{n}$, 19-22II-1966 (S.V. Peris). MÁLAGA: Estepona, 10 $0^{\pi}, 15$-VIII-1981 (A. Rubio) (DBUC). SEVILLA: Gerena, $10^{\prime \prime}$ y 1 ㅇ, 5-XI1988. Sevilla, 1 ㅇ (A. Izquierdo); 1 ㅇ , V-1957 (A. Izquierdo); $50^{x} 0^{x}$ y 3 우 우, IV-1959 (A. Izquierdo). VALENCIA: Jaraco, 1 ㅇ, 14-VIII-1974 (A. Caro Sanabrias) (DBUC).

CANARIAS: FUERTEVENTURA: Río Cabra, $10^{7}$ y 4n (últ. est.), 19-XI-1934 (Cabrera?). Rosa Ucala, 1n (últ. est.), 17-III-1935 (Cabrera?). LA GOMERA: Cuevas Blancas, 1n (1s. est.), 18-30-XII-1921 (Cabrera?). San Sebastián, 1 우, IV1935 (C. Bolívar y F. Bonet). GRAN CANARIA: Azuaje Barranco, 3n (últ. y 1-os est.), 17-X-1930 (Cabrera?). /Gran/ Canaria, $10^{7}$ y 2 ㅇ $ᄋ$, 1890 (Ch. Alluaud).

Encontrada adulta en la Península en febrero, mayo, agosto y noviembre y una ninfa en el último estadio en febrero; en las Canarias se ha capturado adulta en abril, junio y noviembre, así como ninfas en los primeros estadios en octubre y diciembre y en los últimos en marzo, octubre, noviembre $\mathrm{y}$, según Johnsen (1974), también en enero.

Distribución. Citada ya de las provincias de Almería, Cádiz, Huelva y Sevilla (Llorente del Moral, 1980), siendo nueva para las de Málaga y Valencia. Del archipiélago canario ya estaba citada de estas tres islas, así como de la de Tenerife (Bland et al., 1996). También es muy probable su presencia en el sur de Portugal; se encuentra en África y posiblemente en la Península Arábiga y en la región de Madagascar.

\section{Gryllotalpa robusta Townsend, 1983}

El primero en citar esta especie de las Canarias fue Townsend (1983), pero sin indicar ninguna isla en concreto. Años más tarde Kevan y Hsiung (1992) consideraron que podría corresponder a $G$. robusta la cita dudosa de G. gryllotalpa de Tenerife (Brulle, 1839) y recogida posteriormente por varios autores.

Distribución. Nosotros, al igual que Kevan y Hsiung, así como Bland et al. (1996), incluimos con duda esta especie en la fauna canaria, ya que no hemos estudiado ningún ejemplar de este archipiélago. El área de distribución comprende África, al sur del Sahara.

\section{AGRADECIMIENTOS}

Queremos manifestar nuestro más sincero agradecimiento a las Dras. Isabel Izquierdo y Carolina Martín (MNCN), así como al Dr. V. Monserrat (DBUC), Dr. J. J. Presa (DZM), Dr. G. B. Popov y Sr. J. Marshal (NHM), Dr. K. K. Günther y Sr. I. Dorandt (MNHU), Dr. B. Hauser (GNHM), Dr. A. Kaltenbach (NHMW), Dr. M. Donskoff (MNHN), Dr. Ph. Thorens del Bureao d'Etude des Invertébrés, Neuchatel, por su amabilidad en poner a nuestra disposición las colecciones que custodian o el material solicitado. Mención especial merecen el Director de la Escuela Técnica Superior de Ingenieros de Montes de Madrid, Dr. A. Notario, los Dres. P. Barranco, de la Universidad de Almería, R. Gómez y J. E. Pardo, de la Universidad de Castilla-La Mancha, y el Dr. J. M. OlmoVidal, de la Universidad de Barcelona por la donación de algunos grillos que resultaron muy interesantes e imprescindibles para nuestro estudio. También queremos agradecer al Dr. M. A. Alonso Zarazaga por su asesoramiento sobre la nomenclatura zoológica y a los Dres. I. Izquierdo y J. J. Presa por sus comentarios y lectura crítica del manuscrito, así como a D. Jorge Prado y Dña. Mercedes Hitado por la transcripción del mismo y a D. Emilio Soteras por la ayuda prestada en la realización de las figuras.

\section{Referencias}

Aellen, V. \& Thorens, P., 1997. Modicogryllus frontalis (Fieber, 1844), un nouveau Gryllon pour la faune française découvert dans le Var (Orthoptera, Gryllidae). L'Entomologiste, 53(6): 241-246.

Aguirre, A. \& Pascual, F., 1986. Ortópteros del sureste almeriense. I; Inventario de especies. Actas VIII Jornadas de la Asociación española de Entomología, Sevilla: 298-311.

Aguirre-Segura, A., Barranco, P. \& Pascual, F.,1995. La colección de ortópteros de la Estación Experimental de Zonas Áridas (CSIC) de Almería. (Insecta, Orthoptera). Boletín de la Asociación española de Entomología, 19(1-2): 133-155.

Aires, B. \& Menano, H. P.,1916. Catálogo sinóptico dos Ortópteros de Portugal. Coimbra. 58 pp.

AndreEva, E.T., 1982. A contribution to the taxonomy of Gryllidae (Orthoptera) of Bulgaria. Acta Zoologica Bulgarica, 19: 78-83.

Arcos, M. \& Pascual, F., 1986. Distribución ecológica de los ortópteros de la Sierra de Alfacar-Víznar (Granada). Actas VIII Jornadas de la Asociación española de Entomología, Sevilla: 312-325.

Arcos, M. \& Pascual, F., 1988. Ortopterofauna de la Sierra de Alfacar-Víznar (Granada, España). Actas III Congreso Ibérico de Entomología, Granada: 441463.

BACCETTI, B., 1959. Notulae orthopterologicae, 14 (Descrizione di un nuovo genere cavernicole di Ortotteri scoperto in Sardegna). Annali della Facoltà di Agraria dell'Università di Sassari, 7: 313. 
BACCETTI, B., 1966. Notulae orthopterologicae. XXII. Il genere Myrmecophilus Berth. in Italia. Redia, 50: 133.

BACCETTI, B. \& CAPRA, F., 1978. Notulae orthopterologicae. XXXIV. Le specie italiane del genere Gryllotalpa L. Redia, 61: 401-464.

BARranco, P., 1998. Catálogo de los ensífera de Aragón (Insecta: Orthoptera). Catalogus de la entomofauna aragonesa, 18: 3-7.

Barranco, P. \& Pascual, F., 1991. Contribución al conocimiento de los Orthoptera de la provincia de Almería (España). Zoologica baetica, 2: 171-181.

Barranco, P. \& Pascual, F., 1992. Distribución de los ortópteros (Insecta, Orthoptera) en los campos de cultivo del valle del río Andarax (Almería, España). Boletín de Sanidad Vegetal, Plagas, 18: 613-620.

BARranco, P. \& PAScual, F., 1994. Nuevos datos para el conocimiento de la ortoptero-fauna de la provincia de Almería. Boletín de la Asociación española de Entomología, 18(1-2): 207-209.

BARranco, P. \& PAScual, F., 1995. Estadios postembrionarios y estructura de edades en Petaloptila bolivari (Orthoptera: Gryllidae). XIV Jornadas de la Asociación española de Entomología, Cuenca, 3-7 julio 1995: 125.

Bland, R. G., Gangwere, S. K. \& Morales Martín, M., 1996. An annotated list of the Orthoptera (sens. lat.) of the Canary Islands. Journal of Orthoptera Research, 5: 159-173.

Blasco-Zumeta, J., 1998. Los Invertebrados. En: Ecología de Los Monegros. C. Pedrocchi (Coord.), Instituto de Estudios Altoaragoneses. Huesca. 430 pp.

Bolívar, I., 1878. Sinópsis de los Ortópteros de España y Portugal, -4 $4^{\text {a }}$ parte. Anales de la Sociedad Española de Historia Natural, 7: 63-129.

Bolívar, I., 1876-1878. Sinópsis de los Ortópteros de España y Portugal. Impr. Fortanet. Madrid. 333 pp. I-VII Lám.

Bolívar, I., 1885. Diagnoses d'Ortopteres nouveaux. Le Naturaliste, 7: 116-117.

Bolívar, I., 1893. Ortópteros de las islas Canarias. Actas de la Sociedad Española de Historia Natural, (2), 2: 45-53.

Bolívar, I., 1894. Ad cognitionen orthopterorum Europae et confinium II. Sobre el género Gryllodes Sauss. Actas de la Sociedad Española de Historia Natural, 23: 44-58.

Bolívar, I., 1897. Insectos recogidos en Cartagena por D. José Sánchez Gómez. Actas de la Sociedad Española de Historia Natural, 6: 166-174.

Bolívar, I., 1898. Catálogo sinóptico de los Ortópteros de la Fauna Ibérica. Annaes de Sciencias Naturaes, 5(1-4): 1-48; 121-152.
Bolívar, I., 1900. Catálogo sinóptico de los Ortópteros de la Fauna Ibérica. Universidade de Coimbra, 1897-1900. 168 pp.

Bolívar, I., 1912. Estudios entomológicos. II. El género Sciobia Burm. (Platyblemmus Serv.) Trabajos del Museo de Ciencias Naturales, Madrid, 6: 33-46.

Bolívar, I., 1914. Dermápteros y Ortópteros de Marruecos. Memorias de la Sociedad Española de Historia Natural, 8: 157-239.

Bolívar, I., 1925. Orthoptera Palearctica Critica. I. Contribution a la connaissance des Sciobiae (Grill.) Eos, 1: 375-400.

Bolívar, I., 1927. Datos complementarios sobre los Ortópteros de la Península Ibérica.II. Gríllidos. Boletín de la Real Sociedad Española de Historia Natural, 27(1): 96-110.

Brunner-Wattenwyl, C., 1882. Prodromus der Europäischen Orthopteren. Leipzig. I-XXXII + 1466 pp., Taf. I-XI.

Burgos Ramírez, L. \& Herrera Mesa, L., 1986. Los ortópteros de la Rioja. Ciencias de la Tierra. Zoología, 8. Instituto de Estudios Riojanos. Logroño. $146 \mathrm{pp}$.

BurR, M., 1910. A synopsis of the Orthoptera of Western Europe Oliv. Janson. London. 160 pp.

Cazurro, M., 1888. Enumeración de los Ortópteros de España y Portugal. Anales de la Sociedad Española de Historia Natural, 17(3): 435-513.

Cerro, A. Del, 1978. Los Ortopteroidea de la Sierra de Cazorla: Sistemática, distribución y ecología. Tesis Doctoral. Universidad Politécnica de Madrid. Escuela Técnica Superior de Ingenieros de Montes. Madrid. 296 pp.

Cerro, A. Del, 1980. Catálogo sistemático de los Orthopteroidea (sensu lato) del Coto Nacional de las sierras de Cazorla y Segura. En: M.G. de Viedma. (Ed.): Fauna de Cazorla. Invertebrados. Monografías ICONA, 23: 109-114.

ChOpard, L., 1943. Faune de l'Empire Française, I. Orthoptéroïdes de l'Afrique du Nord. Larose. París. $450 \mathrm{pp}$.

Chopard, L., 1951. Orthoptérö̈des. En: Faune de France, vol. 56. Fédération Française des Sociétés de Sciences Naturelles. Paris. 359 pp.

CHOPARD, L., 1954. Insectes Orthoptéroïdes récoltés aux iles Canaries par M. H. Lindberg. Commentationes Biologicae, 14(7): 1-15.

ChOpard, L., 1961. Les divisions du genre Gryllus basées sur l'étude de l'appareil copulateur (Orth. Gryllidae), Eos, 37: 267-287.

Chopard, L., 1967. Gryllides. Fam. Gryllidae: Subfam. Gryllinae (Trib. Gymnogryllini, Gryllini, Gryllomorphini, Nemobiini). En: Orthopterorum Catalogus, vol. 10. Beier, M. (ed.). Uitgeverij Dr. W. Junk. Gravenhage: 1-211. 
Chopard, L., 1968. Gryllides. Fam Gryllidae: Subfam. Mogoplistinae, Myrmecophilinae, Scleropterinae, Cachoplistinae, Pteroplistinae, Pentacentrinae, Phalangopsinae, Trigonidiinae, Encopterinae; Fam. Oecanthidae, Gryllotalpidae. En: Orthopterorum Catalogus, vol. 12. Beier, M. (ed.). Uitgeverij Dr. W. Junk. Gravenhage: 213-500.

EBNER, R., 1931. Einige Orthoptera von Mallorca. Boletín de la Sociedad Española de Historia Natural, 31: 497-503.

EBNER, R., 1941. Orthopterologischen Studien in SüdPortugal. Brotéria, 10(37), 1: 5-28.

Ehrmann, R., 1988. Neue Orthopteren Funde für die Balearen-Inseln Mallorca. Articulata, 3(4): 147 150.

EiroA, M. E. \& NovoA, F., 1987. La entomofauna de las dunas de la playa de Barra (Cangas-Pontevedra): II. Orthoptera. Boletín de la Asociación española de Entomología, 11: 135-141.

FERnANDES, J. A., 1959a. Notas ortopterológicas I. Gryllidae novos ou pouco conhecidos da entomofauna portuguesa. Revista Portuguesa de Zoologia e Biologia Geral, 2: 1-7.

FERnANDES, J. A., 1959b Notes orthoptérologiques. II. Une nouvelle espèce de Gryllomorpha Fieb. et description d'un allotype d'un Ephippigeridae, Callicrania serrata (Bol.). Revista Portuguesa de Zoologia e Biologia Geral, 2: 97-104.

FERNANDES, J. A., 1960. Ortópteros novos ou pouco conhecidos da entomofauna lusitânica. Revista Portuguesa de Zoologia e Biologia Geral, 2: $205-$ 217.

Fernandes, J. A., 1967. Les Gryllides de la Faune Iberique: I - Les genres Gryllodinus Bol. et Eugryllodes Chop. Révision critique. Arquivos do Museu Bocage (2 ser.), 1(17): 351-390.

Fuente, J. M. DE LA, 1894a. Sesión 4 de octubre de 1893. Dos nuevos ortópteros de España. Actas de la Sociedad Española de Historia Natural, 22: 137138.

FuENTE, J. M. DE LA, 1894b. Insectos recogidos en Archena (coleópteros, ortópteros, hemípteros y lepidópteros). Actas de la Sociedad Española de Historia Natural, 23: 119-124.

Gangwere, S. K. \& Morales Agacino, E., 1970. The biogeography of Iberian Orthopteroids. Miscelánea Zoológica, 2(5): 1-67.

Gangwere , S. K., Morales Martín, M. \& Morales AgAcino, E., 1972. The distribution of the Orthopteroidea in Tenerife, Canary Islands, Spain. Contributions of the American Entomological Institute, 8(1): 1-40.

Gangwere, S. K. \& Llorente, V., 1992. Distribution and habits of the Orthoptera (sens. lat.) of the Balearic Islands (Spain). Eos, 68(1): 51-87.
Gogorza, V., 1881. Revisión del género Platyblemmus. Anales de la Sociedad Española de Historia Natural, 10: 509-521.

GoIDANICH, A., 1959. Sulla corologia e la tassonomia di alcuni interessanti Gryllidae in Italia (Orthoptera Ensifera). Frustula Entomologica, 2(3): 1-36.

Gómez, R., Presa, J. J. \& García, M. D., 1991. Orthopteroidea del sur de la provincia de Albacete (España). Ensifera. Mantodea. Phasmoptera. Blattoptera. Dermaptera. Anales de Biología, 17(Biología Animal, 6): 7-21.

Gorochov, A. V., 1979. To the knowledge of crickets (Orthoptera, Gryllidae) of Middle Asia. Entomologicheskoe Obozrenie, 58(1): 92-98. (En ruso).

Gorochov, A. V., 1981. Review of crickets of subfamily Nemobiinae (Orthoptera) of fauna of USSR. Vestnik Zoologii, 2: 21-26. (En ruso).

Gorochov, A. V., 1982. [A new subfamily of crickets (Orthoptera, Gryllidae) from Indo-Malayan region.] Zhivotnyj mir Vietnama. Moscow: 147-151. (En ruso).

Gorochov, A. V., 1984a. [Faunistic and systematic notes on Gryllidae (Orthoptera) of the Crimea.] Vestnik zoologii, 1: 12-20. (En ruso).

Gorochov, A. V., 1984b. [A contribution to the taxonomy of modern Grylloidea (Orthoptera) with a description of new taxa.] Zoologicheskij Zhurnal, 63(11): 1641-1651. (En ruso).

Gorochov, A. V., 1985a. [On the fauna of Grylloidea (Orthoptera) of China.] Entomologicheskoe Obozrenie, 64(1): 89-109. (En ruso).

Gorochov, A. V., 1985b. [Three new species of the genus Sciobia (Orthoptera, Gryllidae) from North Africa.] Vestnik Zoologii, 3: 3-6. (En ruso).

Gorochov, A. V., 1987. [On the fauna of crickets of subfamilies Euscyrtinae, Trigonidiinae and Oecanthinae (Orthoptera, Gryllidae) of Eastern Indochina.] Entomofauna Vietnama. Moscow: 5-17. (En ruso).

Gorochov, A. V., 1988. [New and little known crickets of tribe Gryllini (Orthoptera, Gryllidae) from Africa and South-West Asia.] Entomologicheskoe Obozrenie, 67(1): 88-103. (En ruso).

Gorochov, A. V., 1990. [New and little known taxa of Orthopterans of the suborder Ensifera (Orthoptera) from tropics and subtropics.] Entomologicheskoe Obozrenie, 69(4): 820-834. (En ruso).

Gorochov, A. V., 1993. Grylloidea (Orthoptera) of Saudi Arabia and adjacent countries. Fauna of Saudi Arabia, 13: 79-97.

Gorochov, A. V., 1995a. [System and evolution of the suborder Ensifera (Orthoptera), 2.] Trudy Zoologicheskogo Instituta. Rossiiskaya Akademiya Nauk, 260: 1-213. (En ruso). 
Gorochov, A. V., 1995b. Two new species of the genus Pseudomogoplistes Gorochov (Orthoptera: Mogoplistidae). Zoosystematica Rossica, [1994], 3(2): 249-250.

Gorochov, A. V., 1996. A new species of Pseudomogoplistes from Morocco and Portugal (Orthoptera: Mogoplistidae). Zoosystematica Rossica, [1995], 4(2): 292.

Grosso-Silva, J. M., 2000. Contribuiçao para o conhecimiento dos Grylloidea (Orthoptera, Ensifera) de Portugal. Boletín de la Sociedad Entomológica Aragonesa, 27: 87-89.

HARZ, K., 1969. Die Orthopteren Europas, I. W. Junk, Séries Entomologica, $\mathrm{n}^{\circ}$ 5. The Hague. XX +749 pp.

HARZ, K., 1976. Orthopterologische Beiträge XV. A. Dreiu neue Grillenarten in Europa. B. Das $\sigma^{\pi}$ von Gryllomorpha albanica Ebner. C. Faunistiches. Nachrichtenblatt der Bayerischen Entomologen, 25: 54-58.

Heller, K-G., Korsunovskaya, O., Ragge, D. R., Vedenina, V., Willemse, F., Zhantiev, R. D. \& FrantSEVICH, L., 1998. Check-List of European Orthoptera. Articula, 7: 1-61.

Hernández, A., Clemente, M. E., García, M. D. \& PRESA, J. J., 1998. Inventario y dinámica poblacional de los ortoperoides (Orthoptera, Blattoptera, Mantodea y Phasmoptera) del Parque natural del "Carrascal de la Font Roja" (Alicante, E. España). Zoologica baetica, 9: 185-204.

Herrera, L., 1980. Ortópteros ensíferos de la provincia de Navarra. Boletín de la Sociedad Española de Historia Natural (Sección Biológica), [1979], 77: 393-408.

Herrera, L., 1982. Catalogue of the Orthoptera of Spain. W. Junk, Series Entomologica, $\mathrm{n}^{\mathrm{o}} 22$. The Hague. VIII + 162 pp.

Herrera, L. \& Schnidrig, S., 1983. Andropigios de los Ortópteros de Navarra (Orthoptera). Publicaciones de Biología de la Universidad de Navarra, Serie Zoológica, 10: 1-52.

Herrera Mesa, L., 1993. Beitrag zur Kenntnis der Orthopteren der Balearischen Inseln (Spanien). Articulata, 8(2): 129-144.

HochKIRCH, A., 1997. Notizen zur Heuschreckenfauna von La Gomera (Kanarischen Inseln, Spanien). Articulata, 12(2): 187-200.

JoHnSEN, P., 1974. Contributions to the knowledge of the Dermaptera, Orthoptera and Dictyoptera of the Canary Islands. Natura Jutlandica, 17: 27-57.

Kevan, D. K. McE. \& Hsiung, C.-C., 1992. A summary of the orthopteroid insects known from Lanzarote, Canary Islands, with description of a new cricket species of the genus Hymenoptila Chopard, 1943 (Grylloptera; Grylloidea; Gryllidae). Vieraea, 21: 77-100.
Kevan, D. K. McE. \& Kevan, P. G., 1995. A preliminary record of orthopteroid insects of the Maldive Islands. Journal of Orthoptera Research, 4: 223-236.

KIRBY, W. F., 1906. A synonymic Catalogue of the Orthoptera. Vol. 2. Orthoptera Saltatoria. Part I. British Museum. London. 562 pp.

Krauss, H. A., 1892. Systematisches Verzeichniss der Kanarischen Dermapteren und Orthopteren mit Diagnosen der neuen Gattungen und Arten. Zoologischer Anzeiger, 15: 163-171.

Kruseman, G., 1988. Materiaux pour faunistique des Orthopteres de France, Fasc. III: Les Ensiferes et des Caeliféres: les Tridactyloides et les Tetrigoides des Musees de Paris et d'Amsterdam. Verslagen en Technische Gegevens - Instituut voor Taxonomische Zoölogie, 51: 1-164.

LA GRECA, M., 1994. Ortotteri italiani nuovi o poco noti (Orthoptera). Memorie della Società entomologica italiana, [1993], 72: 211-220.

Lock, K., 1999. Contribution to the knowledge of the Portuguese grasshoppers. Boletín de la Asociación española de Entomología, 23(3-4): 315-324.

López Seonne, V., 1878. Orthopteros de la península hispano-lusitana. Entomologische Zeitung, Stettin, 39: 365-376.

Llorente del Moral, V., 1980. Los Ortopteroides del Coto Doñana (Huelva). Eos, [1978], 54: 117-165.

Moragues, F., 1894. Insectos de Mallorca. Anales de la Sociedad Española de Historia Natural, 23: 73-87.

Morales Agacino, E., 1933. Nota sobre una colección de Ortópteros recogidos por D. Bartolomé Muñoz Rodríguez en Teruel y sus alrededores. Boletín de la Real Sociedad Española de Historia Natural, 33(1): 207-217.

Morales Agacino, E., 1941. Los Gryllotalpinae de España. Boletín de Patología Vegetal y Entomología Agrícola, 9: 212-233.

Morales Agacino, E., 1956. Apuntes sobre Gryllidae marroquies del Instituto Español de Entomología. Eos, 32: 146-184.

NAVÁs, L., 1899a. Una excursión al Montsant (provincia de Tarragona). Actas de la Sociedad Española de Historia Natural, 28: 45-48.

NAVÁs, L., 1899b. Notas entomológicas II. Ortópteros del Montseny (Barcelona). Actas de la Sociedad Española de Historia Natural, 28: 268-272.

NAVÁs, L., 1900. Notas entomológicas IV. Ortópteros del Moncayo (Zaragoza). Actas de la Sociedad Española de Historia Natural, 29: 140-144.

NAVÁs, L., 1904a. Notas zoológicas V. Excursión al Moncayo. Boletín de la Sociedad Aragonesa de Ciencias Naturales, 3(5-6): 1-31.

NAVÁs, L., 1904b. Notas zoológicas VI. Excursión de la Sociedad Aragonesa de Ciencias Naturales a la Sierra 
de Guara en julio de 1903. Boletín de la Sociedad Aragonesa de Ciencias Naturales, 3(7): 190-201.

NAVÁs, L., 1909a. Notas zoológicas XVI. Ortópteros de Mallorca. Boletín de la Sociedad Aragonesa de Ciencias Naturales, 8: 197-201.

NAVÁs, L., 1909b. Mis excursiones entomológicas durante el verano de 1909. (2 julio-3 agosto). Butlleti de la Institució Catalana d'Història Natural, 7: 3274.

NAVÁs, L., 1921. Mis excursiones científicas del verano de 1919. Memorias de la Real Academia de Ciencias y Artes de Barcelona, 17(6): 143-169.

NAVÁs, L., 1923. Excursiones entomológicas de l'istiu de 1922 (26 de juny-26 de juliol). Arxius de l'Institut de Ciències. Institut d'Estudis Catalans, Barcelona, 1: 34 .

NAVÁs, L., 1924. Excursió Entomológica al Cabrerés (Girona-Barcelona) del 8 al 18 de juliol de 1923. Trabajos del Museo de Ciencias Naturales de Barcelona, 4(10): 1-59.

NAVÁs, L., 1928. Comunicaciones entomológicas. 9. Mis excursiones científicas en 1927. Revista de la Academia de Ciencias de Zaragoza, 11: 79-137.

Olmo, J. M., 1990. Els Ortópteres del delta del Llobregat (Orthoptera). Sessió Conjunta d'Entomologia de la Institució Catalana d'Història Natural-Societat Catalana de Lepidopterologia, VI (1989): 3-18.

Olmo, J. M., 1993. Estudi preliminar dels ortópteres de Menorca. Sessió Conjunta d'Entomologia de la Institució Catalana d'Història Natural-Societat Catalana de Lepidopterologia, VII (1991): 3-11.

Olmo-Vidal, J. M. \& Hernando, C., 2000. A new cave cricket of the genus Petaloptila from the Pyrenean montains (N. Iberian peninsula) (Orthoptera: Gryllidae). Journal of Orthoptera Research, 9: 135138.

OrTIZ, E., 1951. Los cariotipos de Gryllotalpa gryllotalpa (L.) de la Península Ibérica. Boletín de la Real Sociedad Española de Historia Natural, 49: 153158.

OrTIZ, E., 1958. El valor taxonómico de las llamadas razas cromosómicas de Gryllotalpa gryllotalpa (L.). Publicaciones del Instituto de Biología Aplicada, 27(2): 181-194.

Oтте, D., 1994. Crickets (Grylloidea). Orthoptera Species File, 1. Orthopterists' Society and The Academy of Natural Sciences of Philadelphia: 1120.

Otte, D. \& Alexander, R. D., 1983. The Australian crickets (Orthoptera: Gryllidae). Academy of Natural Sciences of Philadelphia. Monographs., 22: 1-477.

Otте, D. \& CADE, W., 1984. Áfrican crickets (Gryllidae). 4. The genus Platygryllus from Eastern and Southern Africa (Gryllinae, Gryllini).
Proceedings of the Academy of Natural Sciences of Philadelphia, 136: 45-66.

PAntel, P. J., 1886. Contribution a l'Orthoptérologie de l'Espagne Central. 2-e partée. Catalogue raisonée des espéces recoltées á Uclés et dans les localités voisines. Anales de la Sociedad Española de Historia Natural, 15: 256-287.

PAntel, P. J., 1890. Notes orthoptérologiques. I. Révision monographique du genre Gryllomorpha Fieb. III. Les orthoptéres des environs d'Uclés. Anales de la Sociedad Española de Historia Natural, 19: 335-370; 405-422.

PAnTel, P. J., 1896. Notes orthoptérologiques V. Les orthoptéres du "Sitio" dans la Sierra de Cuenca. Anales de la Sociedad Española de Historia Natural, 25: 59118.

Pardo, J. E., Gómez, R. \& Del Cerro, A. 1993. Orthopteroidea de los sistemas montañosos de Castilla-La Mancha (España). II. Ensifera. Zoologica baetica, 4: 113-148.

PArís, M., 1994. Catálogo de tipos de Ortopteroides (Insecta) de Ignacio Bolívar, I: Blattaria, Mantodea, Phasmoptera y Orthoptera (Stenopelmatoidea, Rhaphidophoroidea, Tettigoniodea, Grylloidea, Tetrigoidea). Eos, [1993], 69: 143-264.

PAscual, F., 1978a. Estudio preliminar de los Ortópteros de Sierra Nevada, I: Introducción general e inventario de especies. Boletín de la Asociación Entomológica española, [1977], 1: 163-173.

Pascual, F., 1978b. Estudio preliminar de los Ortópteros de Sierra Nevada, II: Claves para la determinación de especies. Trabajos y Monografías del Departamento de Zoología (Nueva Serie), 1(1): 1-63.

Pinedo, M. C. \& Llorente, V., 1988a. Orthopteroidea de la provincia de Castellón, con especial referencia a la marisma de Oropesa. Graellsia, [1987], 43: 93109.

Pinedo, M. C. \& Llorente, V., 1988b. Los Orthopteroidea del País Vasco. I. Dermaptera, Blattodea, Mantodea, Phasmoptera, Tettigonioidea y Grylloidea. Actas II Congreso Mundial Vasco de Biología Ambiental, II: 409-424.

Pulido, L., 1990. Los Orthoptera, Mantodea, Phasmoptera (Insecta) de la Sierra de Alcaraz (Albacete) S.E. España. Boletín de Sanidad Vegetal, Plagas (Fuera de Serie), 20: 137-144.

RaGGe, D. R., 1965. Ortópteros y Dermápteros colectados en la Península Ibérica, durante los años 1962 y 1963 por misiones del British Museum (Natural History). Graellsia, 21: 95-119.

RAMBUR, P., 1839. Faune entomologique de l'Andalousie, vol. 2. Orthoptères. París: 12-94.

SAussure, H., 1877. Gryllides. Mémoires de la Société de Physique et d'Histoire Naturelle de Genève, 25(1): 1-352. 
Saussure, H., 1878. Gryllides. Mémoires de la Société de Physique et d'Histoire Naturelle de Genève, 25(2): 369-704.

SchmidT, G., 1999. Ein Beitrage zur Höhenverteilung der Orthopteroidea in der Sierra Nevada /Spanien. Articulata, 14(1): 41-61.

TorralbA, A., 1995. Contribución al conocimiento de la entomofauna del valle de Xanobás (Pirineo aragonés). Boletín de la Sociedad Entomológica Aragonesa 11: 47-49.

Townsend, B. C., 1983. A revision of Afrotropical molecrickets (Orthoptera: Gryllotalpidae). Bulletin of the British Museum Natural History (Entomology), 46(2): 175-203.
Uvarov, B. P., 1948. Andalusian Orthoptera described by Rambur. Eos, 24: 369-390.
Recibido, el 15-XI-2000

Aceptado, el 7-X-2001

Publicado, el 21-XII-2001 